\title{
Strepimidazoles A-G from the Plant Endophytic Streptomyces sp. PKU-EA00015 with Inhibitory Activities against a Plant Pathogenic Fungus
}

Xiaoxu Sun,,$^{\dagger}$ Guiyang Wang, ${ }^{\dagger}$ Hua Xiao, ${ }^{\dagger}$ Jingyi Jiang, ${ }^{,}$Dongliang Xiao, ${ }^{\S}$ Baiying

Xing, ${ }^{\dagger}$ Annan Li, ${ }^{\dagger}$ Yingtao Zhang, ${ }^{\dagger}$ Kai Sun, ${ }^{\star}$ Yuquan Xu, ${ }^{\S}$ Lanping Guo, ${ }^{\star}$ Donghui Yang, ${ }^{*}, \dot{\dagger}$ Ming $M a{ }^{*}$,

†State Key Laboratory of Natural and Biomimetic Drugs, Department of Natural Medicines, School of Pharmaceutical Sciences, Peking University, 38 Xueyuan Road, Haidian District, Beijing 100191, China

\#State Key Laboratory Breeding Base of Dao-di Herbs, National Resource Center for Chinese Materia Medica, China Academy of Chinese Medical Sciences, Beijing 100700, China

${ }^{\S}$ Biotechnology Research Institute, Chinese Academy of Agricultural Sciences, 12 Zhongguancun South Street, Beijing 100081, China.

*To whom correspondence should be addressed: Donghui Yang, E-mail: ydhui@bjmu.edu.cn; Ming Ma, E-mail: mma@bjmu.edu.cn 


\section{Supporting Information}

Figure S1. The representative natural products discovered from plant endophytic actinomycetes .......................................................S3

Figure S2. The phylogenetic analysis of strain PKU-EA00015 ...................S4

Figure S3. The ${ }^{1} \mathrm{H}$ NMR spectrum of $\mathbf{1 a}$ compared to those of $\mathbf{1}$ recorded in different solvents and at different temperatures..........................S5

Figure S4. The key COSY and HMBC correlations of 3a-5a ......................S7

Figure S5. The representative natural products containing the 2aminoimidazole moiety or its oxidized/reduced forms...............S8

Figure S6-S9. The NMR, HRESIMS and IR spectra of 1 ..............................S9

Figure S10-S15. The NMR and HRESIMS spectra of 1a .................................S13

Figure S16-S22. The NMR and HRESIMS spectra of 1b ................................S19

Figure S23-S24. The NMR spectra of $\mathbf{1}$ in DMSO- $d_{6}$ with TFA added ................S26

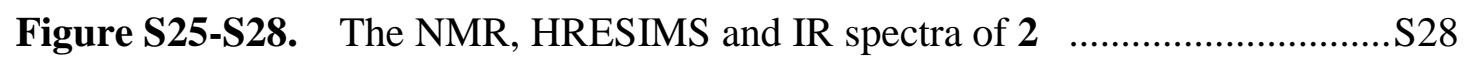

Figure S29-S35. The NMR and HRESIMS spectra of 2a ................................S32

Figure S36-S39. The NMR, HRESIMS and IR spectra of 3 ..........................S39

Figure S40-S45. The NMR and HRESIMS spectra of 3a ...............................S43

Figure S46-S49. The NMR, HRESIMS and IR spectra of 4 ...........................S49

Figure S50-S55. The NMR and HRESIMS spectra of 4a …............................S53

Figure S56-S59. The NMR, HRESIMS and IR spectra of 5 ...........................S59

Figure S60-S65. The NMR and HRESIMS spectra of 5a ..................................66

Figure S66-S69. The NMR, HRESIMS and IR spectra of 6 .............................S69

Figure S70-S75. The NMR and HRESIMS spectra of 6a ...............................S73

Figure S76-S79. The NMR, HRESIMS and IR spectra of 7 .............................S79

Figure S80-S85. The NMR and HRESIMS spectra of 7a ...............................S83 
Figure S1. The representative natural products discovered from plant endophytic actinomycetes.
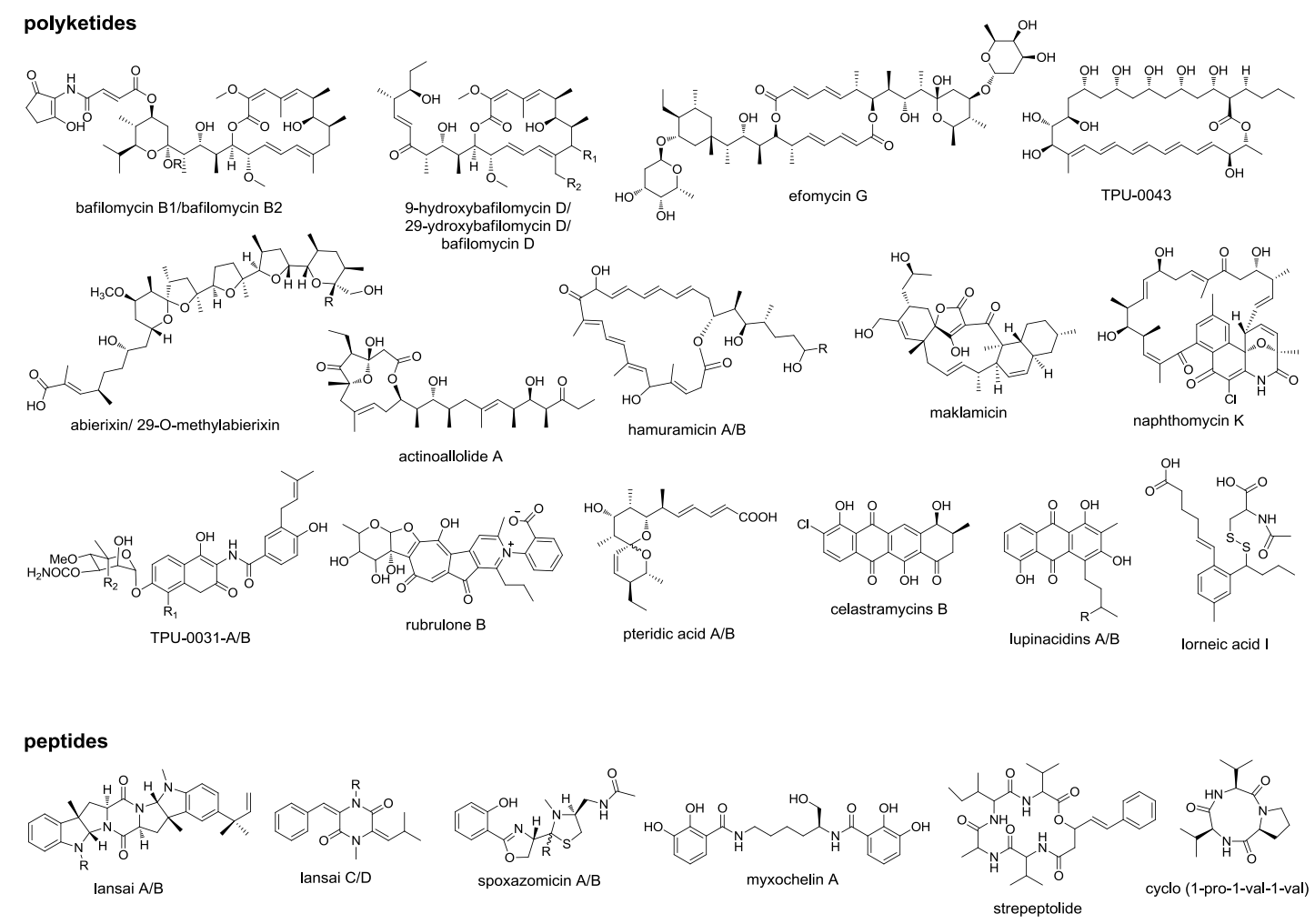

alkaloids
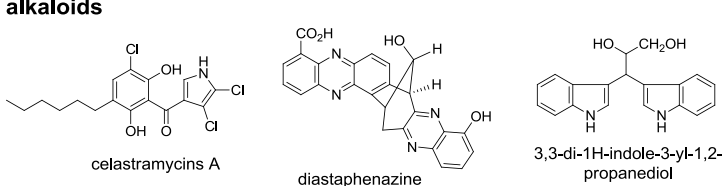

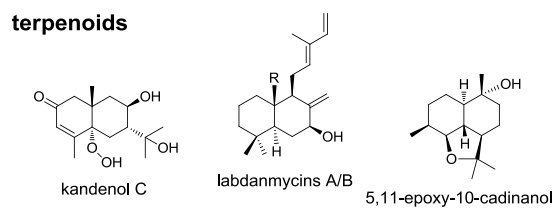

others

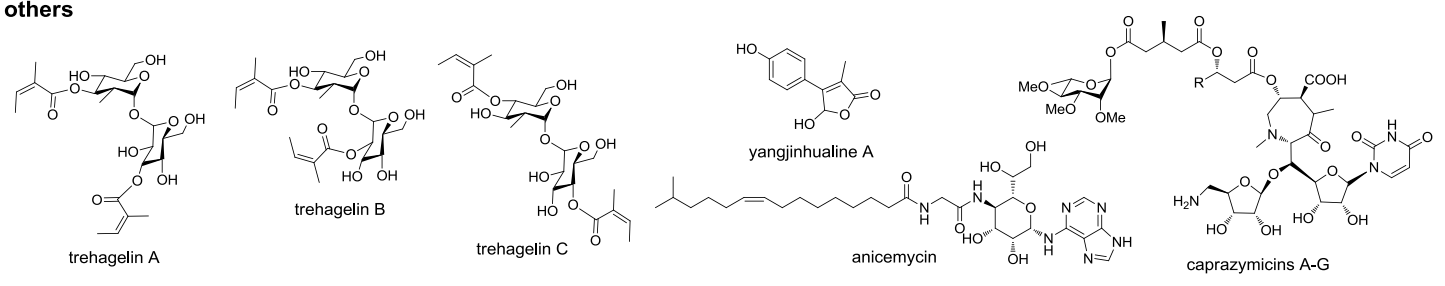


Figure S2. The phylogenetic analysis of strain PKU-EA00015 (labeled in red) based on comparison of $16 \mathrm{~S}$ rRNA sequences. The sequence of 16S rRNA of Kitasatospora arboriphila ACT25 was used as an outgroup. The GenBank accession numbers are shown in parentheses.

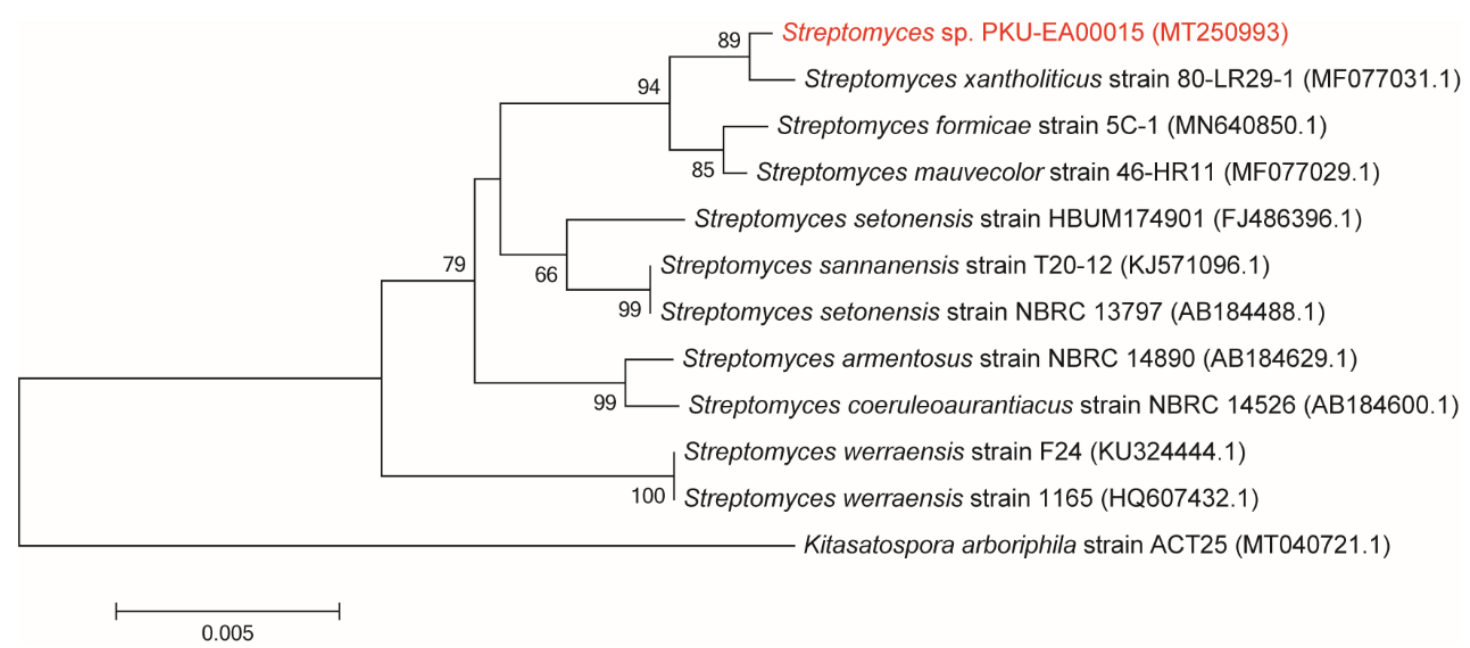


Figure S3. The ${ }^{1} \mathrm{H}$ NMR spectrum of $\mathbf{1 a}$ compared to those of $\mathbf{1}$ recorded in different solvents and at different temperatures. (A) The ${ }^{1} \mathrm{H}$ NMR spectrum of 1a compared to those of 1 recorded in different solvents. (I) $1 \mathrm{a}$ in $\mathrm{CDCl}_{3}, 600 \mathrm{MHz}$. (II) 1 in $\mathrm{CDCl}_{3}$, $400 \mathrm{MHz}$. (III) 1 in DMSO- $d_{6}, 400 \mathrm{MHz}$. (IV) 1 in methanol- $d_{4}, 600 \mathrm{MHz}$. (V) 1 in pyridine- $d_{5}, 400 \mathrm{MHz}$. (VI) 1 in acetone- $d_{6}, 400 \mathrm{MHz}$. All spectra were recorded at $25{ }^{\circ} \mathrm{C}$. (B) The ${ }^{1} \mathrm{H}$ NMR spectrum of 1 a compared to those of 1 recorded at different temperatures. (I) $\mathbf{1 a}$ in $\mathrm{CDCl}_{3}, 600 \mathrm{MHz}, 25^{\circ} \mathrm{C}$. (II) 1 in DMSO- $d_{6}, 400 \mathrm{MHz}, 25^{\circ} \mathrm{C}$. (III) 1 in DMSO- $d_{6}, 400 \mathrm{MHz}, 30{ }^{\circ} \mathrm{C}$. (IV) 1 in DMSO- $d_{6}, 400 \mathrm{MHz}, 40{ }^{\circ} \mathrm{C}$. (V) 1 in DMSO- $d_{6}, 400 \mathrm{MHz}, 50{ }^{\circ} \mathrm{C}$. (VI) 1 in DMSO- $d_{6}, 400 \mathrm{MHz}, 60{ }^{\circ} \mathrm{C}$.

A

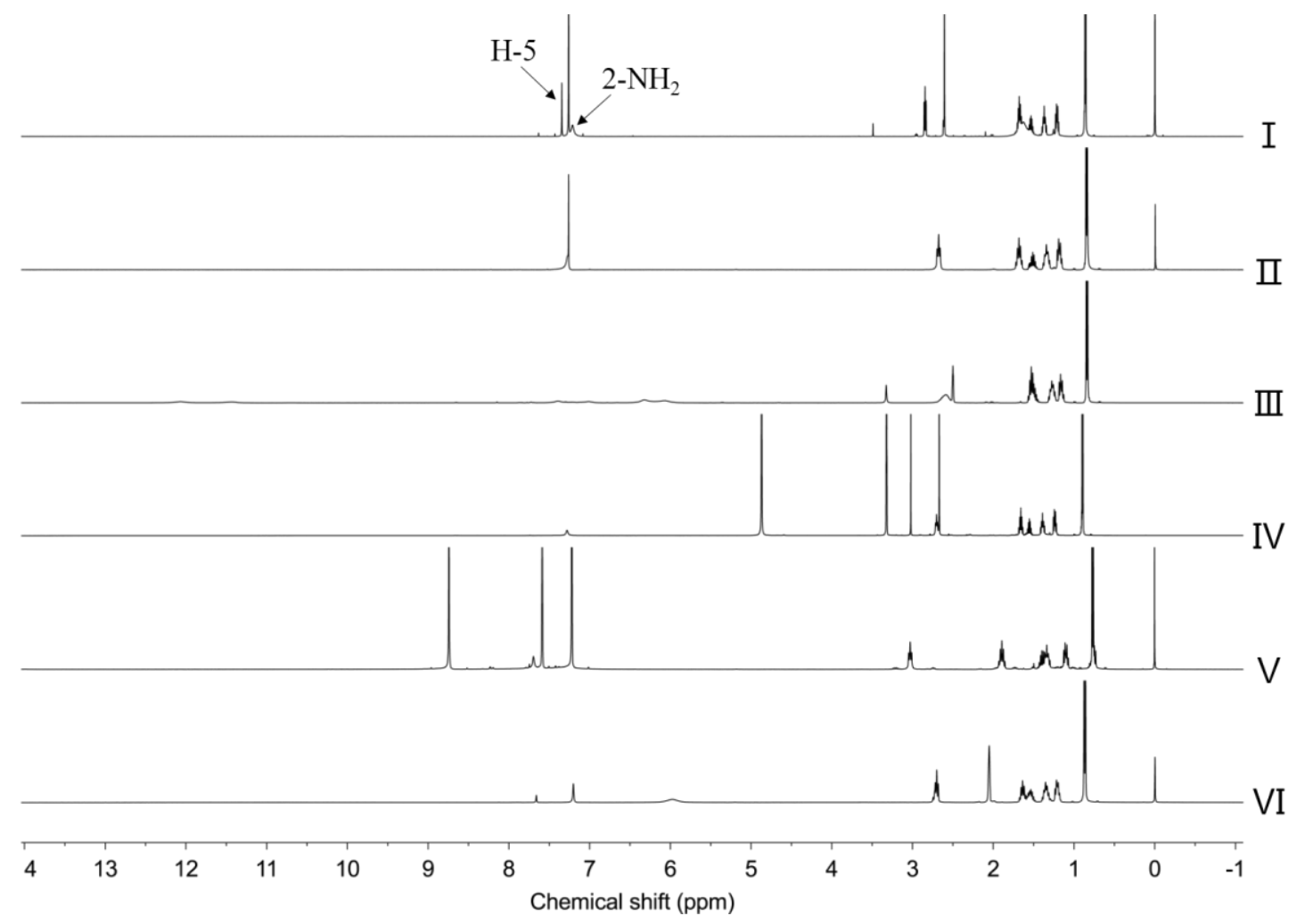


B

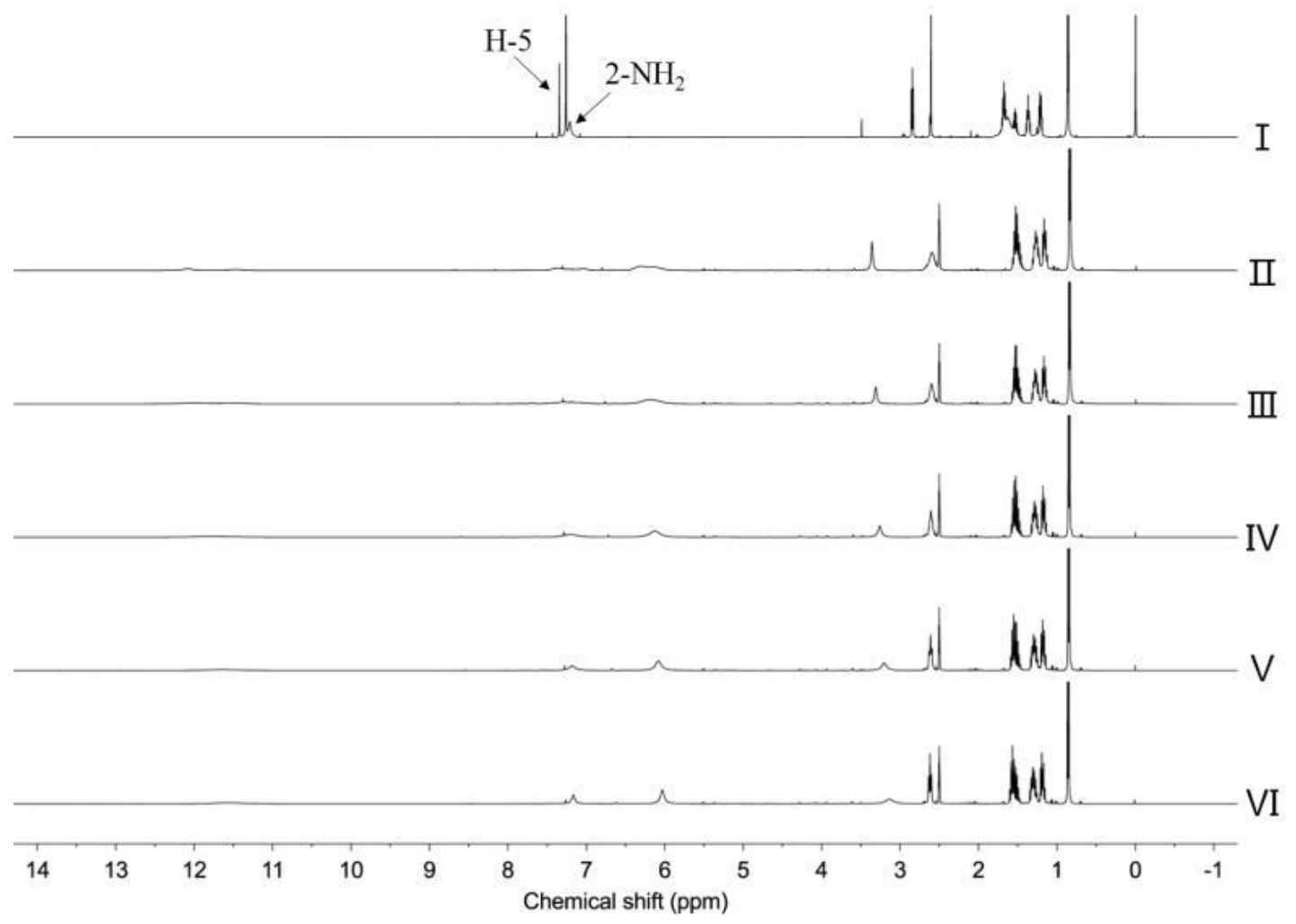


Figure S4. The key COSY and HMBC correlations of 3a-5a.

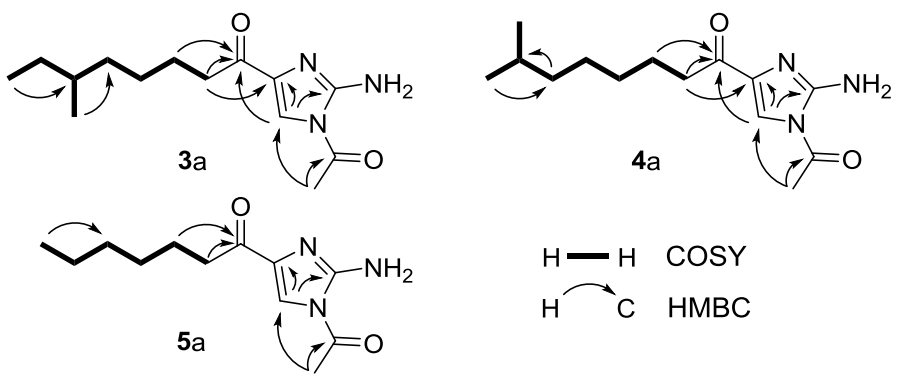


Figure S5. The representative natural products containing the 2-aminoimidazole moiety or its oxidative/reductive forms.

\section{pyrrole-2-aminoimidazoles}
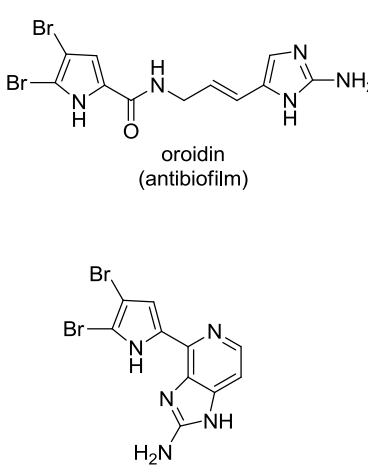

ageladine $A$ (antiangiogenic)

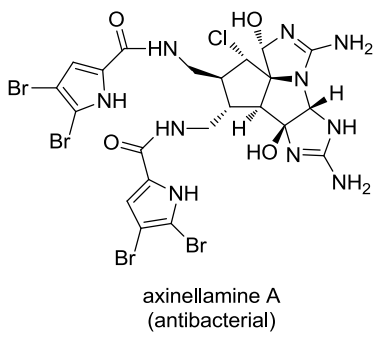
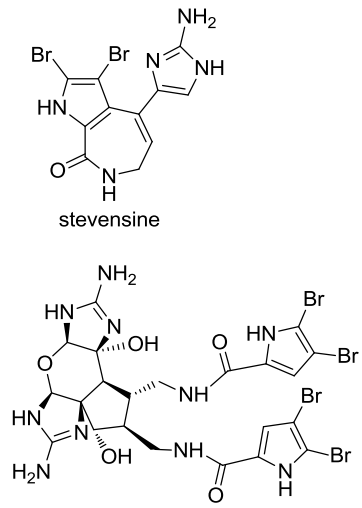

massadine
( geranylgeranyltransferase type I inhibitor )

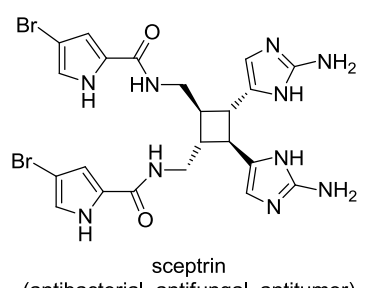

(antibacterial, antifungal, antitumor)
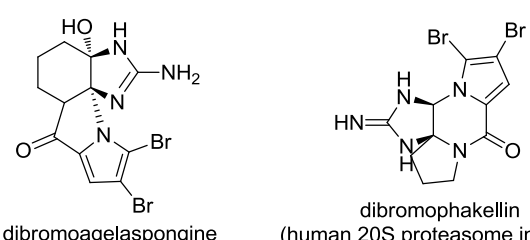

(human $20 \mathrm{~S}$ proteasome inhibitor)
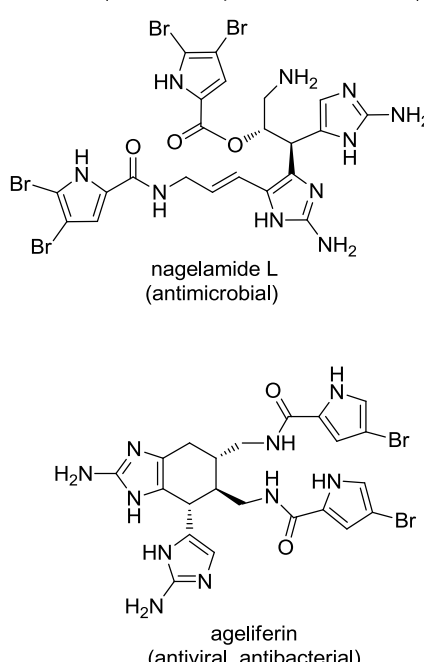

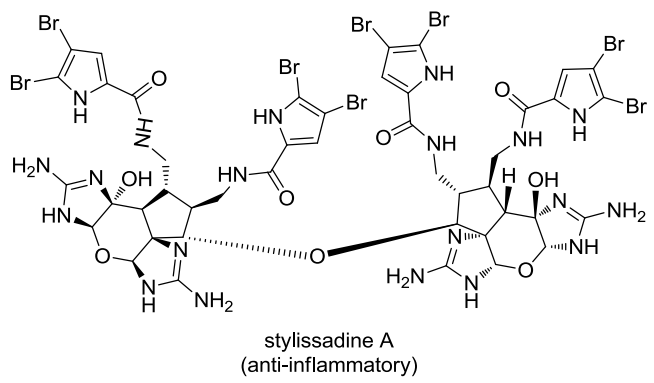

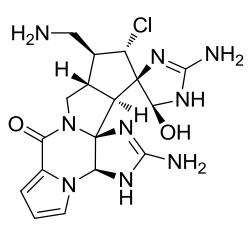

palau'amine

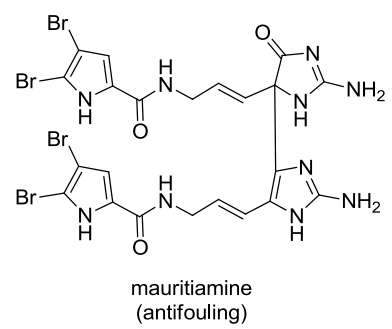

\section{others}
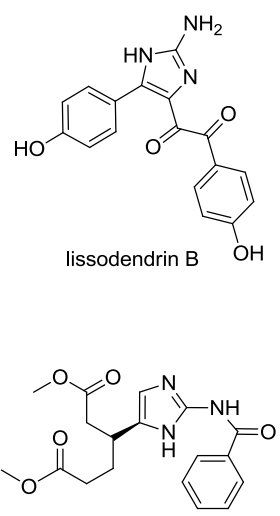

terrazoanthine $\mathrm{C}$
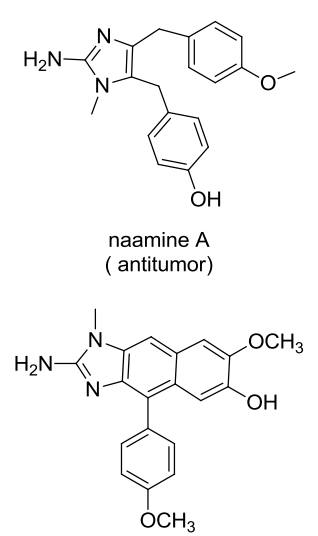

kealiinine $\mathrm{A}$ (cytotoxicity)

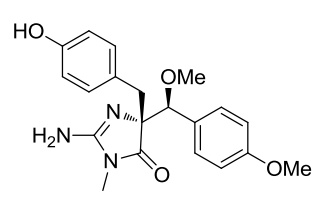

calcaridine A

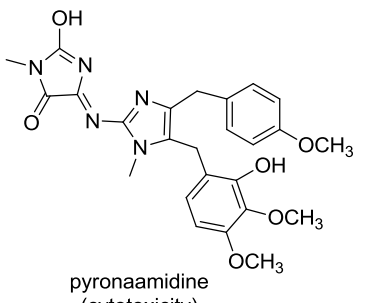

(cytotoxicity)

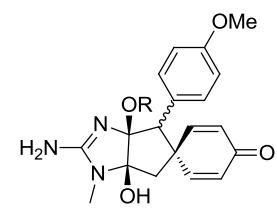

spirocalcaridine A R=H spirocalcaridine $B \quad R=M e$

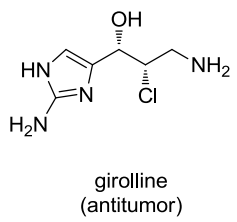


Figure S6. The ${ }^{1} \mathrm{H}$ NMR spectrum of compound $1\left(\mathrm{CDCl}_{3}, 400 \mathrm{MHz}\right)$

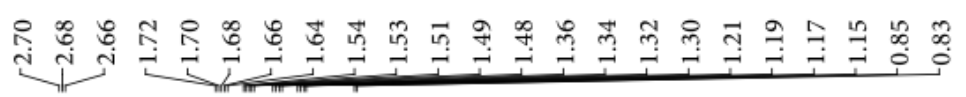
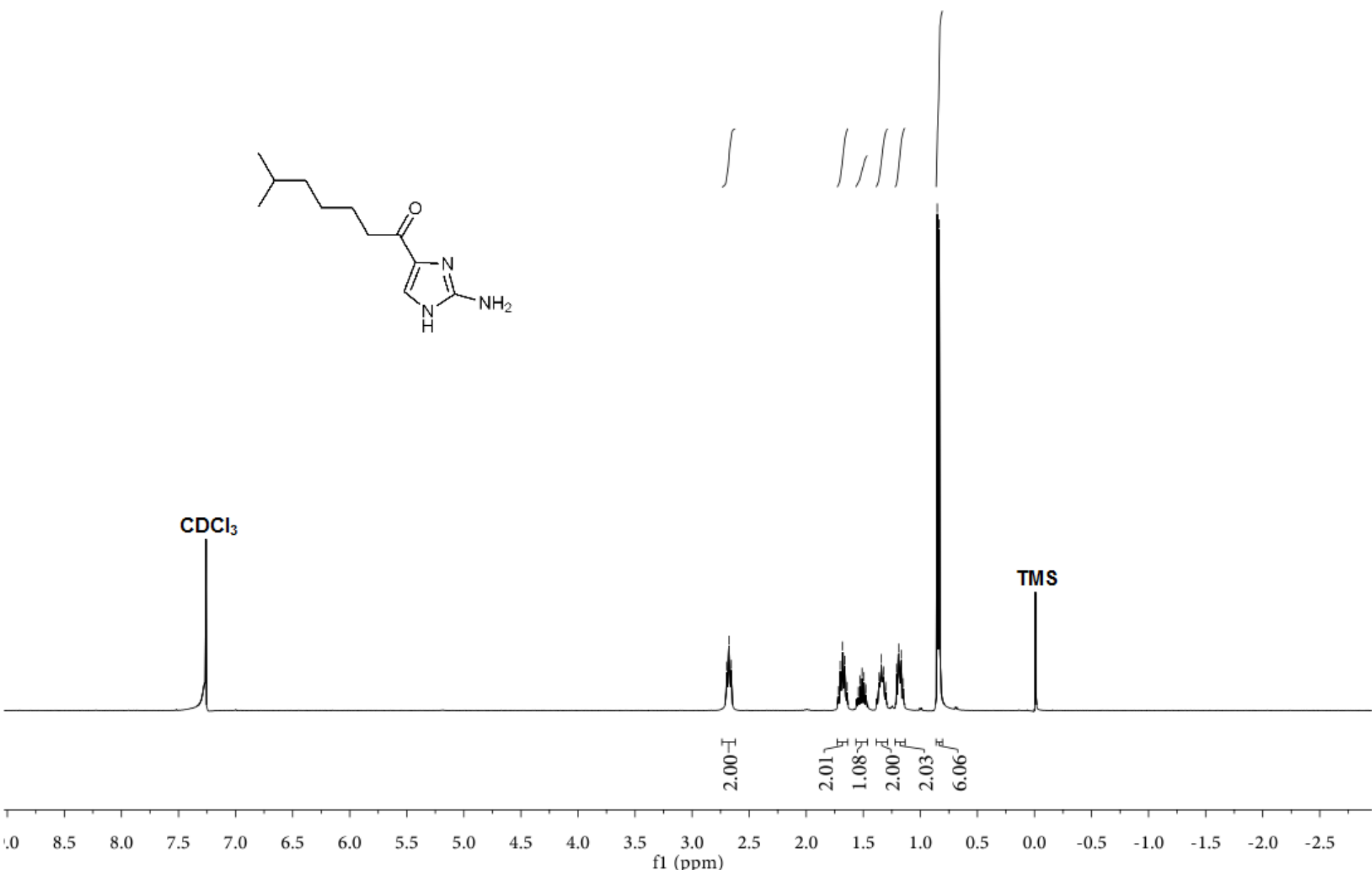
Figure S7. The ${ }^{13} \mathrm{C}$ NMR spectrum of compound $1\left(\mathrm{CDCl}_{3}, 100 \mathrm{MHz}\right)$

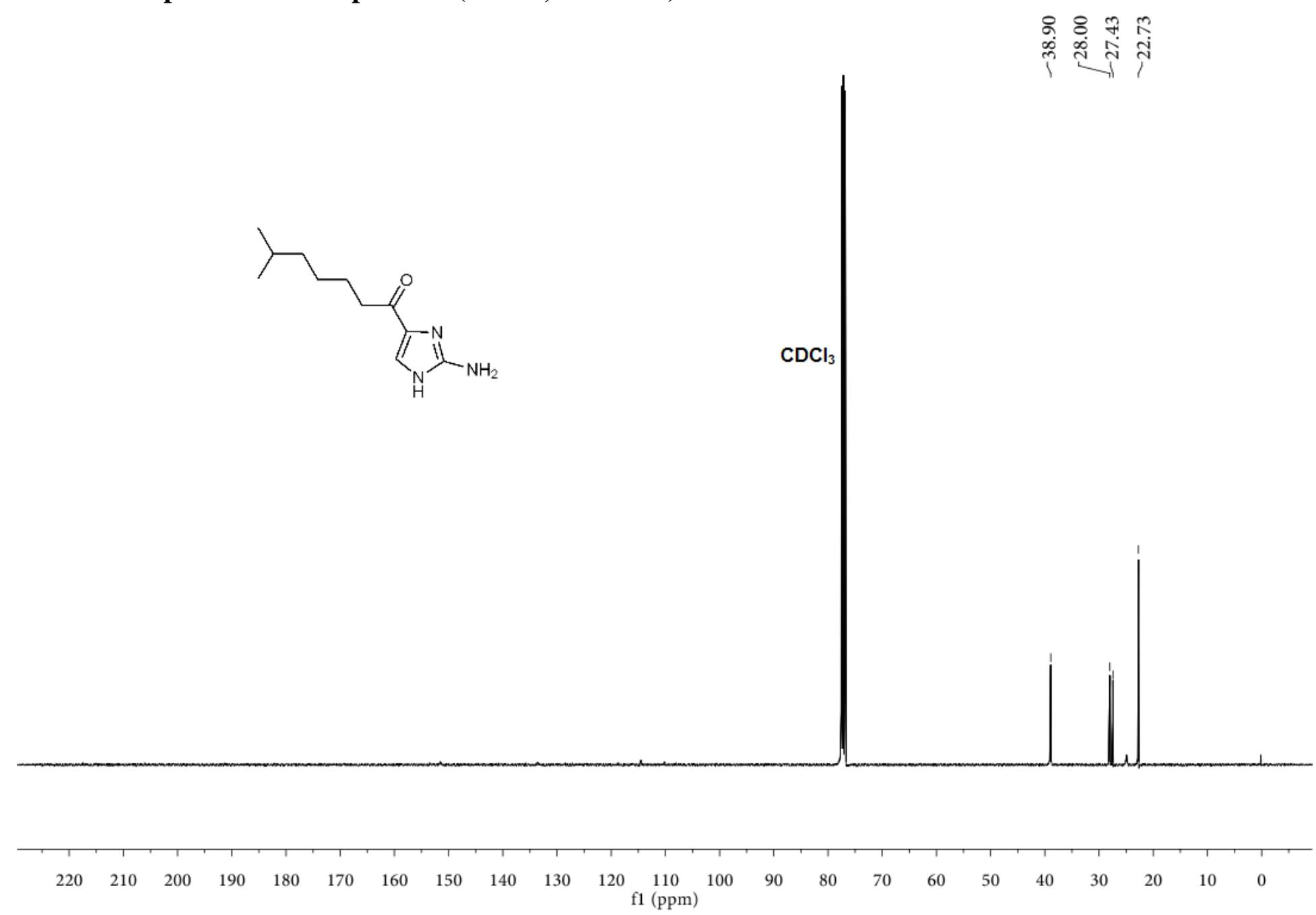


Figure S8. The HRESIMS spectrum of compound 1

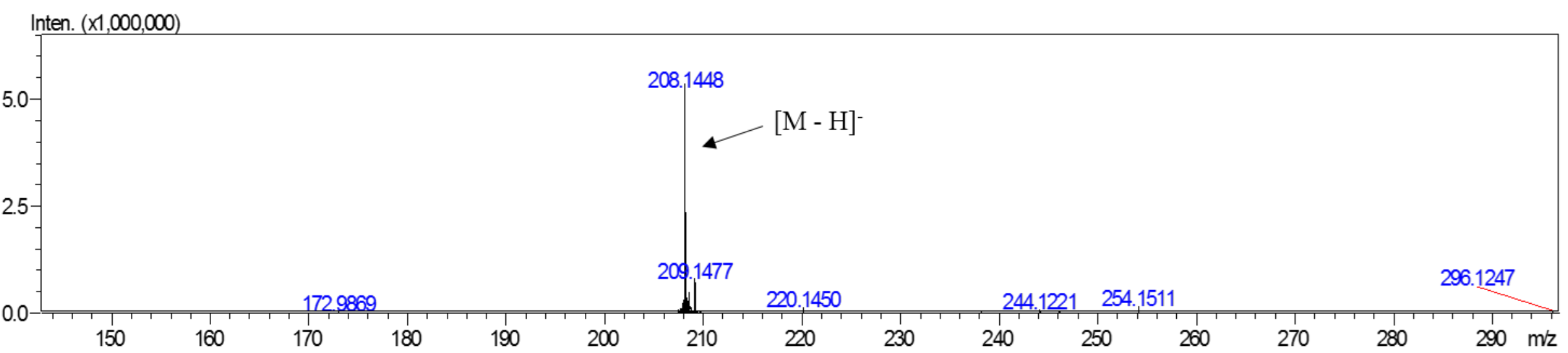


Figure S9. The IR spectrum of compound 1

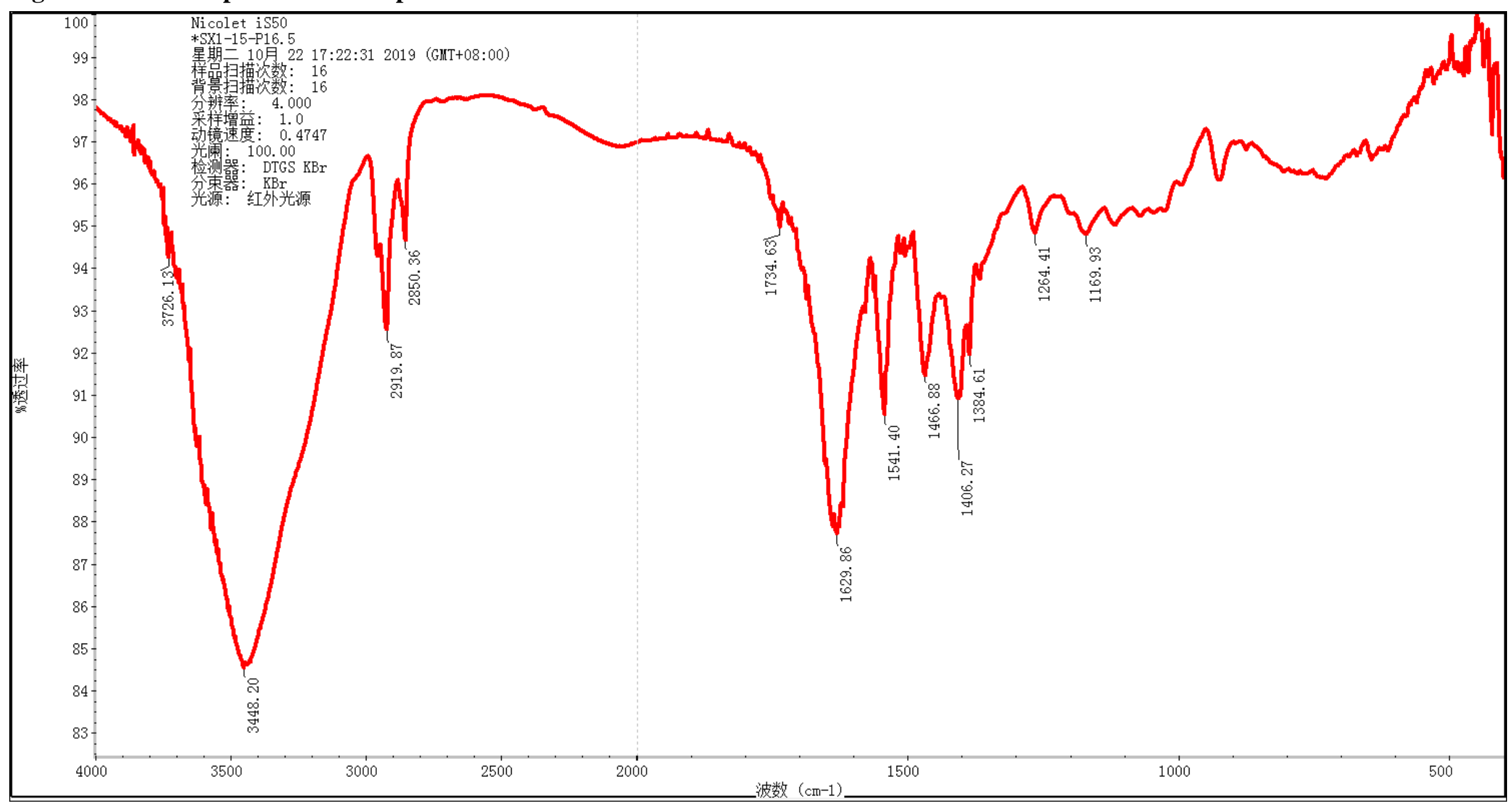


Figure S10. The ${ }^{1} \mathrm{H}$ NMR spectrum of compound $1 \mathrm{a}\left(\mathrm{CDCl}_{3}, 600 \mathrm{MHz}\right)$

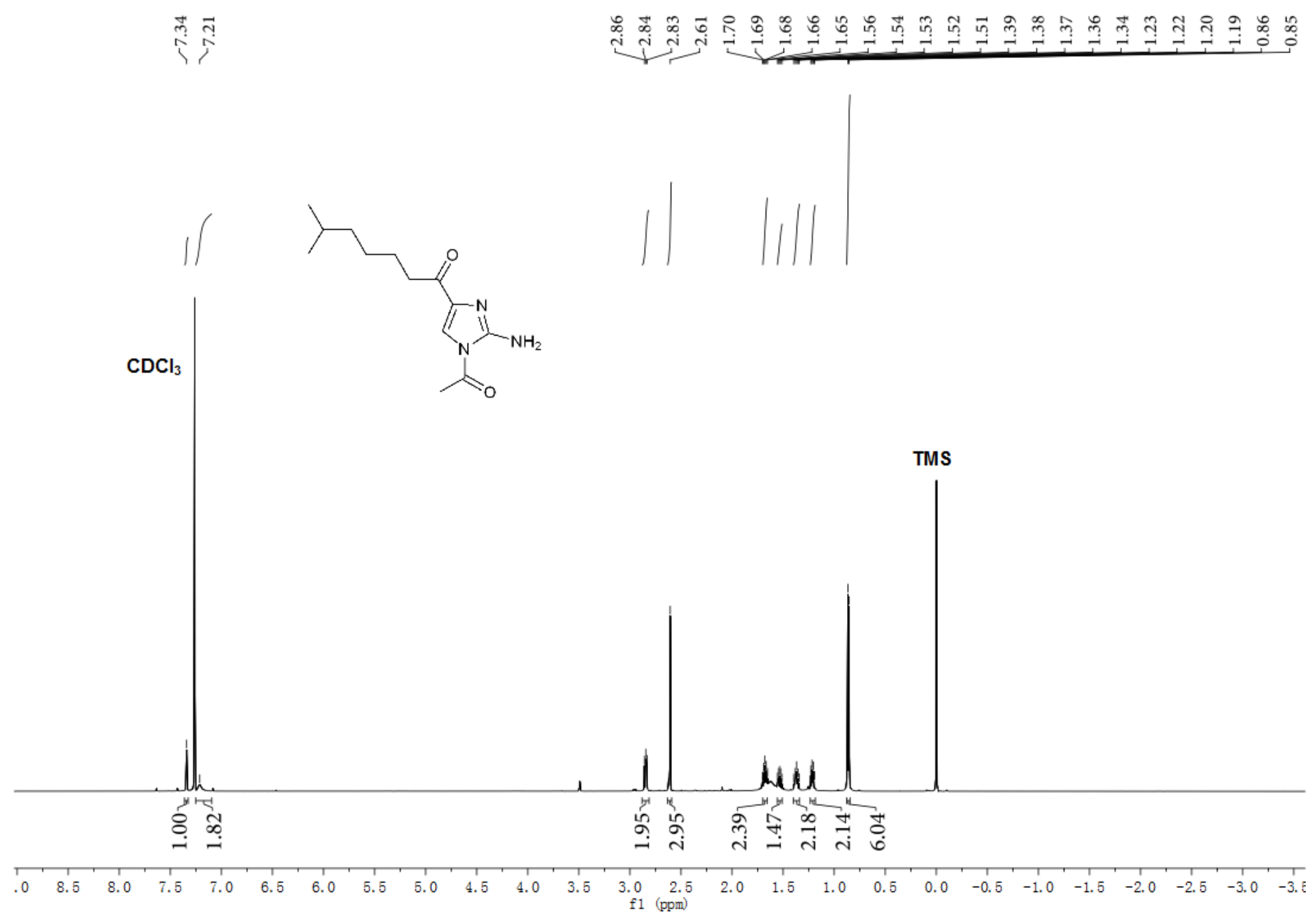


Figure S11. The ${ }^{13} \mathrm{C}$ NMR spectrum of compound $1 \mathrm{a}\left(\mathrm{CDCl}_{3}, 150 \mathrm{MHz}\right)$

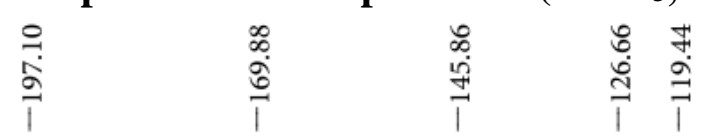

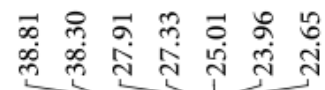

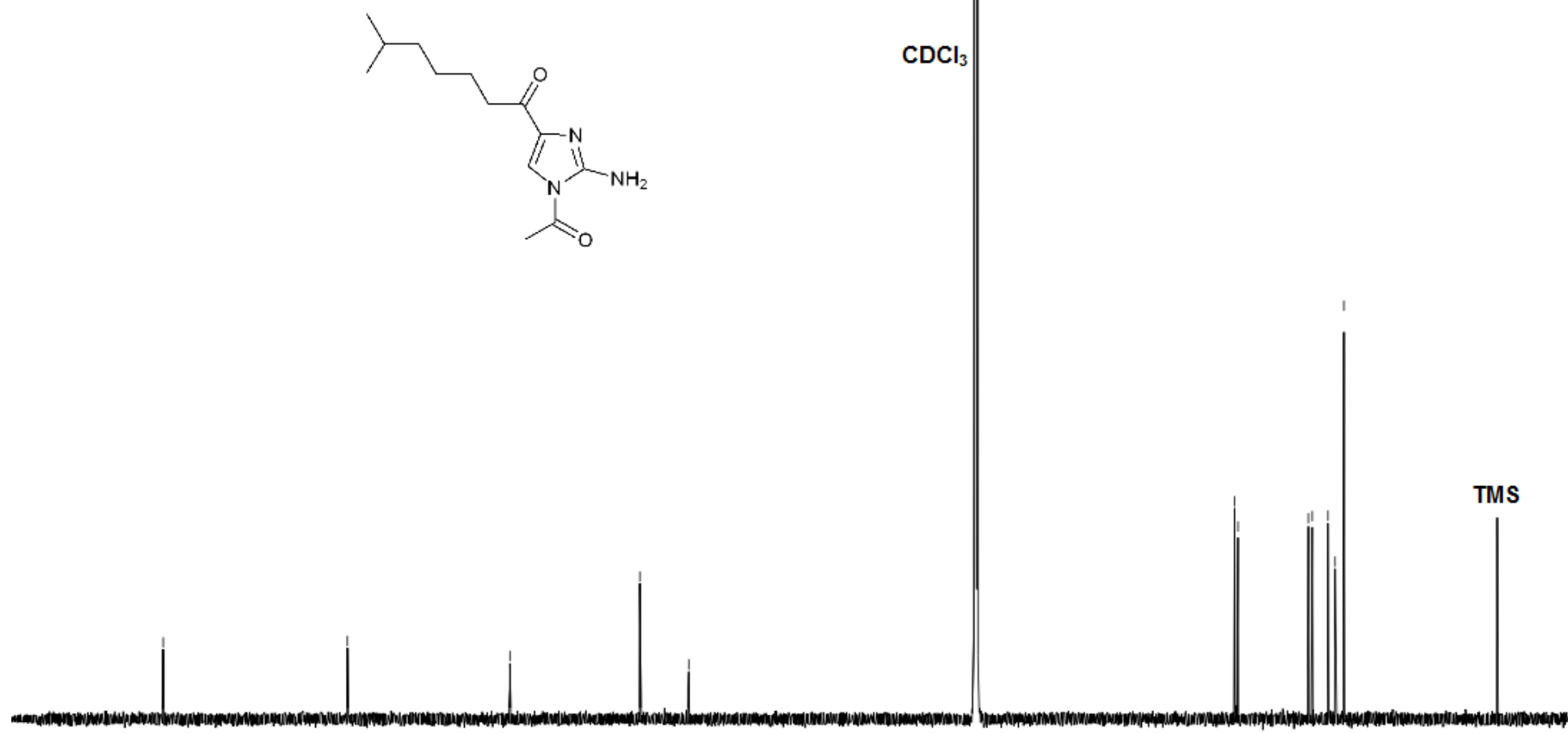

$\mathrm{CDCl}_{3}$

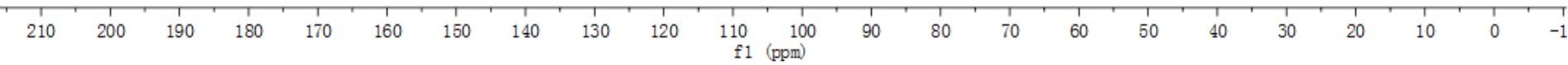


Figure S12. The COSY spectrum of compound $1 \mathrm{a}\left(\mathrm{CDCl}_{3}, 600 \mathrm{MHz}\right)$

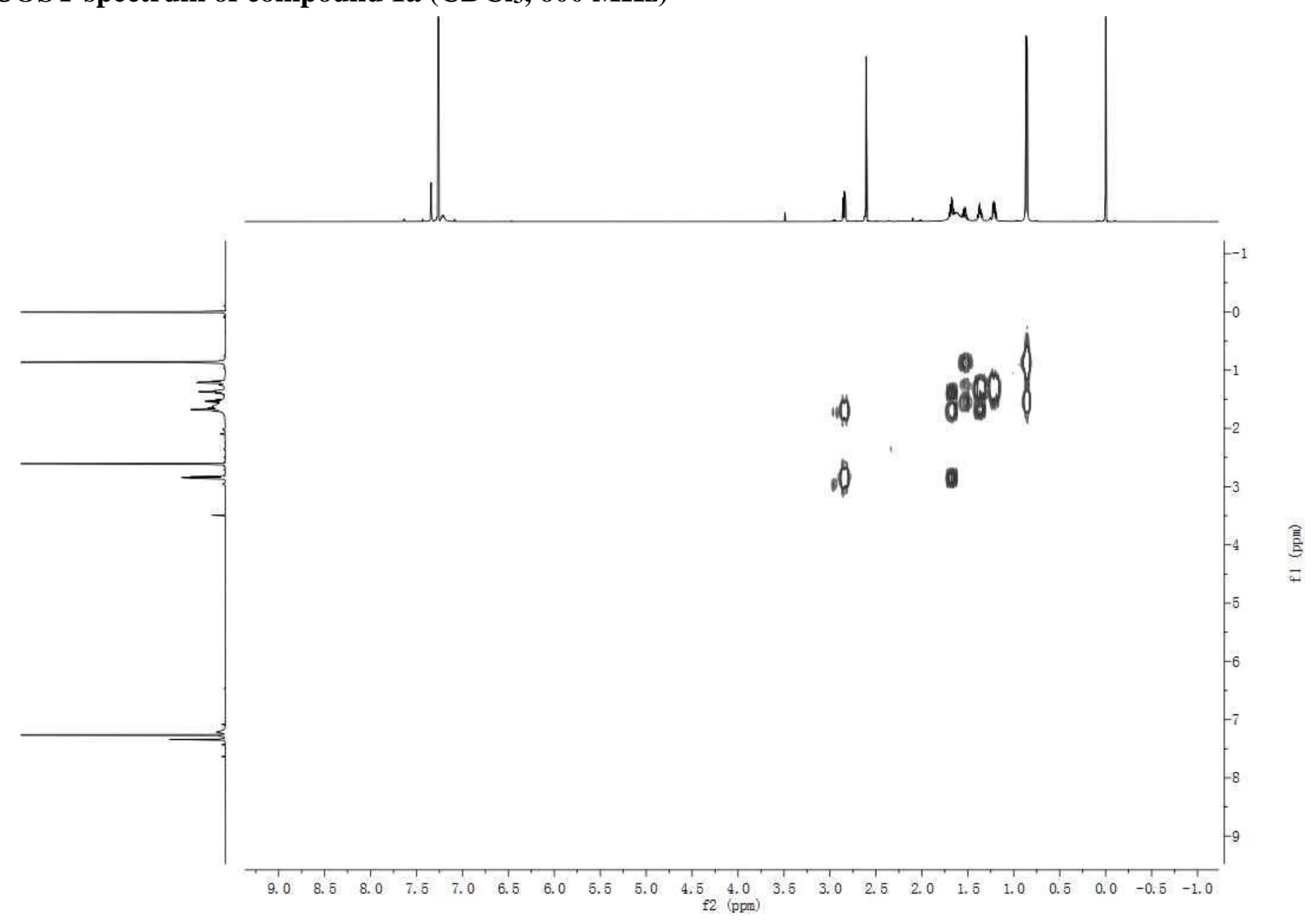




$$
\bar{F}
$$




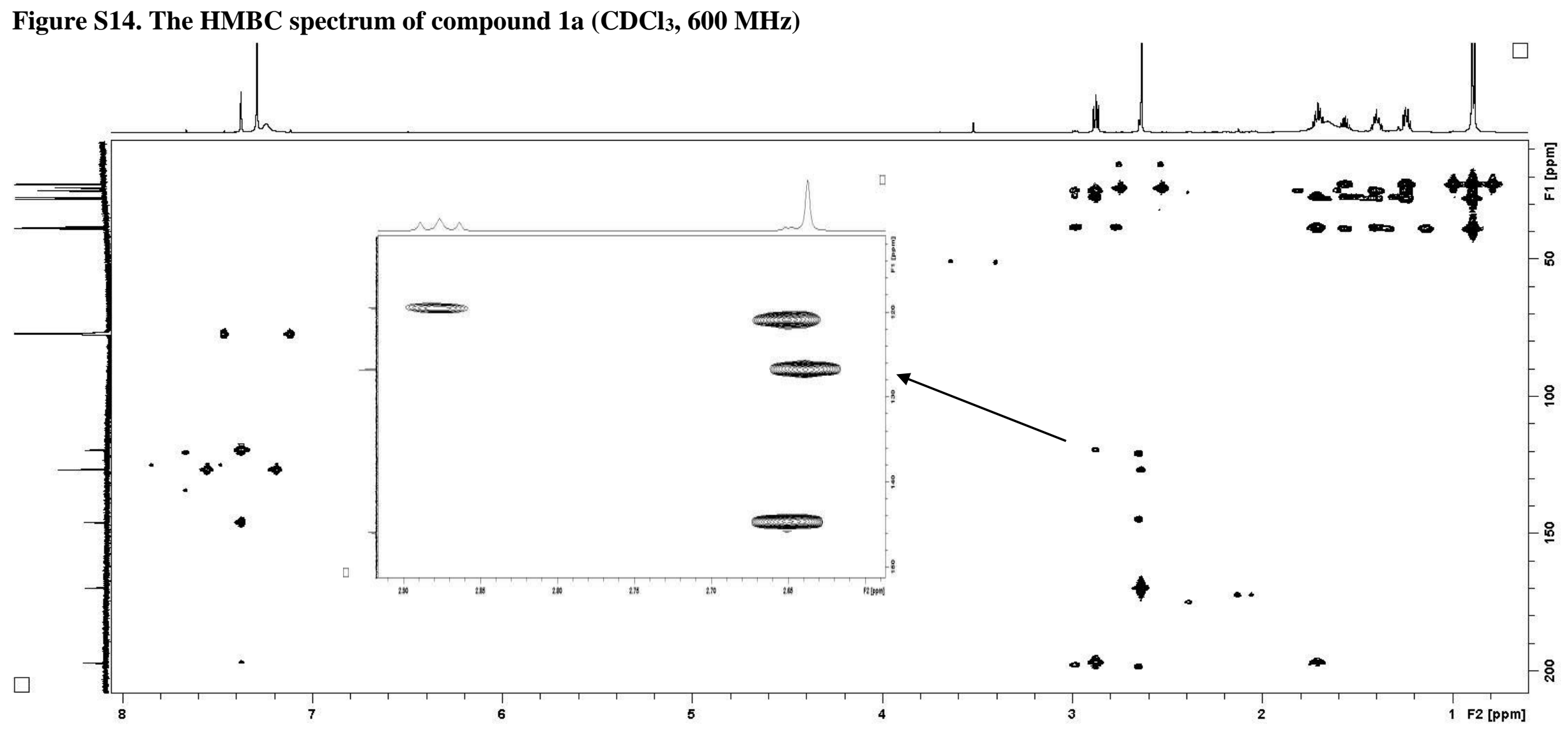


Figure S15. The HRESIMS spectrum of compound 1a

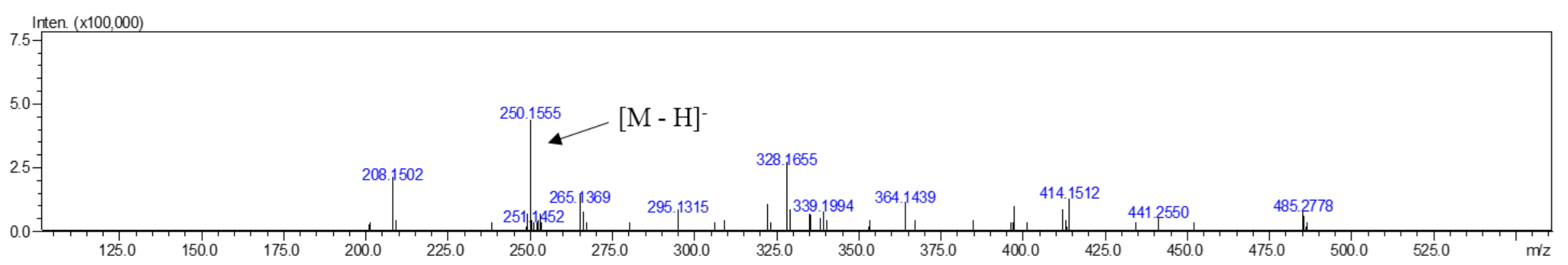


Figure S16. The ${ }^{1} \mathrm{H}$ NMR spectrum of compound $1 \mathrm{~b}\left(\mathrm{CDCl}_{3}, 600 \mathrm{MHz}\right)$. This compound was contaminated by tetrahydrofuran $(\mathrm{THF})$ in sample transfer process.

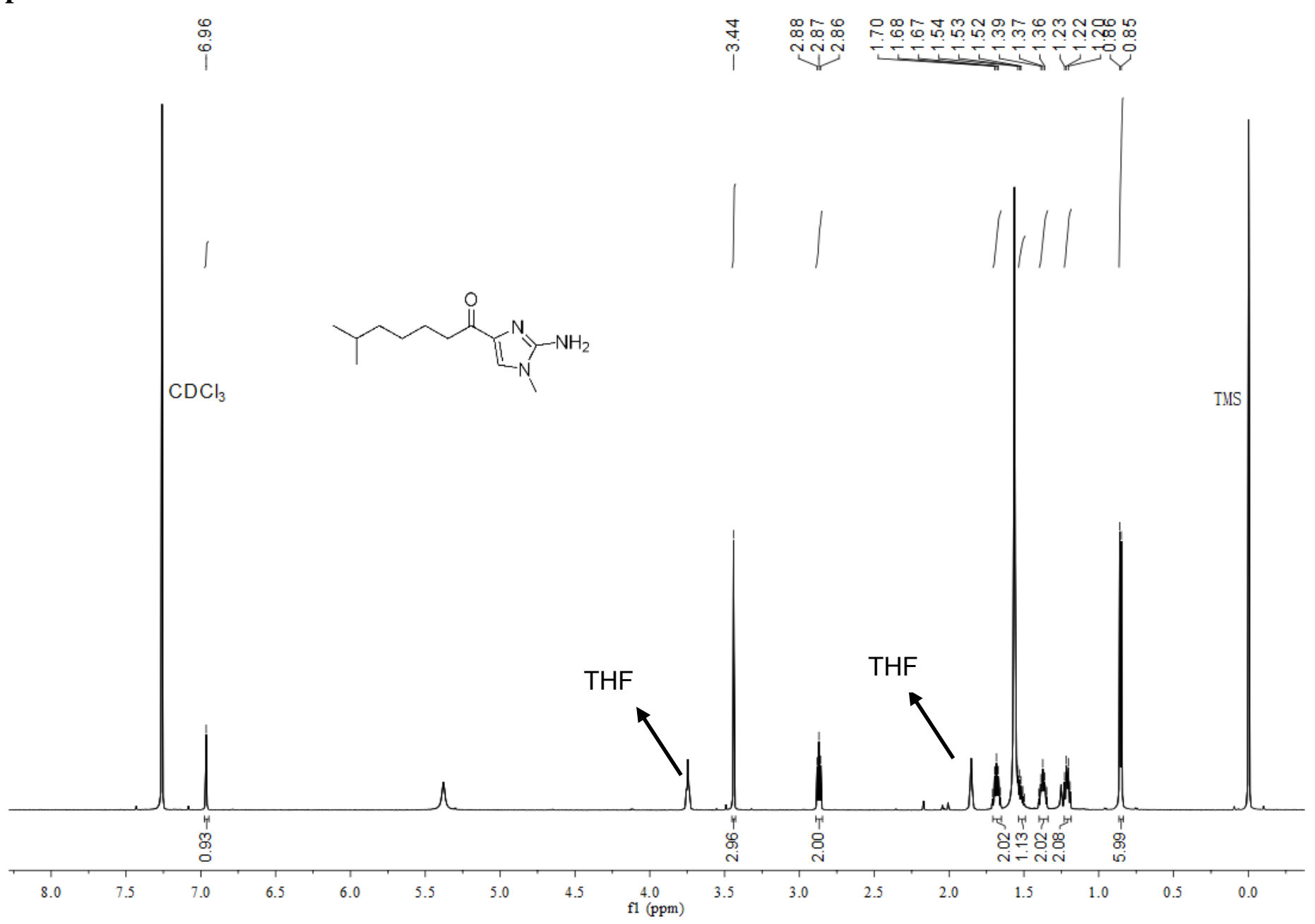


Figure S17. The ${ }^{13} \mathrm{C}$ NMR spectrum of compound $1 \mathrm{~b}\left(\mathrm{CDCl}_{3}, 150 \mathrm{MHz}\right)$

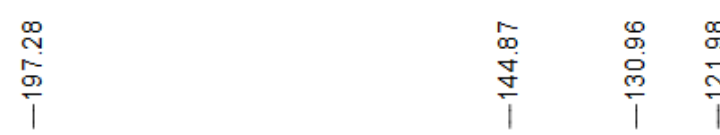

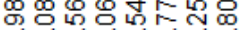

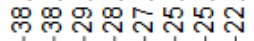

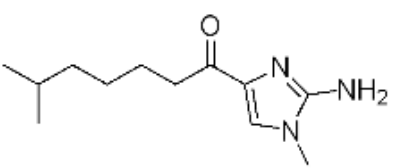

$\mathrm{CDCl}_{3}$

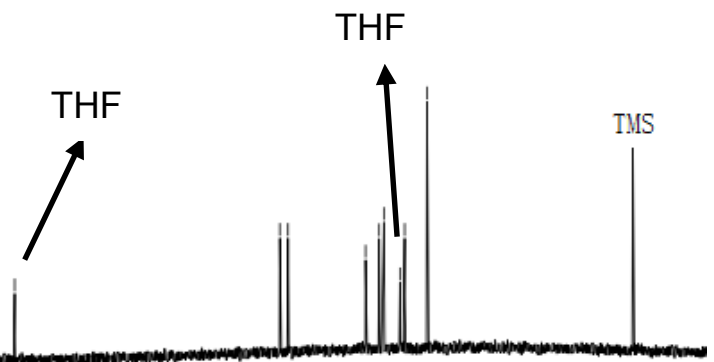

$\begin{array}{lllllllllll}200 & 190 & 180 & 170 & 160 & 150 & 140 & 130 & 120 & 110 & \begin{array}{c}100 \\ \mathrm{f} 1(\mathrm{ppm})\end{array}\end{array}$ 
Figure S18. The COSY spectrum of compound $1 \mathrm{~b}\left(\mathrm{CDCl}_{3}, 600 \mathrm{MHz}\right)$

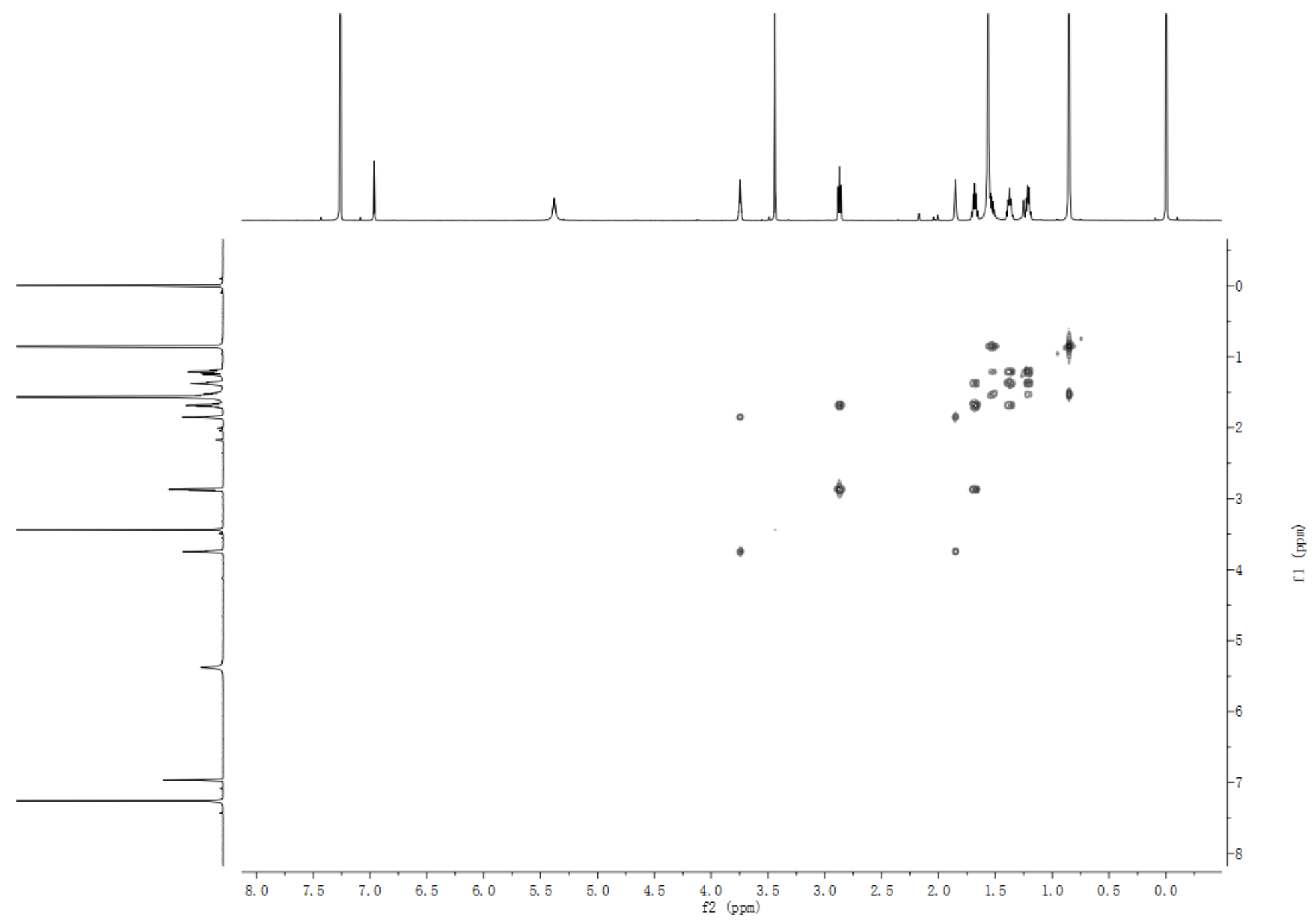


Figure S19. The HSQC spectrum of compound $1 \mathrm{~b}\left(\mathrm{CDCl}_{3}, 600 \mathrm{MHz}\right)$

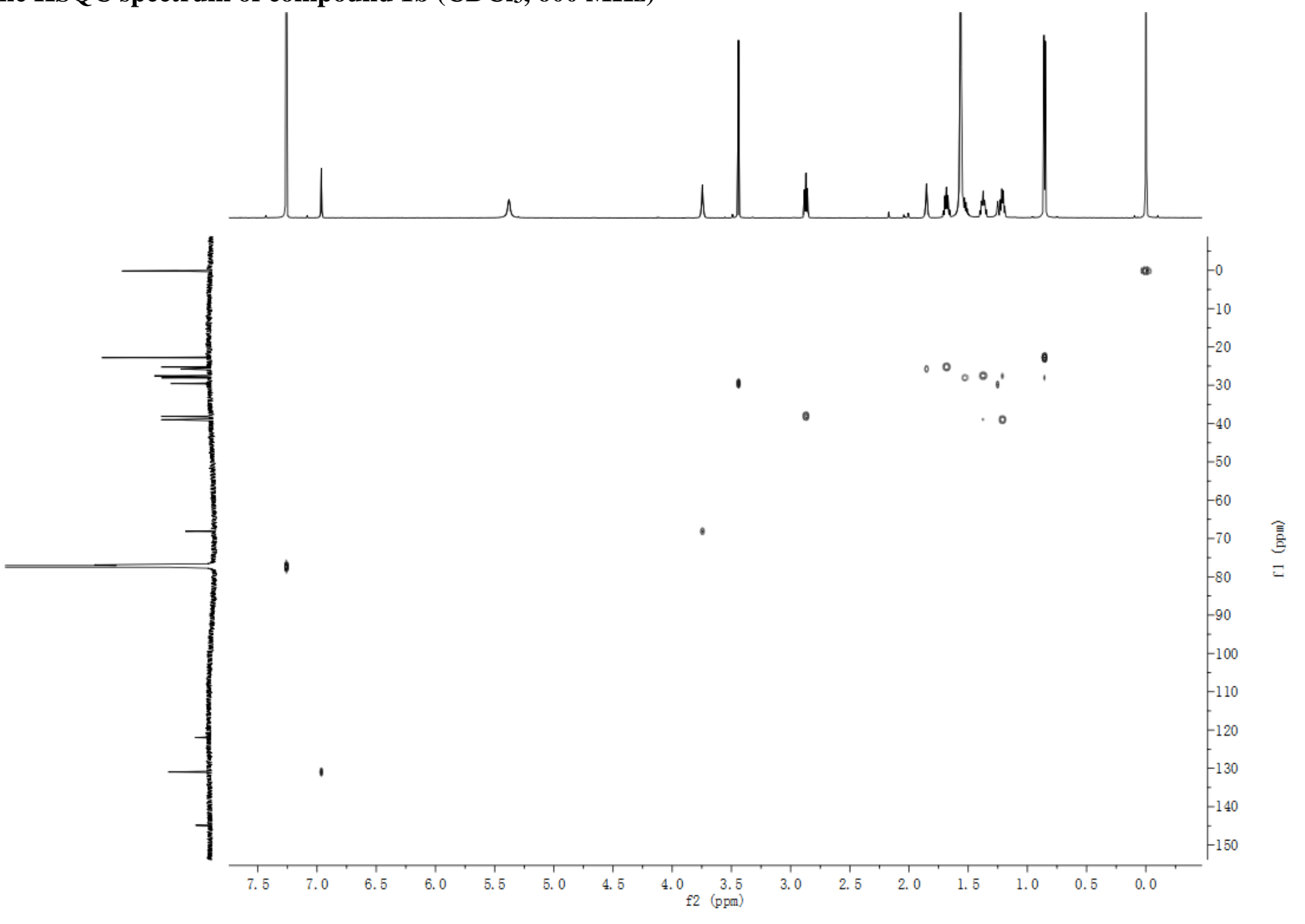


Figure S20. The HMBC spectrum of compound $1 \mathrm{~b}\left(\mathrm{CDCl}_{3}, 600 \mathrm{MHz}\right)$

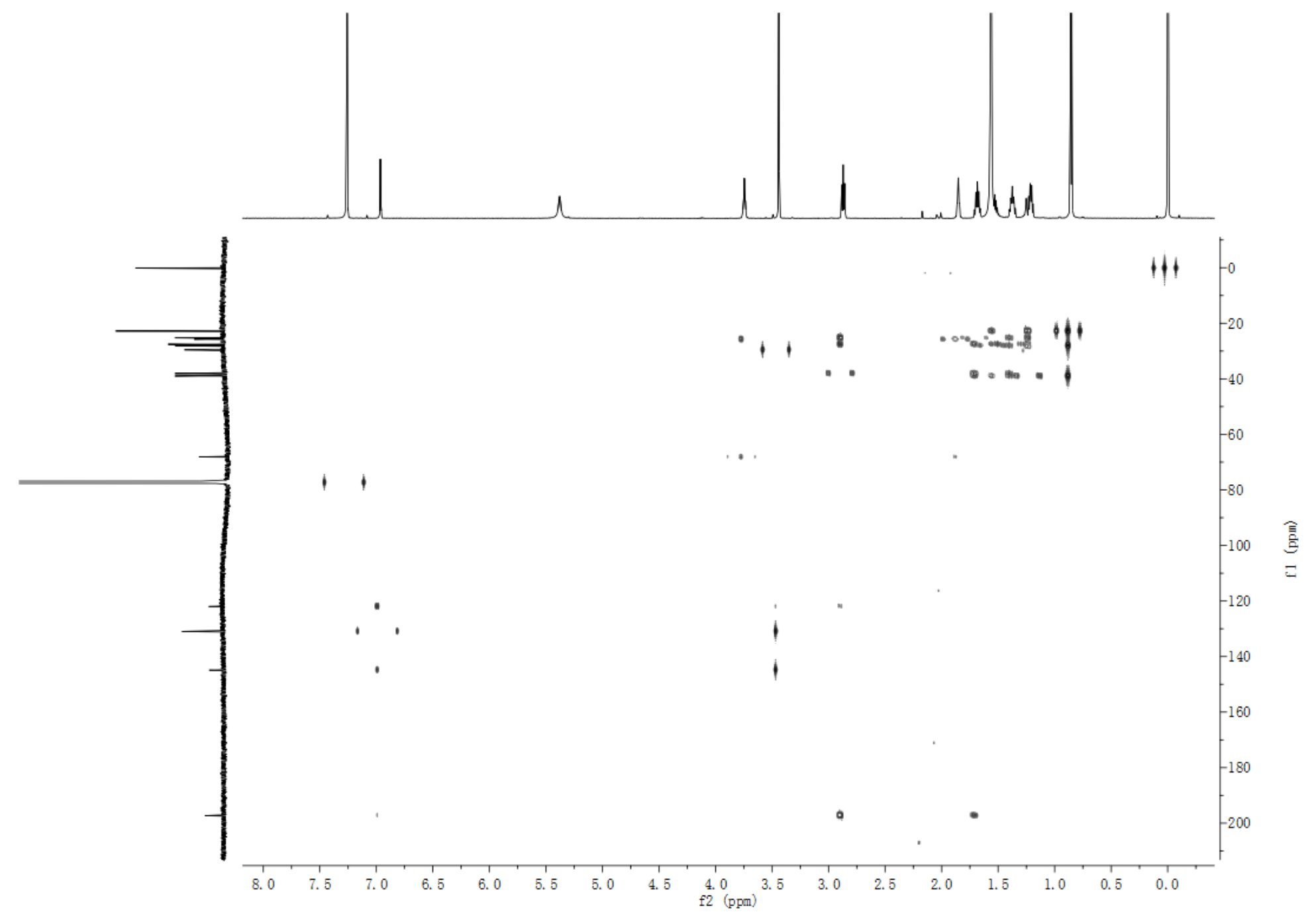


Figure S21. The NOESY spectrum of compound $1 \mathrm{~b}\left(\mathrm{CDCl}_{3}, 600 \mathrm{MHz}\right)$

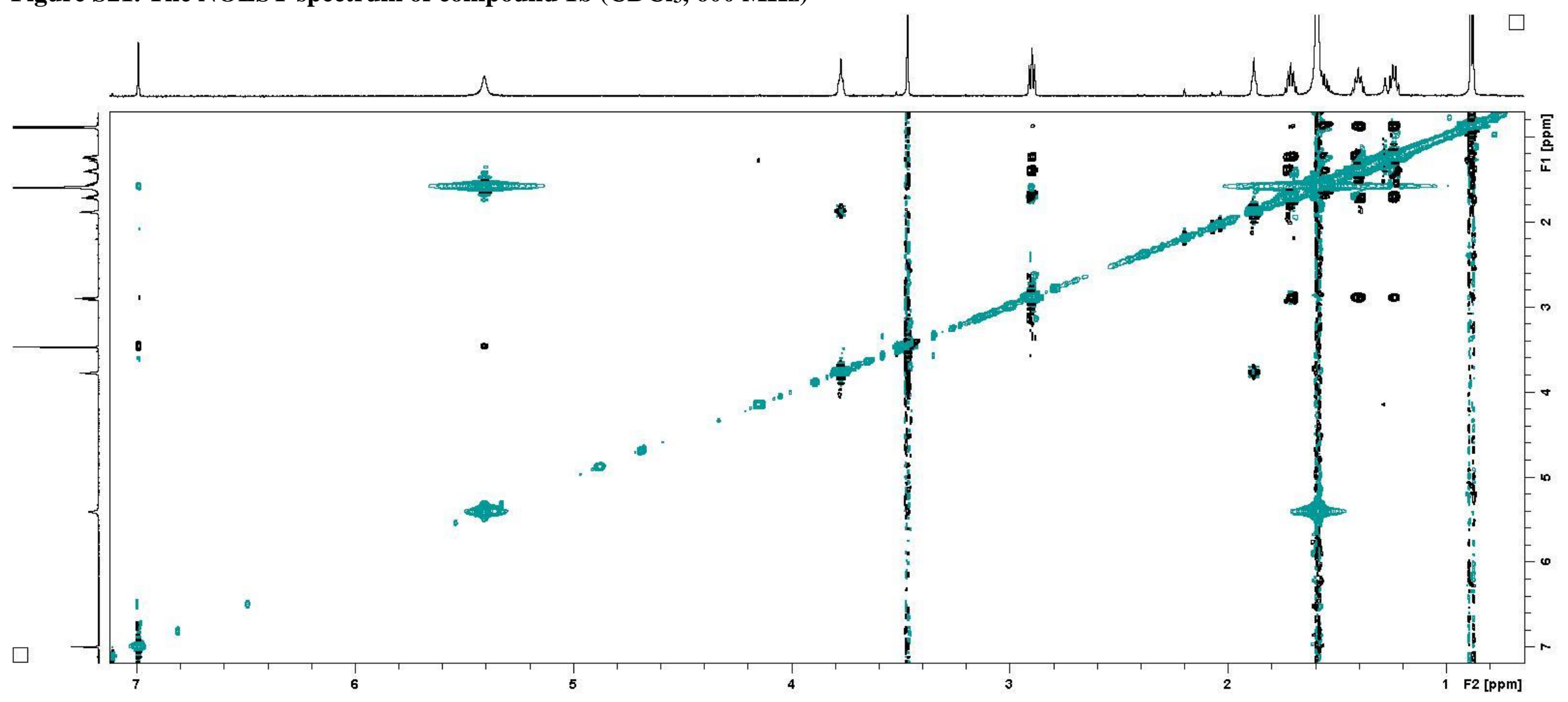


Figure S22. The HRESIMS spectrum of compound 1b

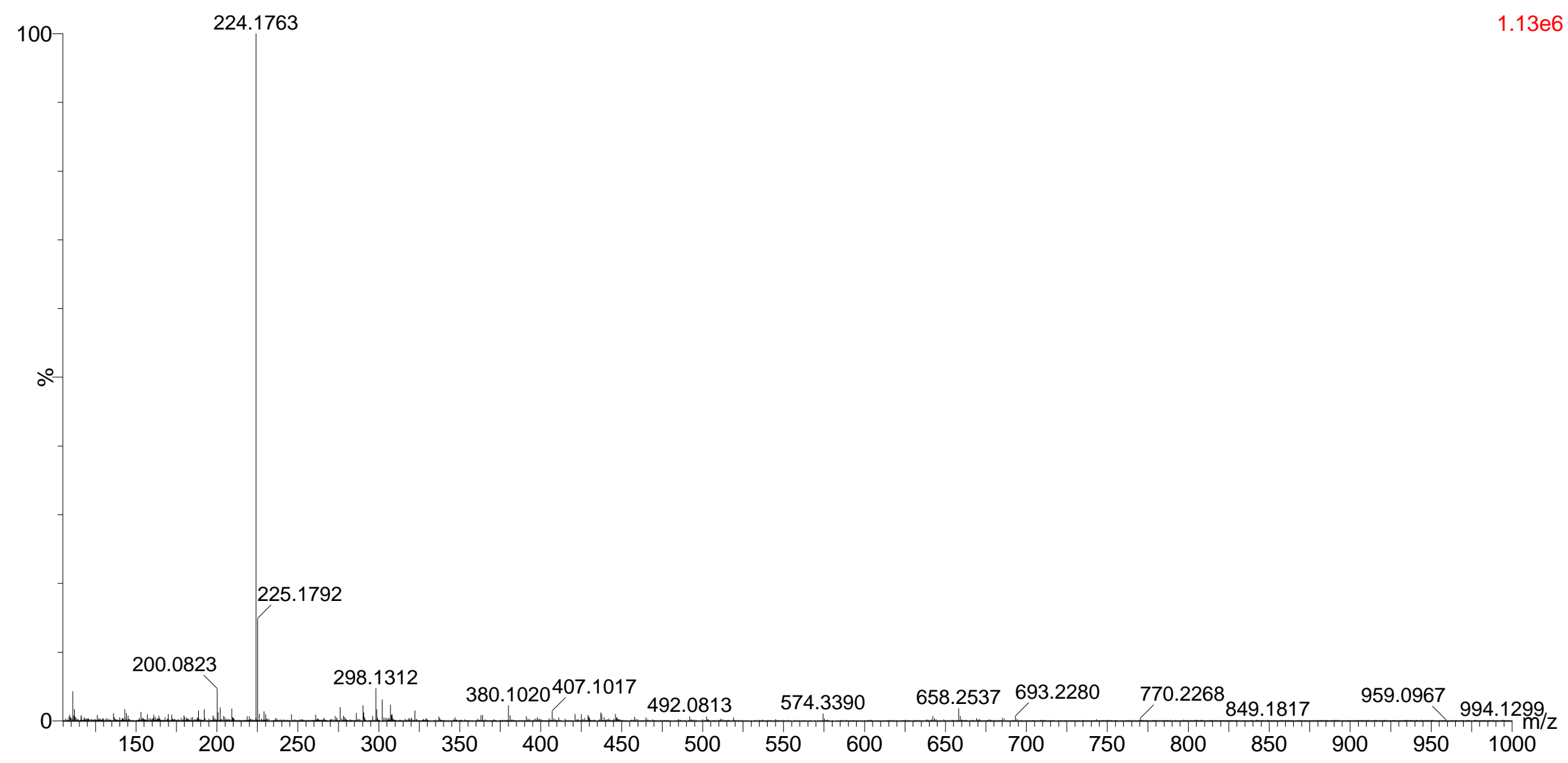


Figure S23. The ${ }^{1} \mathrm{H}$ NMR spectrum of compound 1 (DMSO- $d_{6}$ with TFA, $600 \mathrm{MHz}$ )

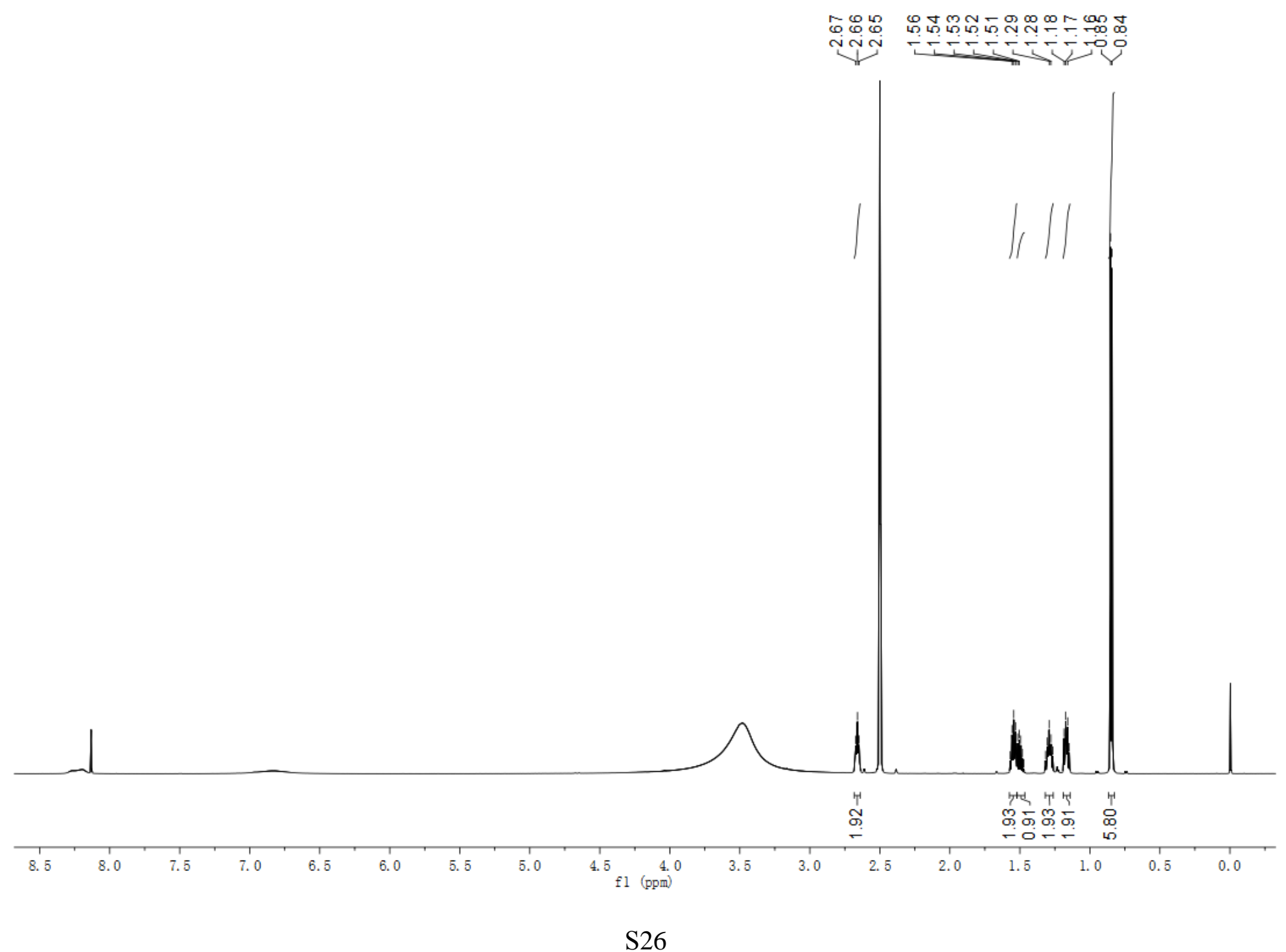


Figure S24. The ${ }^{13} \mathrm{C}$ NMR spectrum of compound 1 (DMSO-d 6 with TFA, $150 \mathrm{MHz}$ )

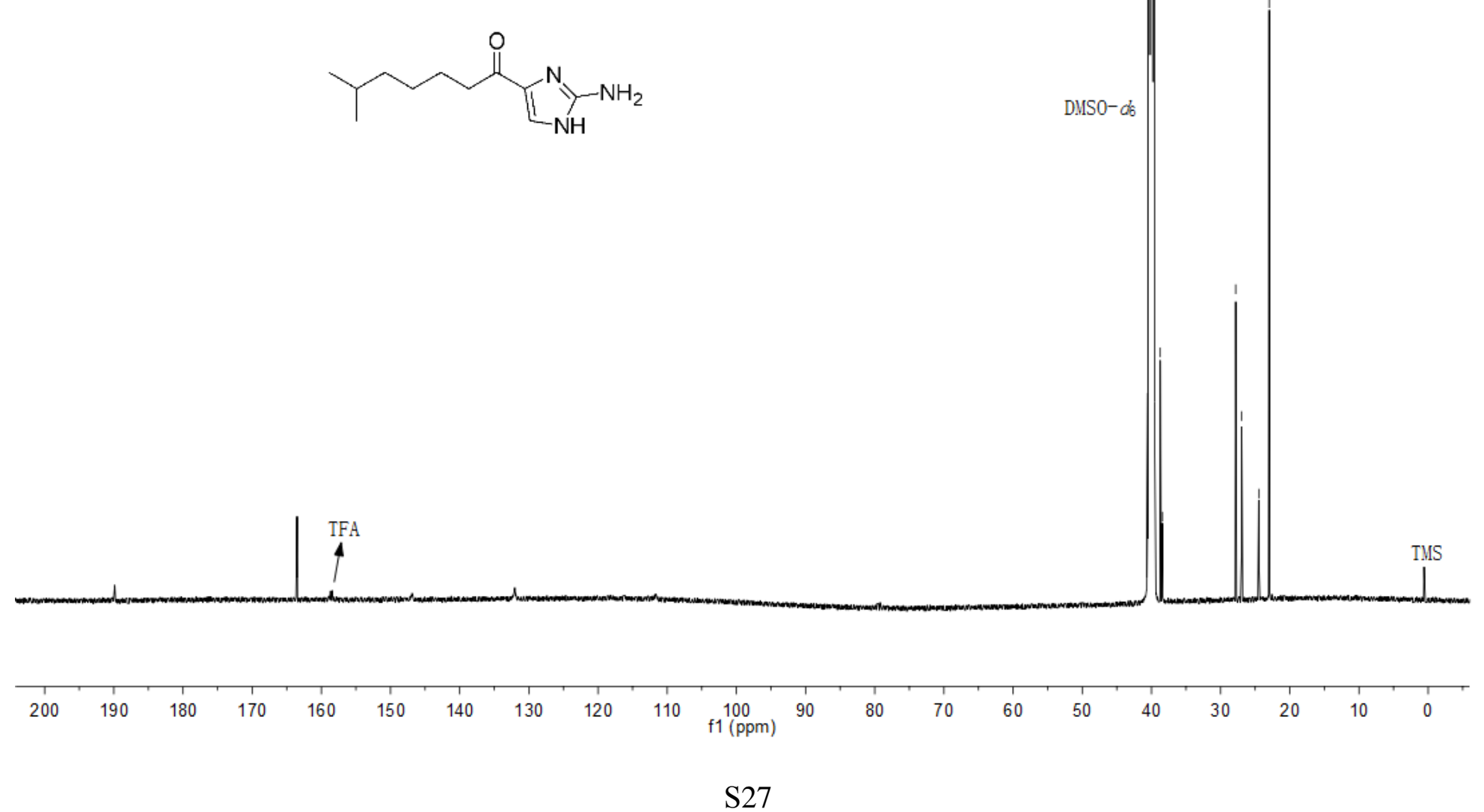


Figure S25. The ${ }^{1} \mathrm{H}$ NMR spectrum of compound $2\left(\mathrm{CDCl}_{3}, 400 \mathrm{MHz}\right)$

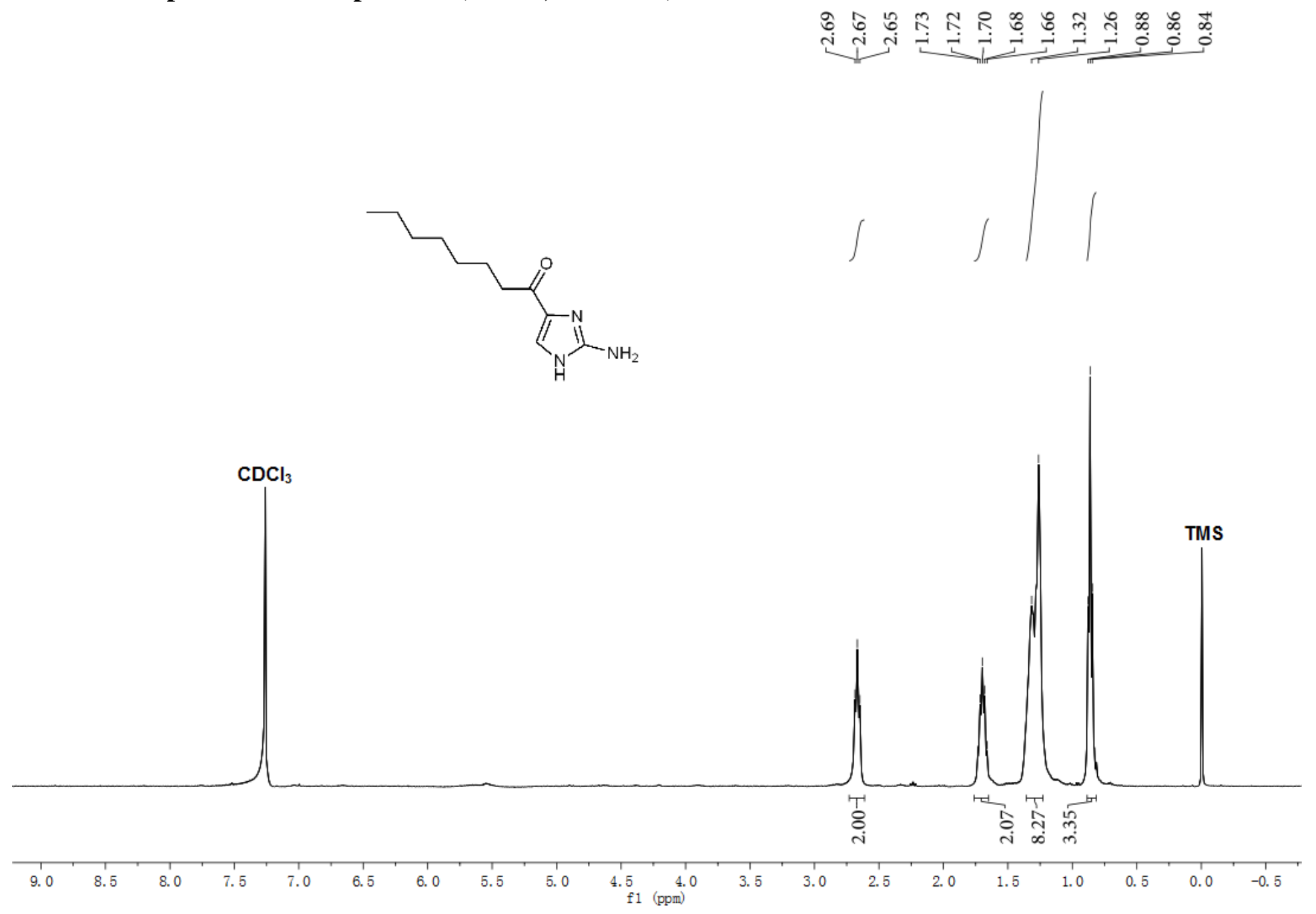


Figure S26. The ${ }^{13} \mathrm{C}$ NMR spectrum of compound $2\left(\mathrm{CDCl}_{3}, 100 \mathrm{MHz}\right)$

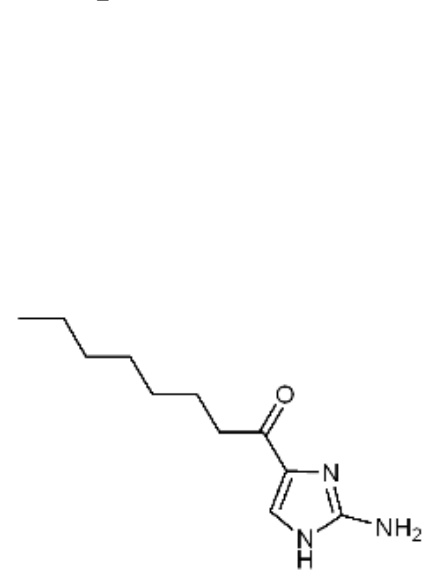

m.

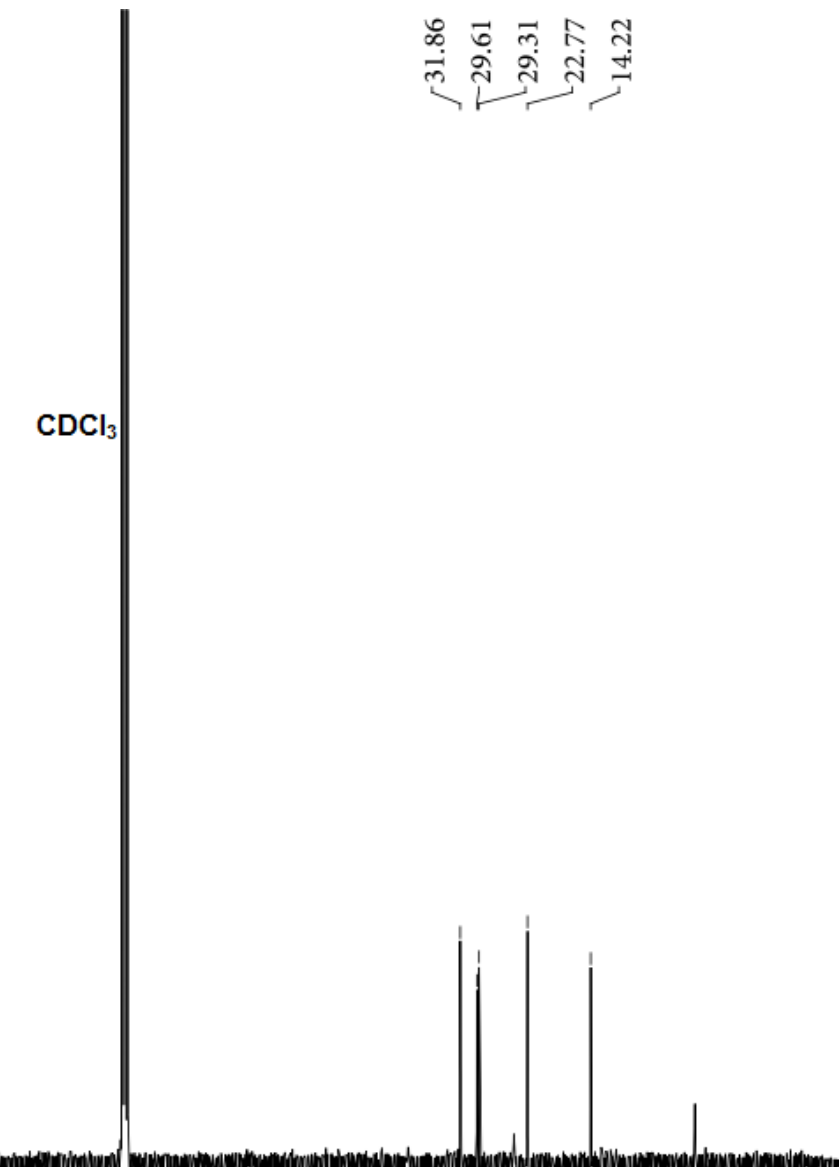

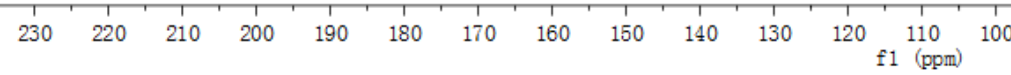


Figure S27. The HRESIMS spectrum of compound 2

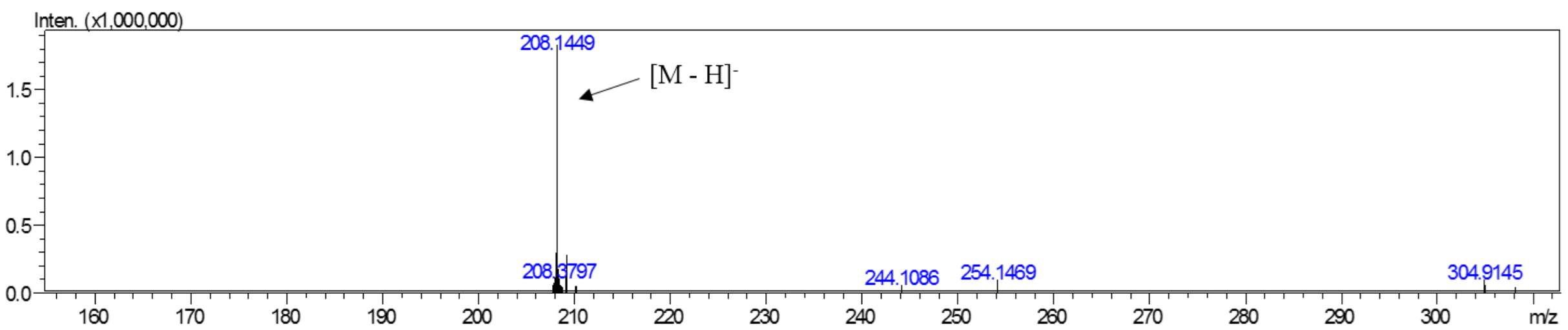


Figure S28. The IR spectrum of compound 2

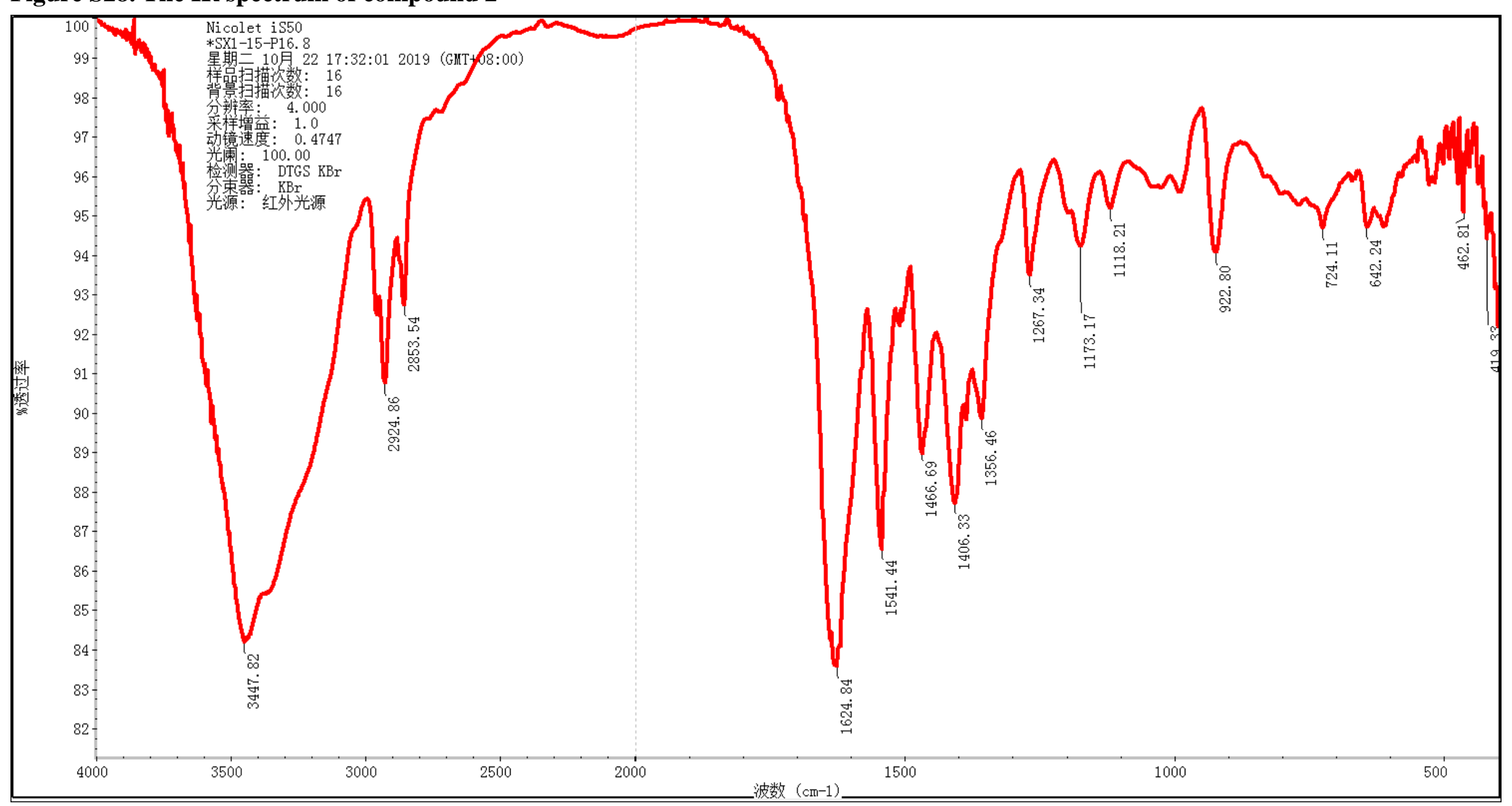


Figure S29. The ${ }^{1} \mathrm{H}$ NMR spectrum of compound $2 \mathrm{a}\left(\mathrm{CDCl}_{3}, 600 \mathrm{MHz}\right)$

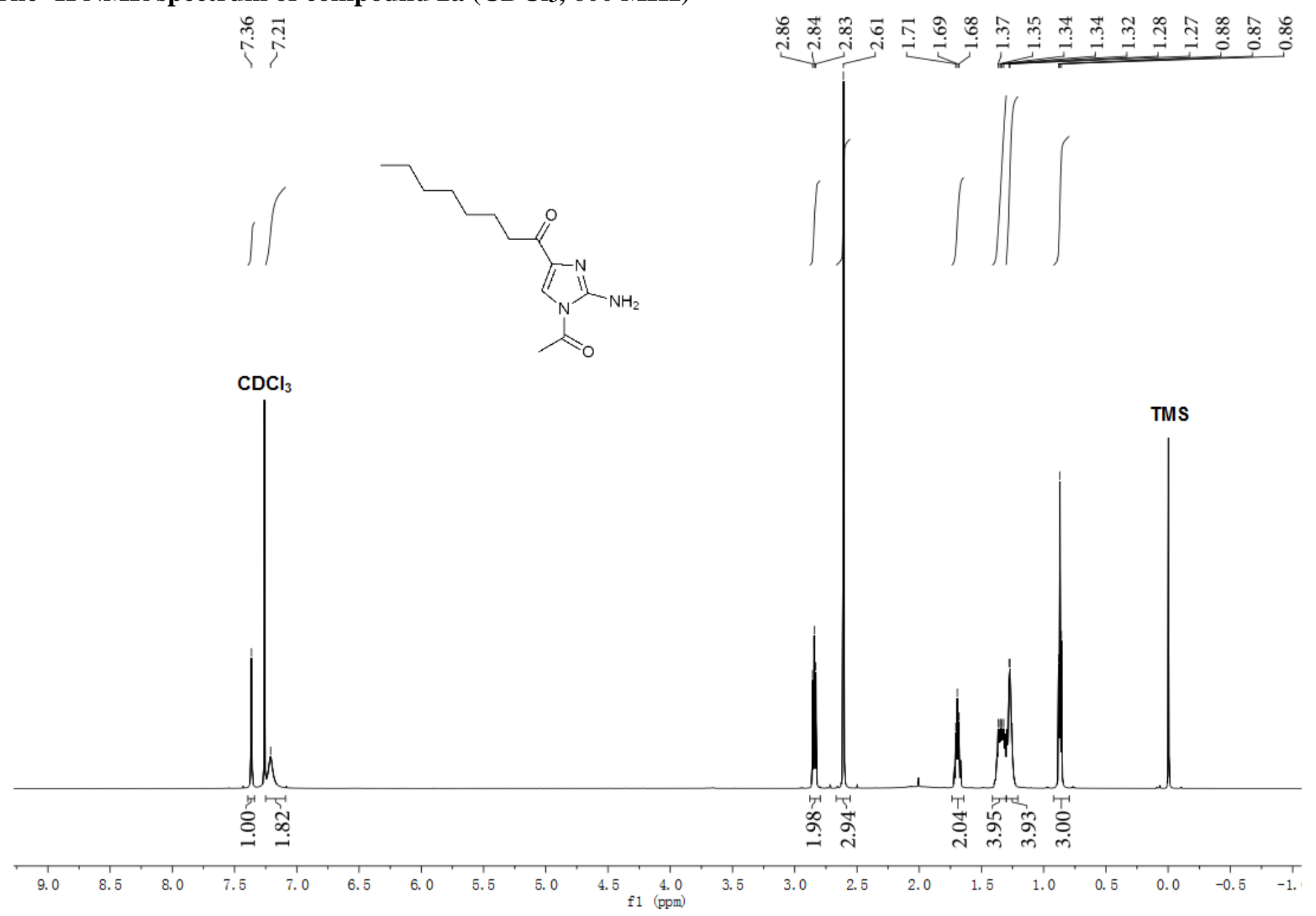


Figure S30. The ${ }^{13} \mathrm{C}$ NMR spectrum of compound $2 \mathrm{a}\left(\mathrm{CDCl}_{3}, 150 \mathrm{MHz}\right)$

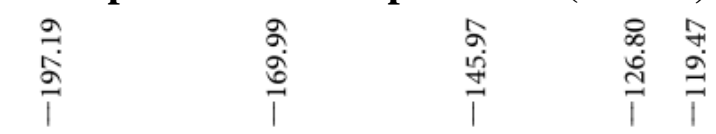

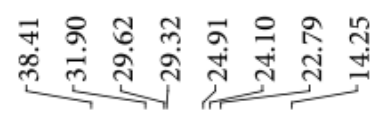

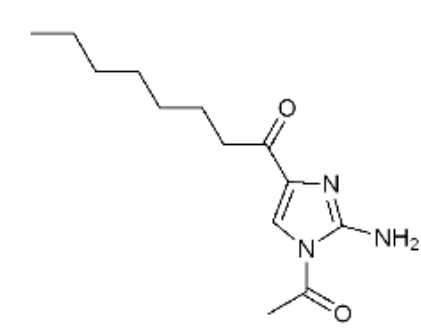

$\mathrm{CDCl}_{3}$

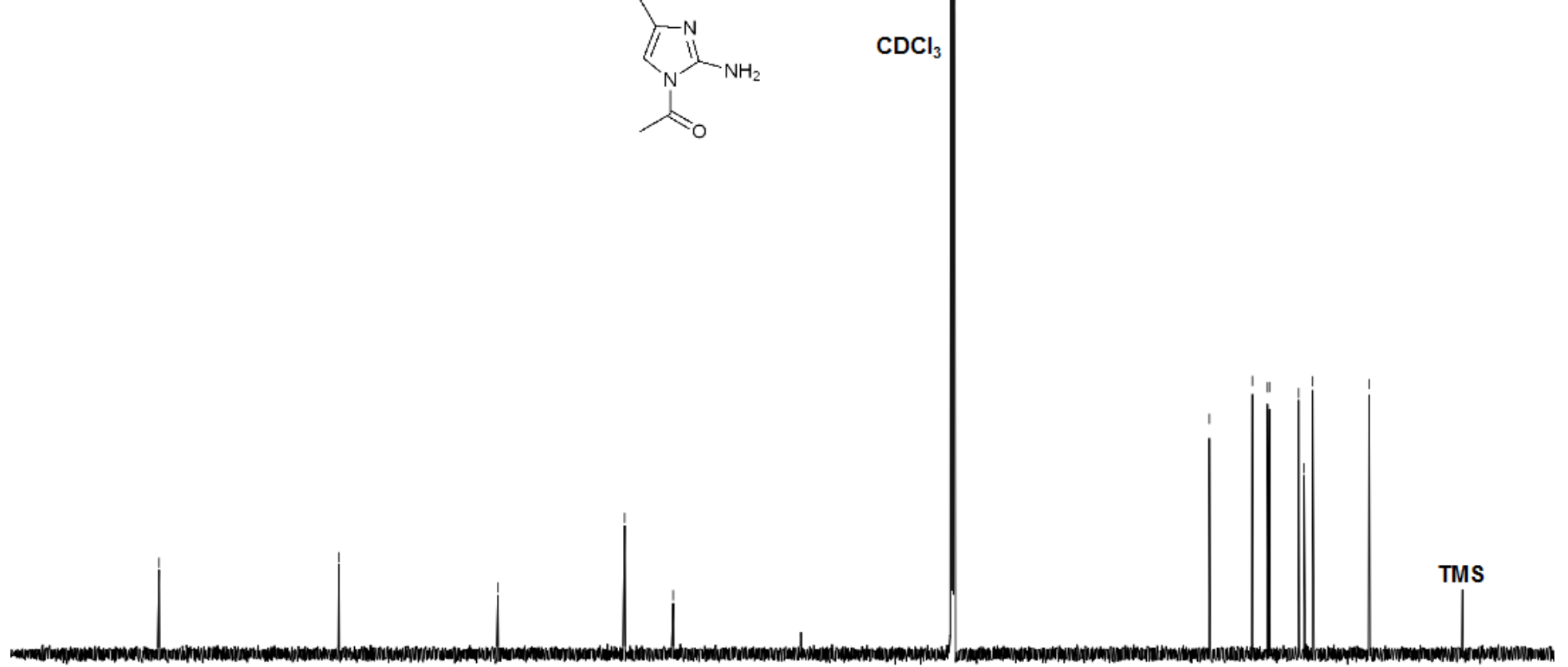

$\begin{array}{llllllllllll}210 & 200 & 190 & 180 & 170 & 160 & 150 & 140 & 130 & 120 & 110 & 100\end{array}$ 
Figure S31. The COSY spectrum of compound $2 \mathrm{a}\left(\mathrm{CDCl}_{3}, 600 \mathrm{MHz}\right)$

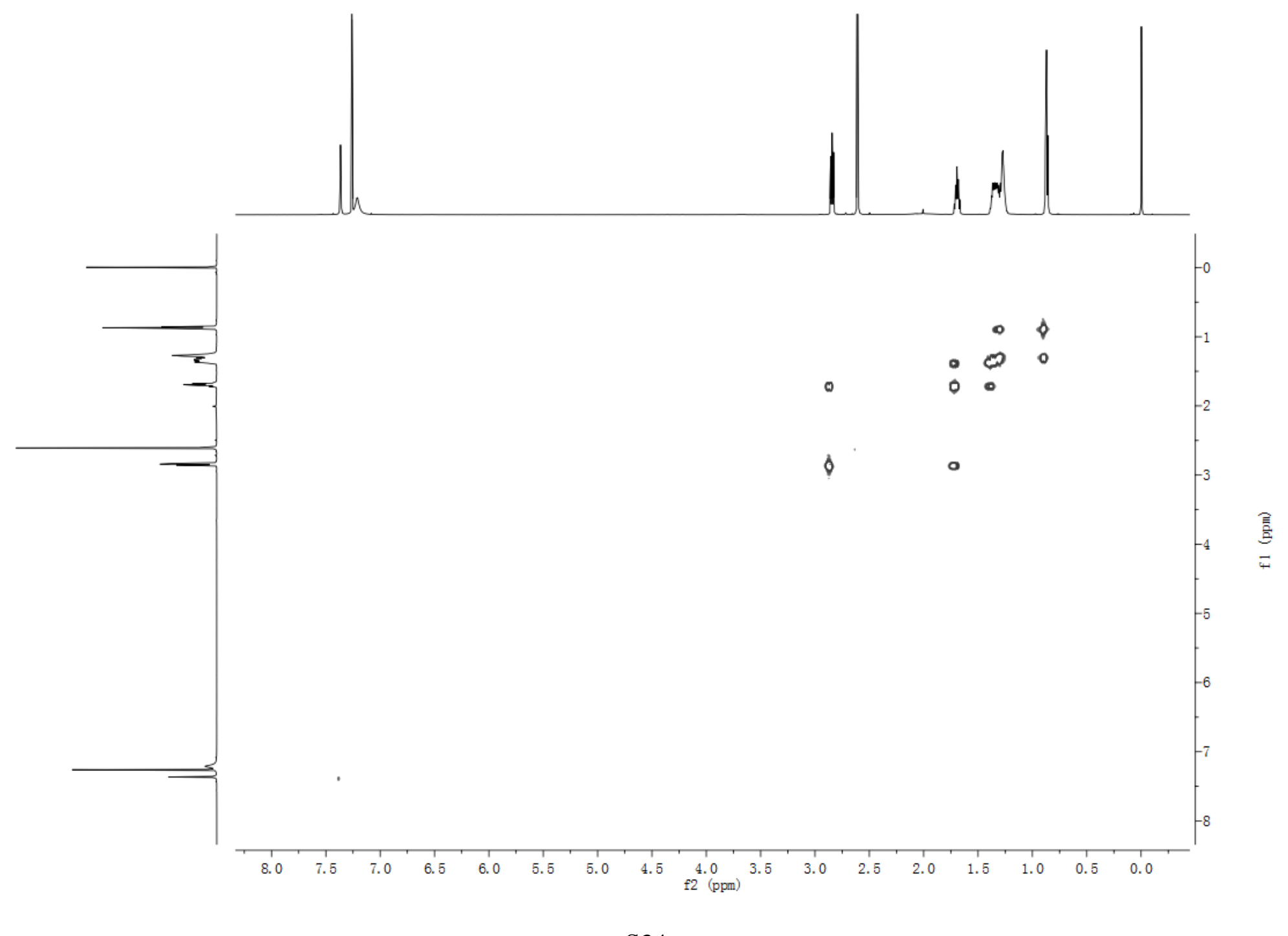


Figure S32. The HSQC spectrum of compound $2 \mathrm{a}\left(\mathrm{CDCl}_{3}, 600 \mathrm{MHz}\right)$

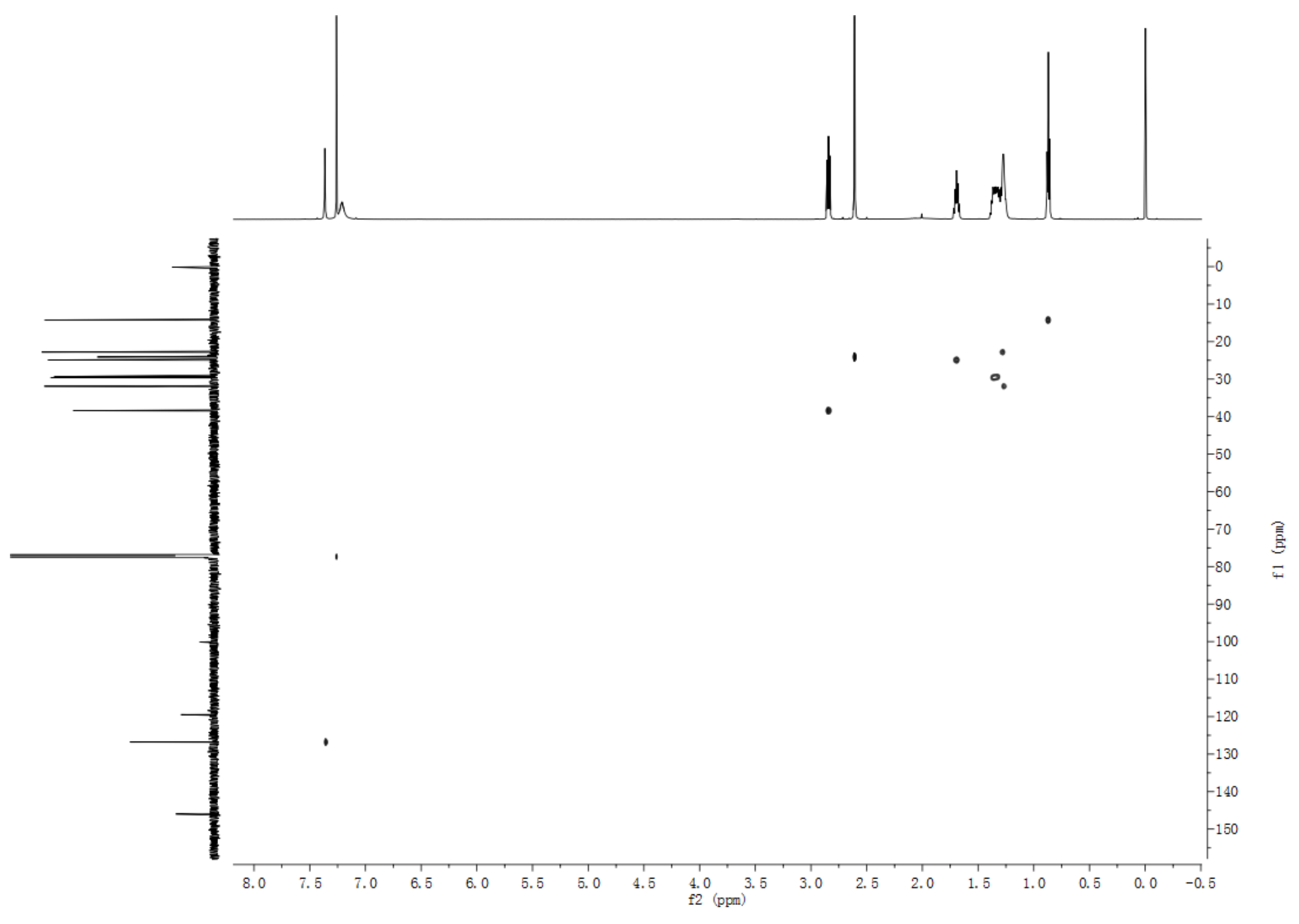


Figure S33. The HMBC spectrum of compound $2 \mathrm{a}\left(\mathrm{CDCl}_{3}, 600 \mathrm{MHz}\right)$

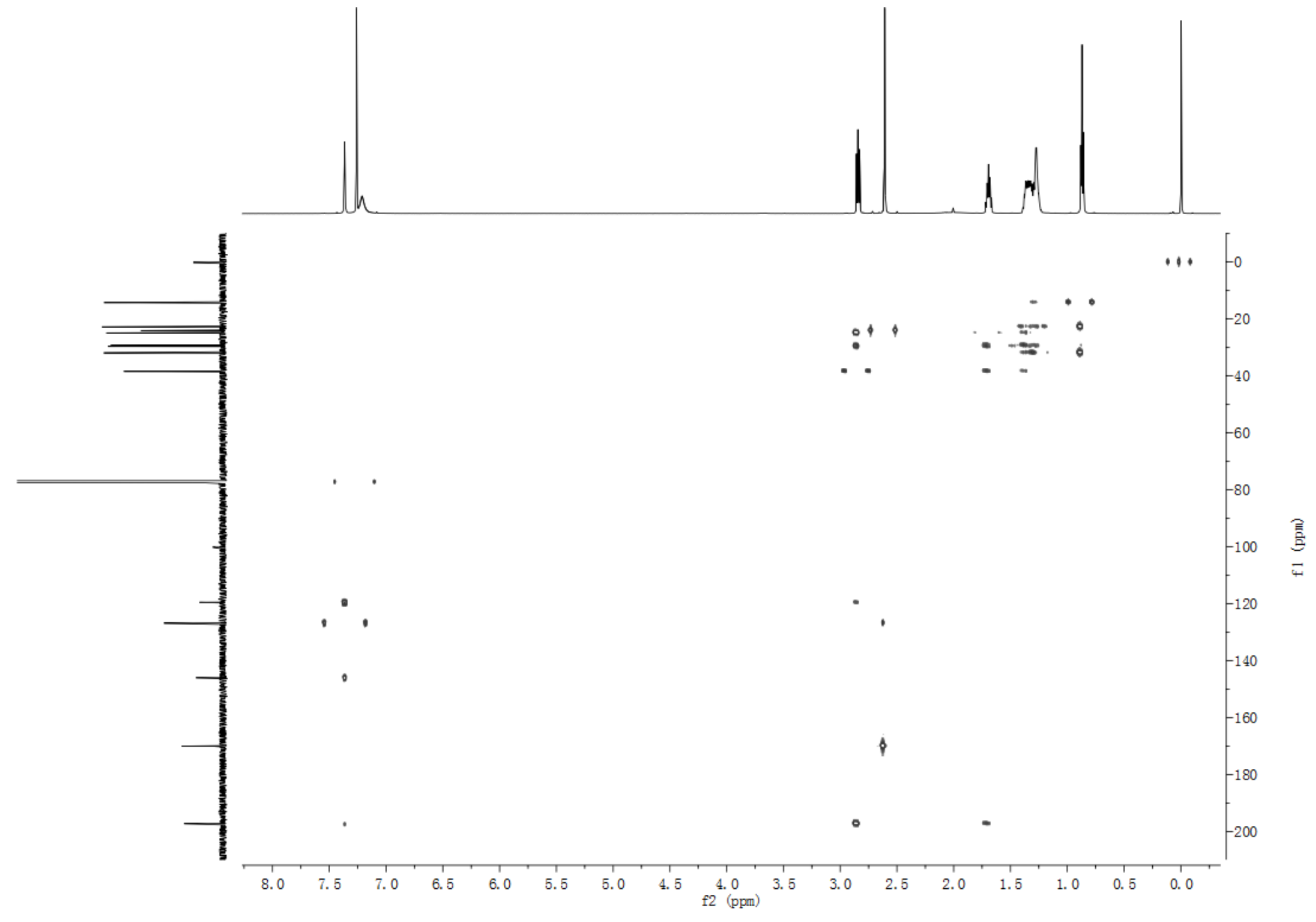


Figure S34. The NOESY spectrum of compound 2a $\left(\mathrm{CDCl}_{3}, 600 \mathrm{MHz}\right)$

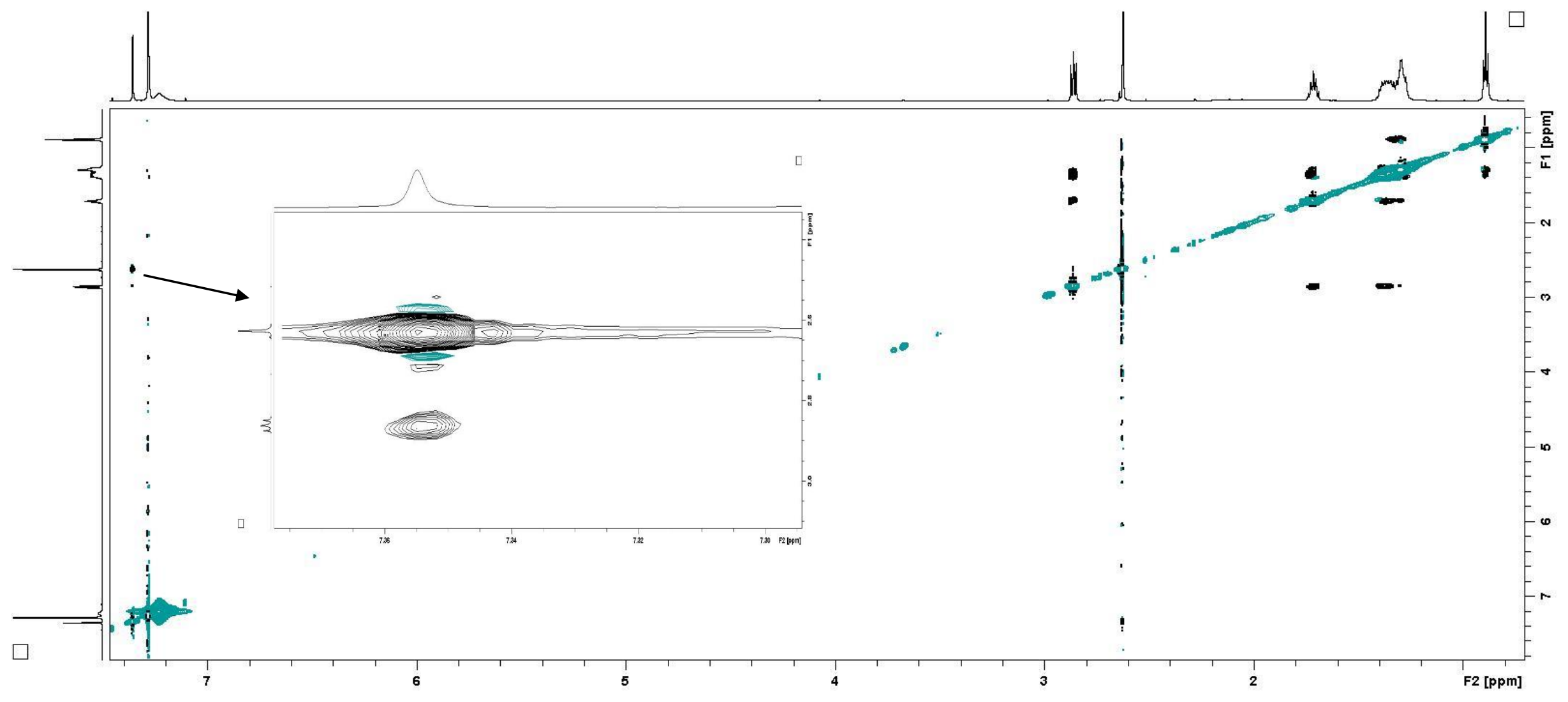


Figure S35. The HRESIMS spectrum of compound 2a

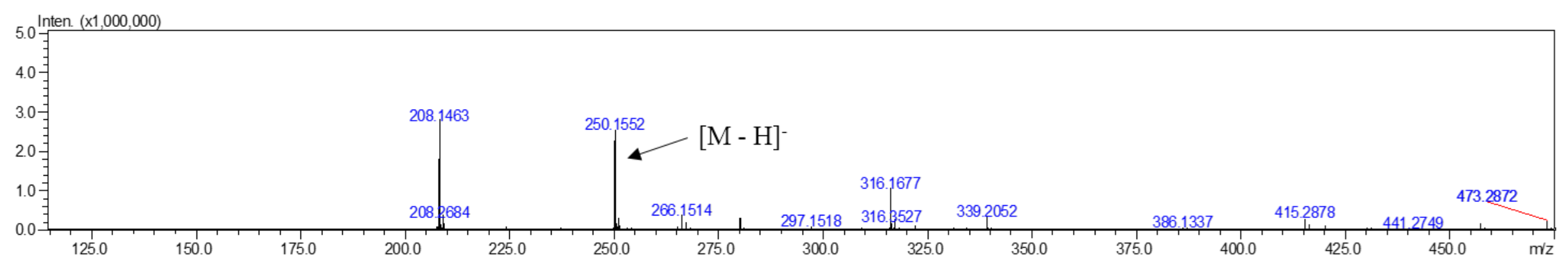


Figure S36. The ${ }^{1} \mathrm{H}$ NMR spectrum of compound $3\left(\mathrm{CDCl}_{3}, 400 \mathrm{MHz}\right)$

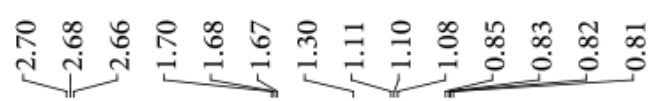
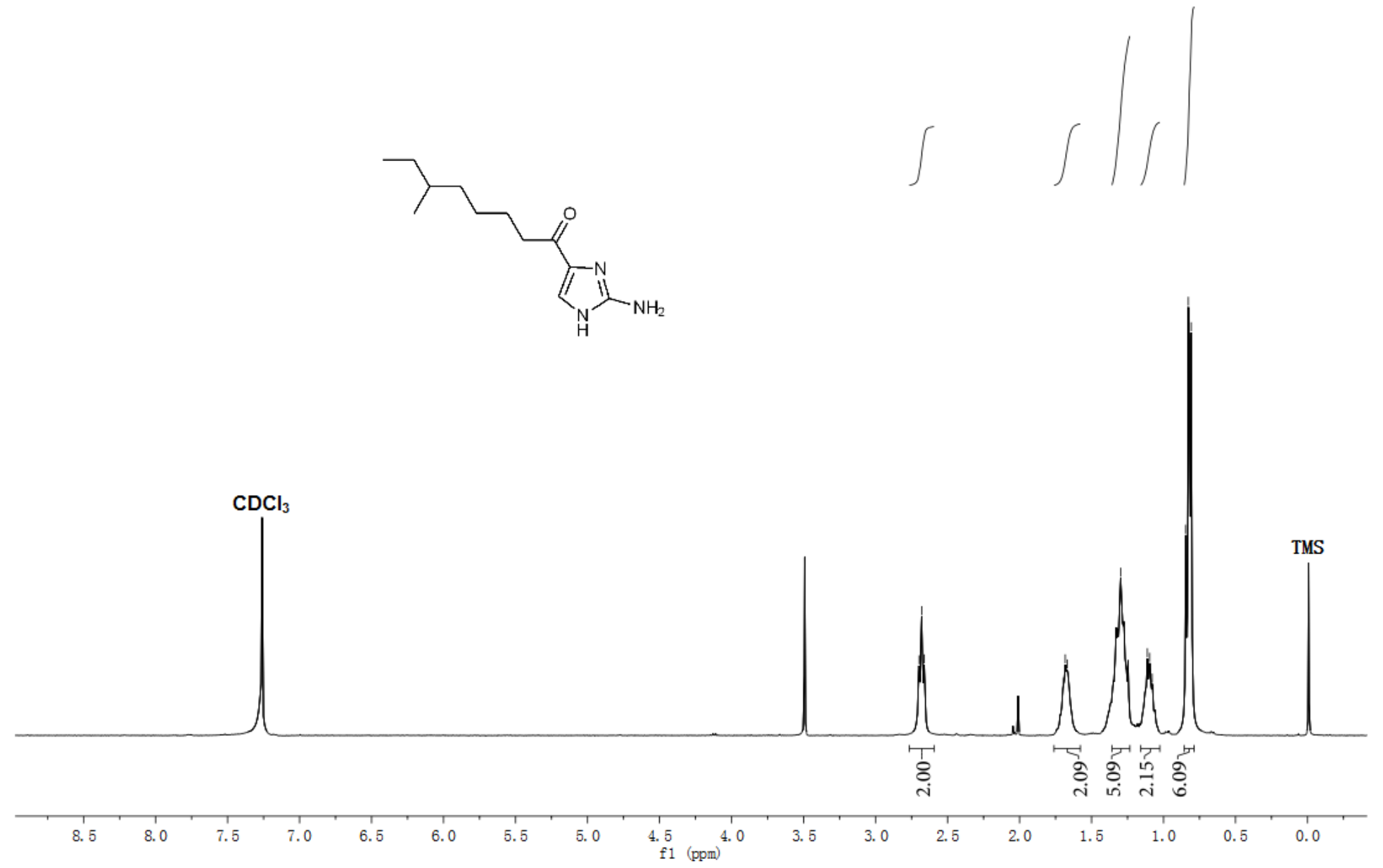
Figure S37. The ${ }^{13} \mathrm{C}$ NMR spectrum of compound $3\left(\mathrm{CDCl}_{3}, 100 \mathrm{MHz}\right)$
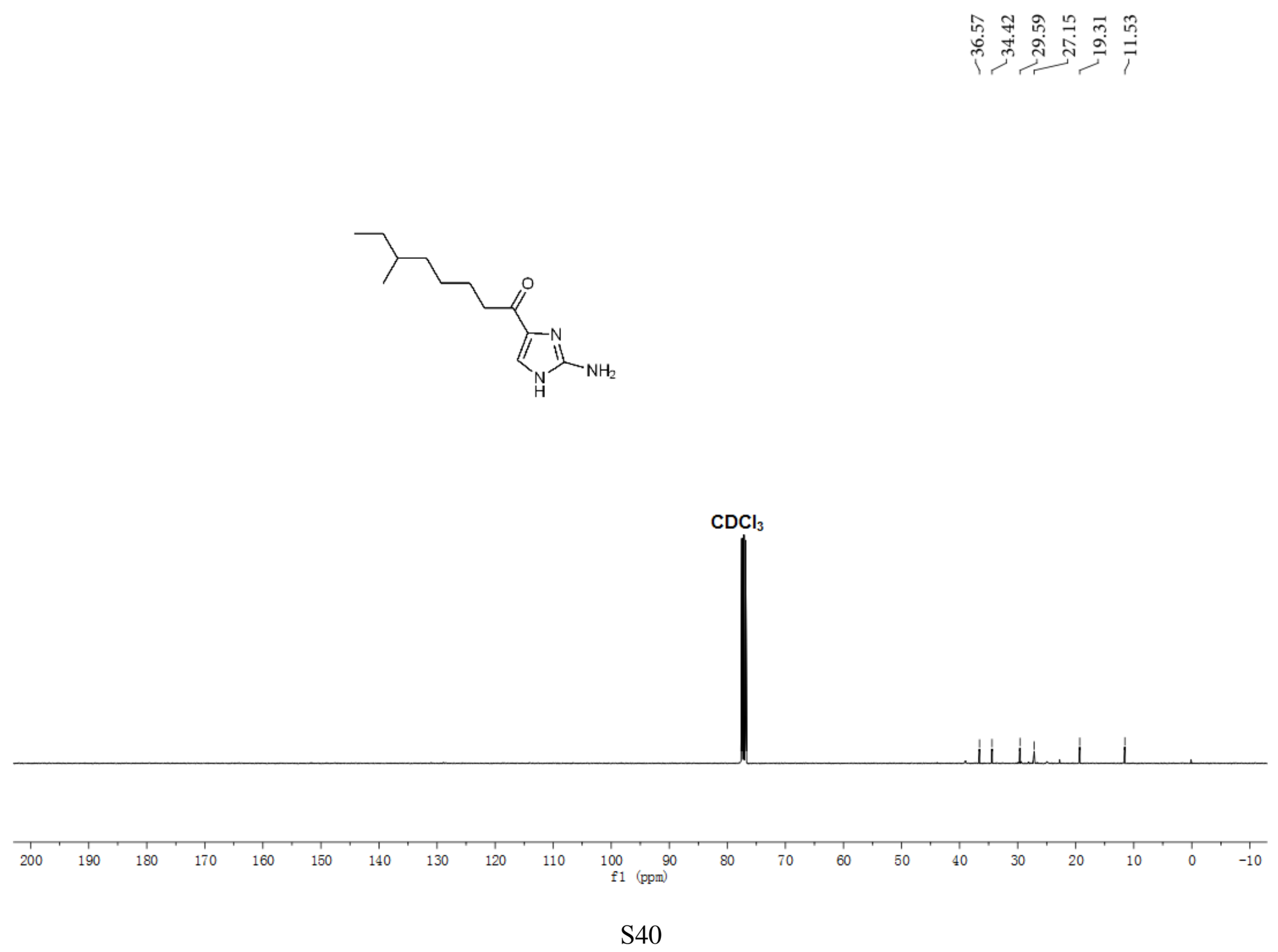
Figure S38. The HRESIMS spectrum of compound 3

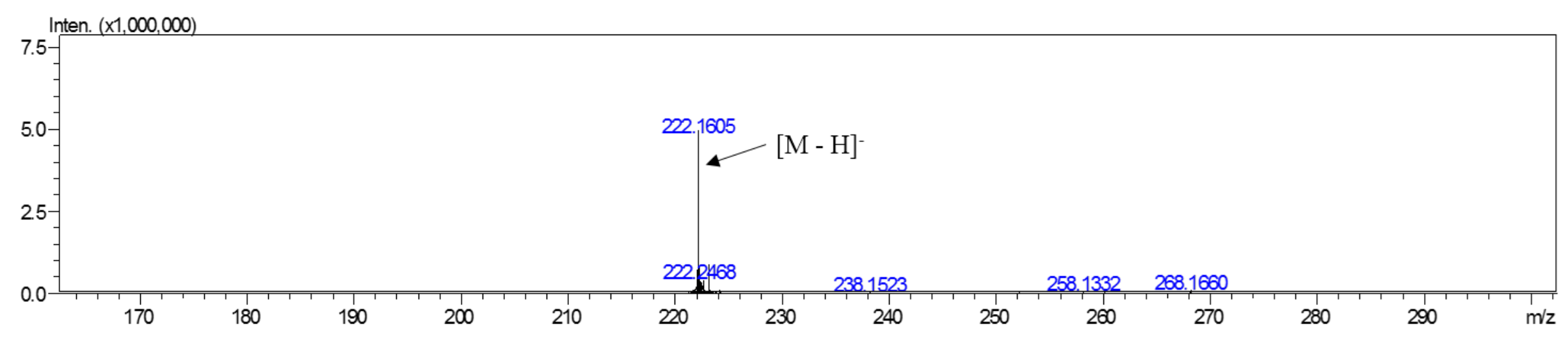


Figure S39. The IR spectrum of compound 3

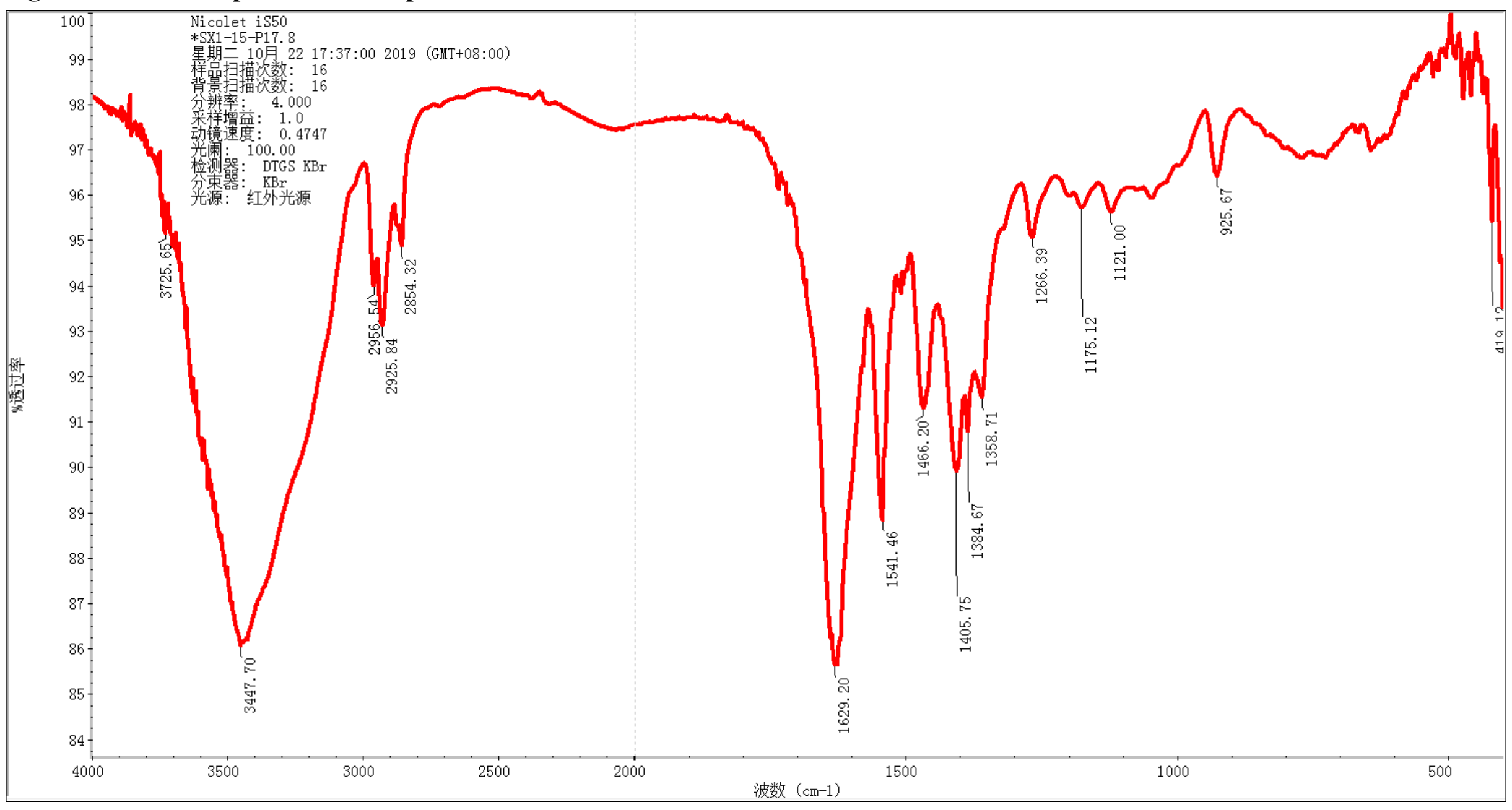


Figure S40. The ${ }^{1} \mathrm{H}$ NMR spectrum of compound 3a $\left(\mathrm{CDCl}_{3}, 600 \mathrm{MHz}\right)$

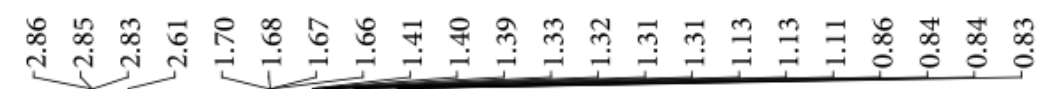

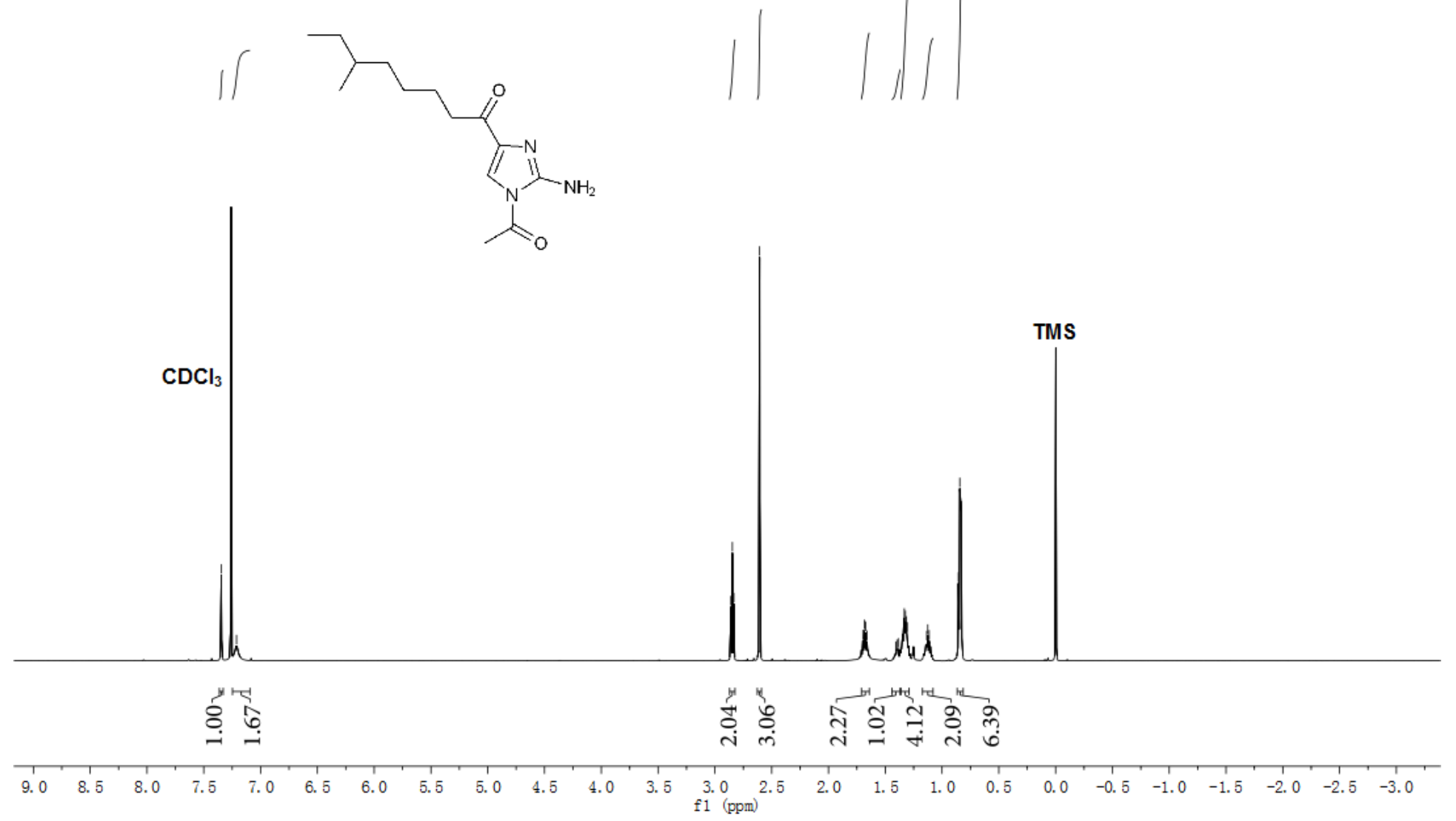


Figure S41. The ${ }^{13} \mathrm{C}$ NMR spectrum of compound $3 \mathrm{a}\left(\mathrm{CDCl}_{3}, 150 \mathrm{MHz}\right)$

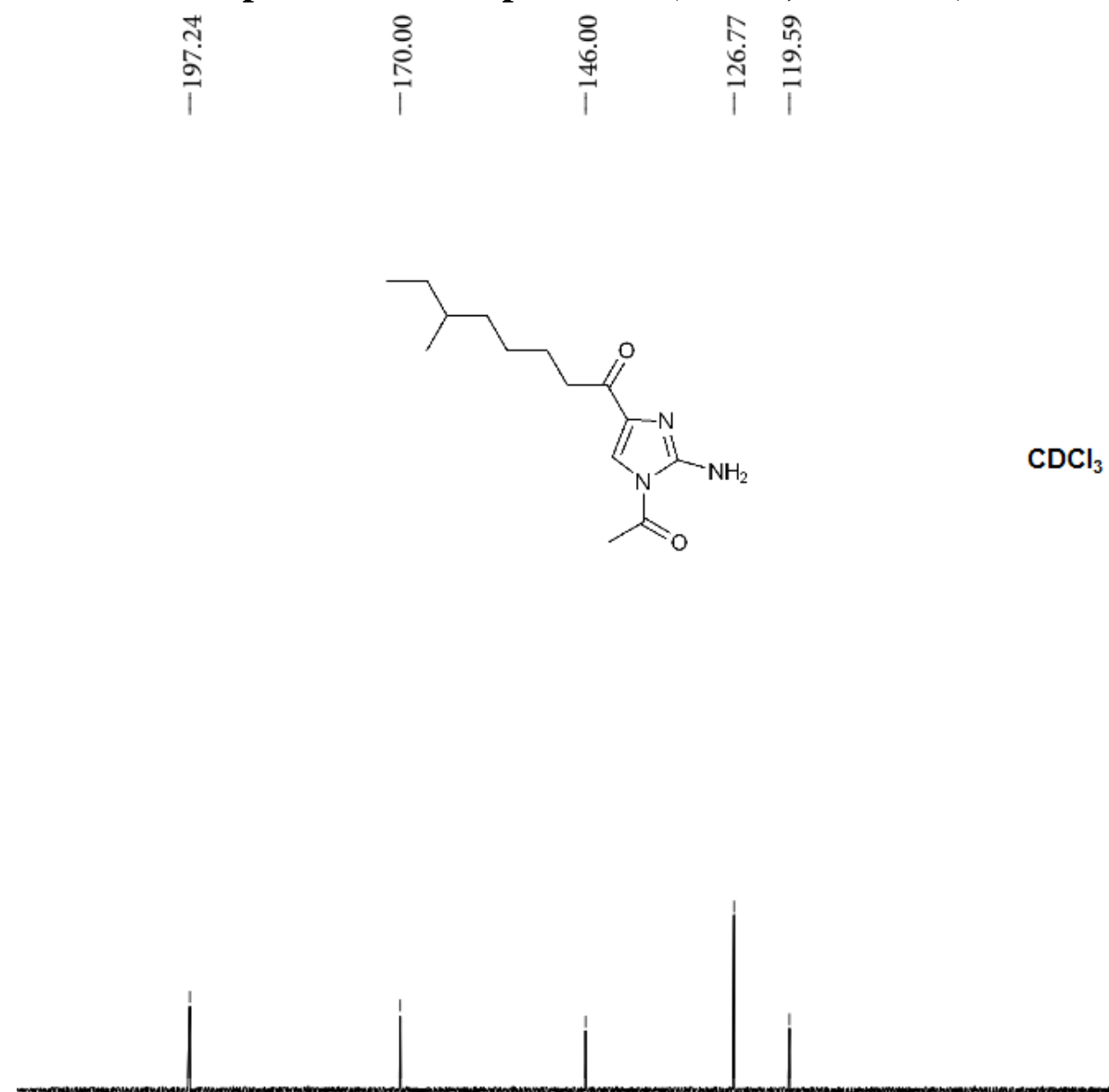

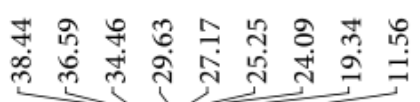

点
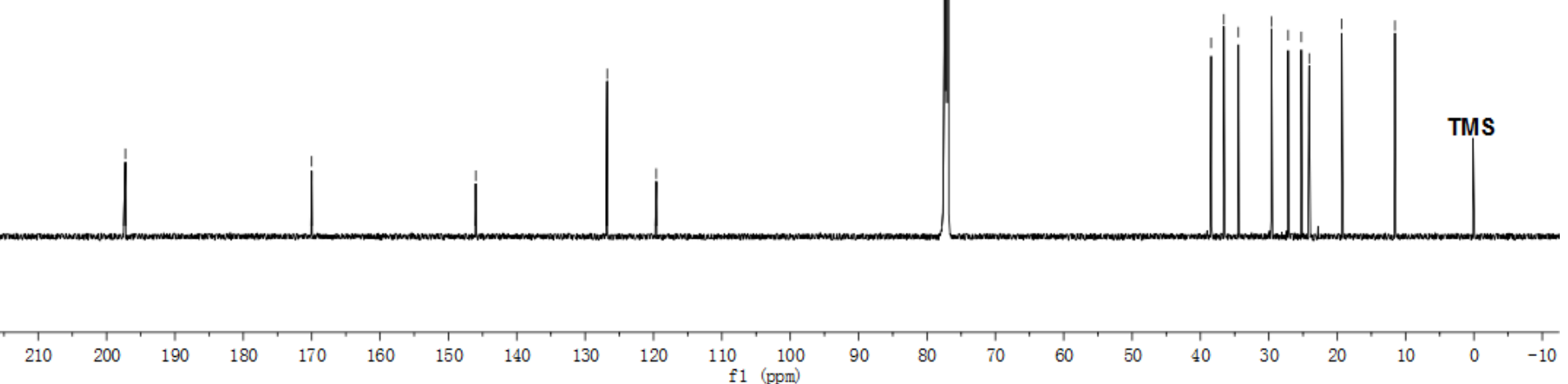
Figure S42. The COSY spectrum of compound $3 \mathrm{a}\left(\mathrm{CDCl}_{3}, 600 \mathrm{MHz}\right)$

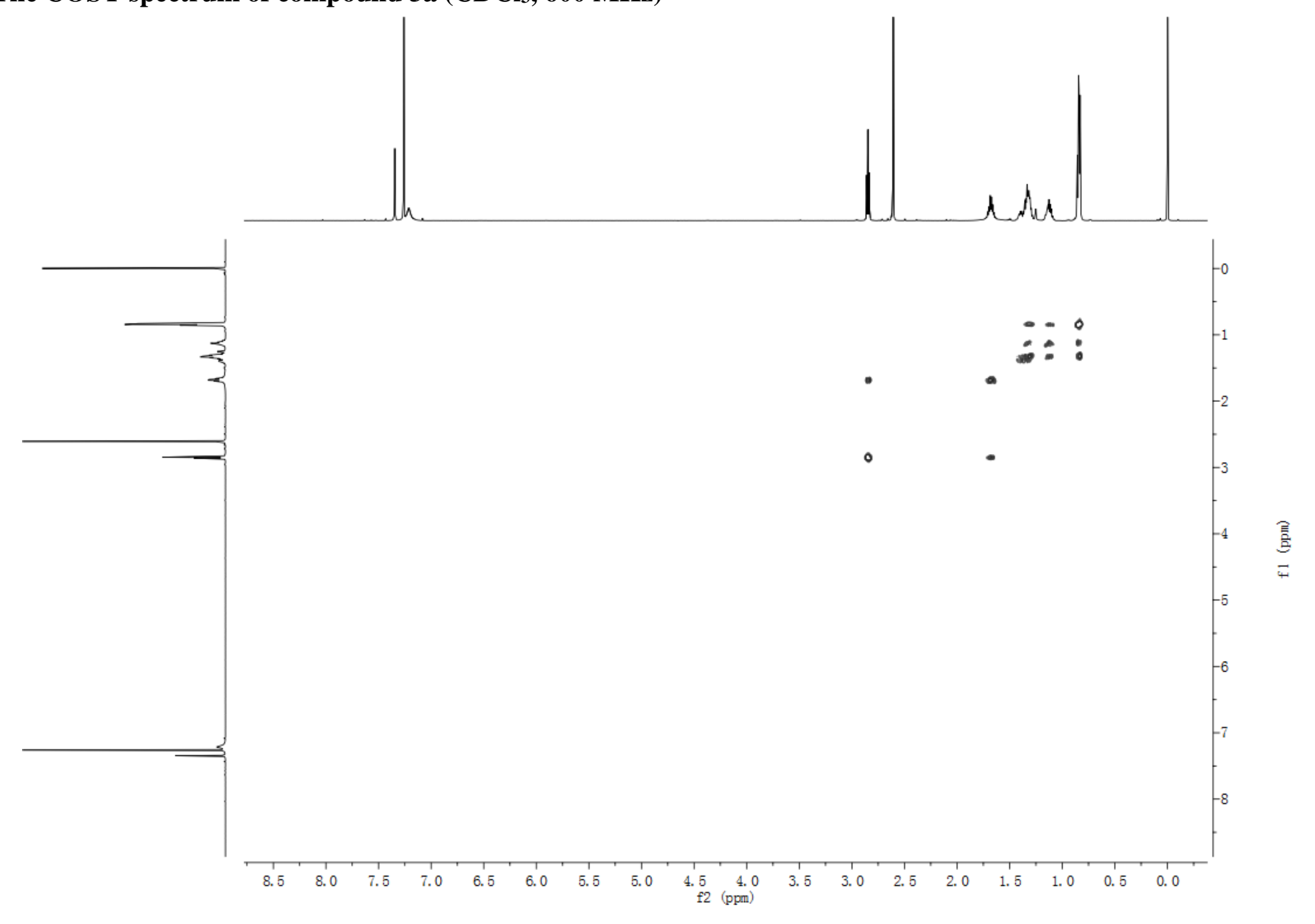


Figure S43. The HSQC spectrum of compound $3 \mathrm{a}\left(\mathrm{CDCl}_{3}, 600 \mathrm{MHz}\right)$

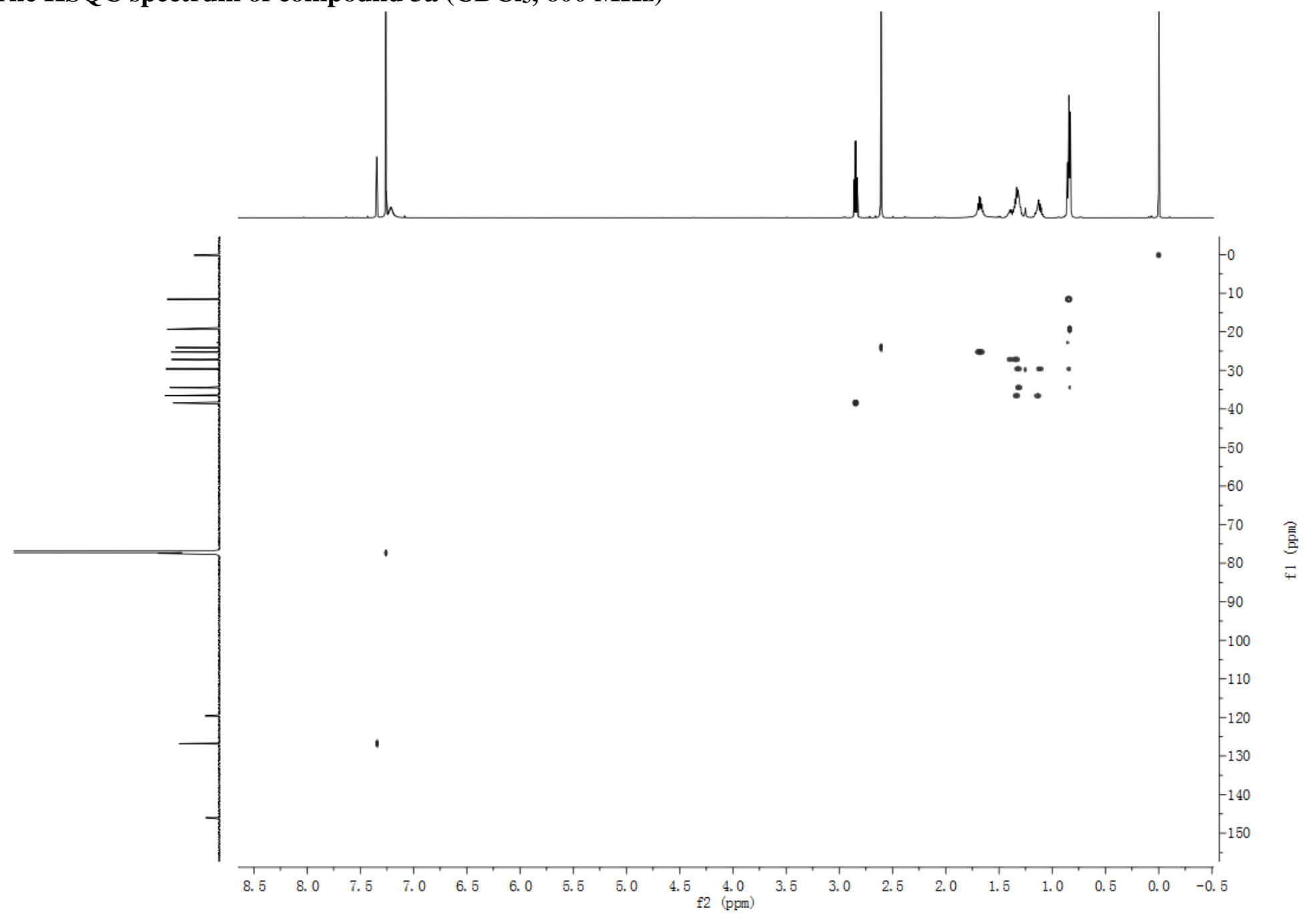


Figure $\mathrm{S44}$. The HMBC spectrum of compound $3 \mathrm{a}\left(\mathrm{CDCl}_{3}, 600 \mathrm{MHz}\right)$

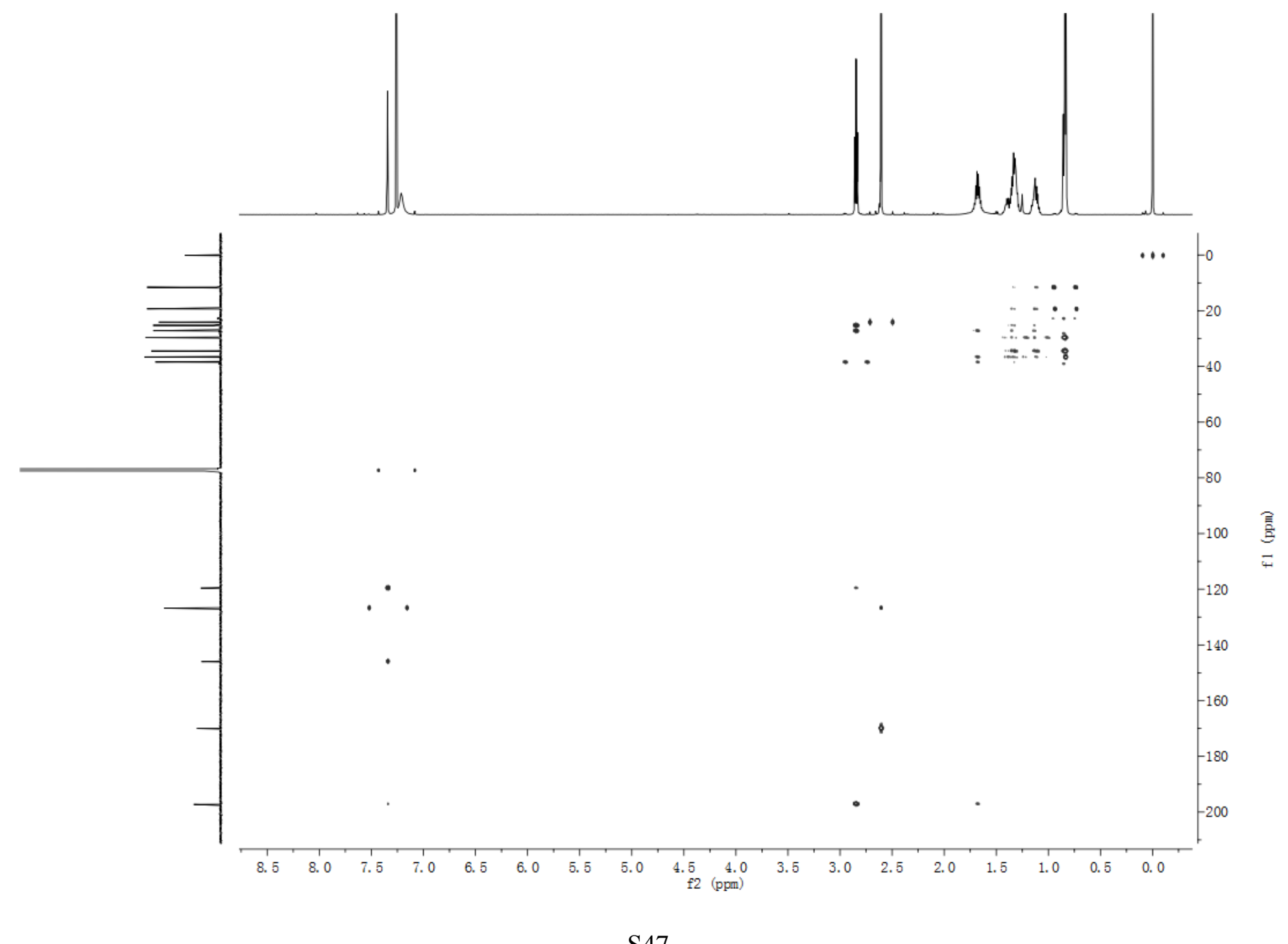


Figure S45. The HRESIMS spectrum of compound 3a

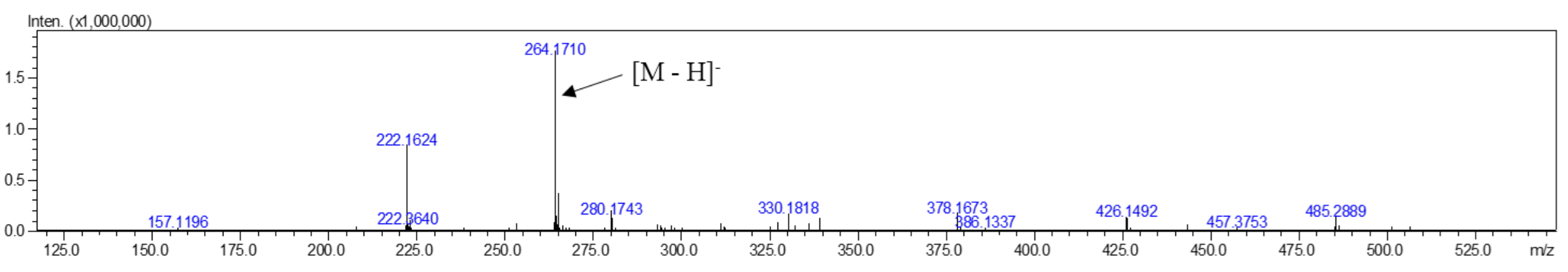


Figure S46. The ${ }^{1} \mathrm{H}$ NMR spectrum of compound $4\left(\mathrm{CDCl}_{3}, 400 \mathrm{MHz}\right)$

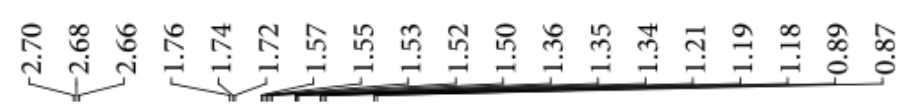
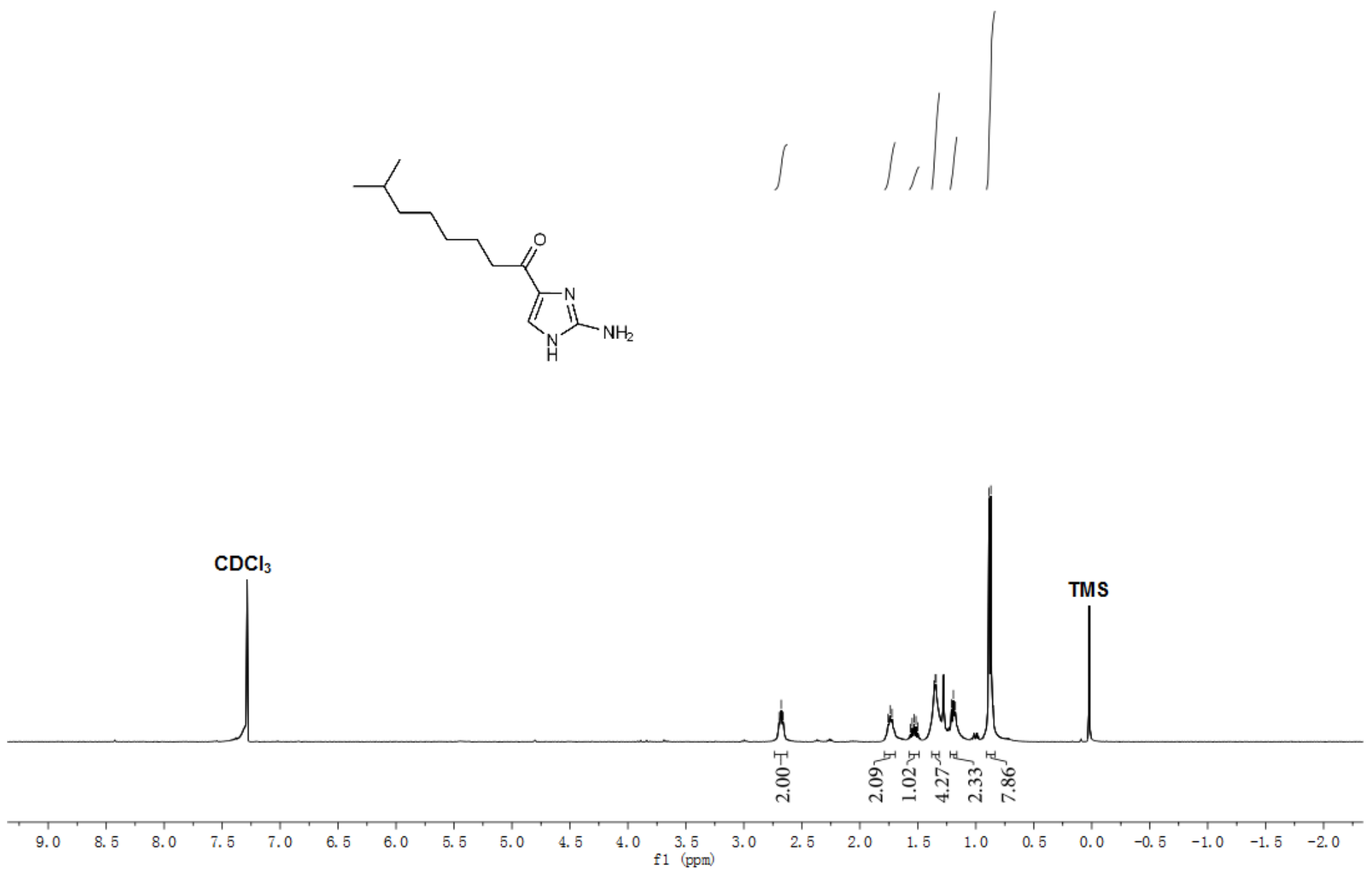
Figure S47. The ${ }^{13} \mathrm{C}$ NMR spectrum of compound $4\left(\mathrm{CDCl}_{3}, 100 \mathrm{MHz}\right)$

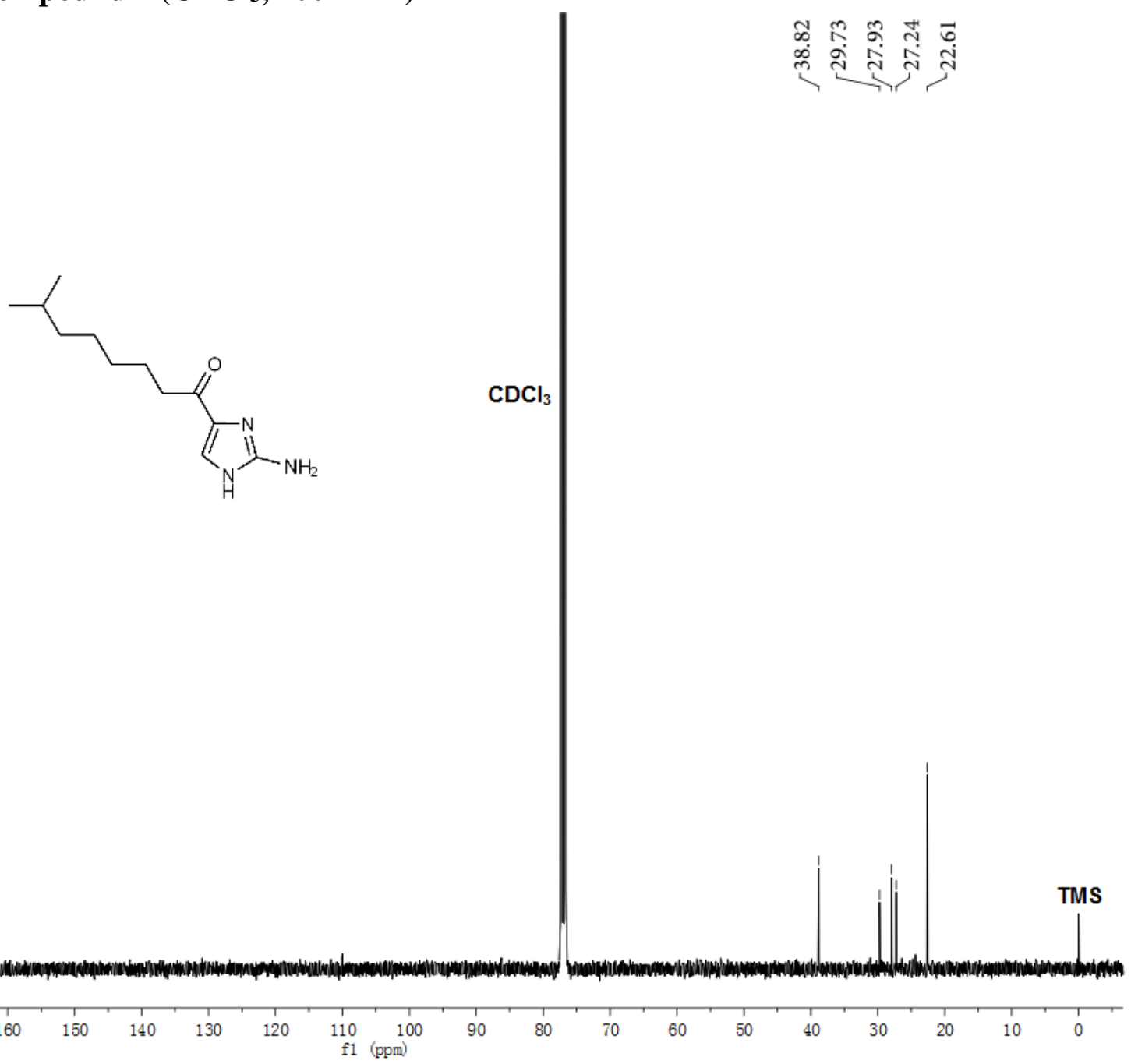


Figure S48. The HRESIMS spectrum of compound 4

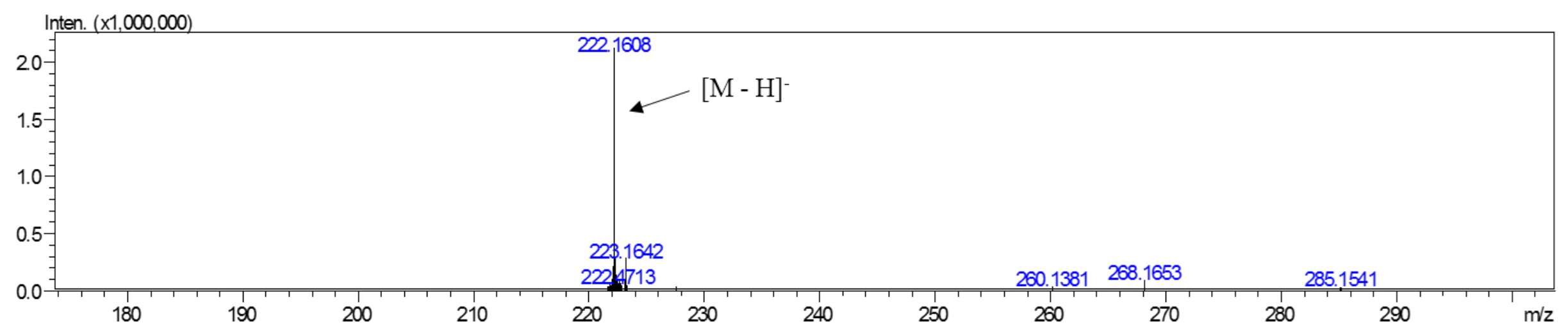


Figure S49. The IR spectrum of compound 4

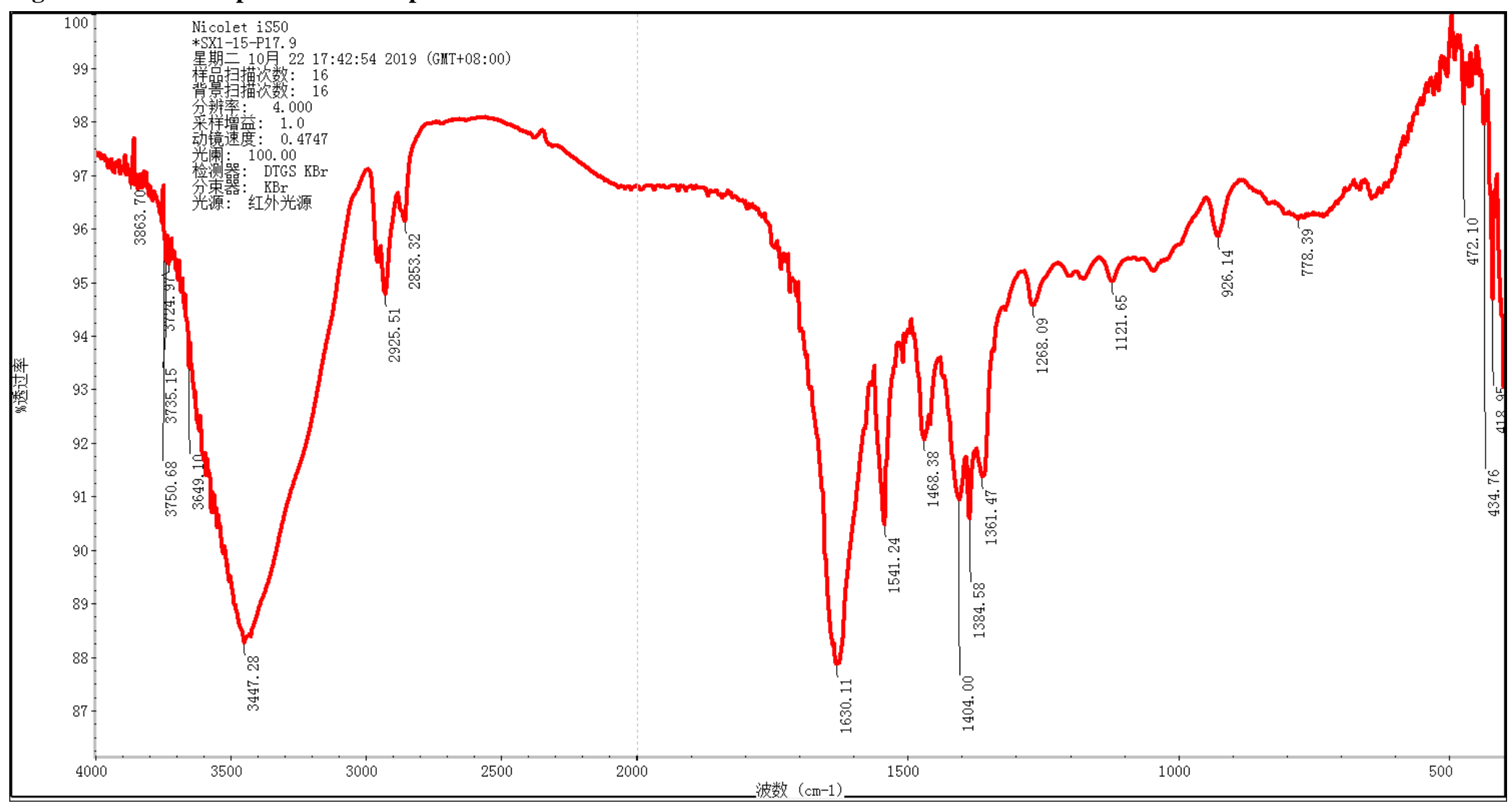


Figure S50. The ${ }^{1} \mathrm{H}$ NMR spectrum of compound $4 a\left(\mathrm{CDCl}_{3}, 600 \mathrm{MHz}\right)$

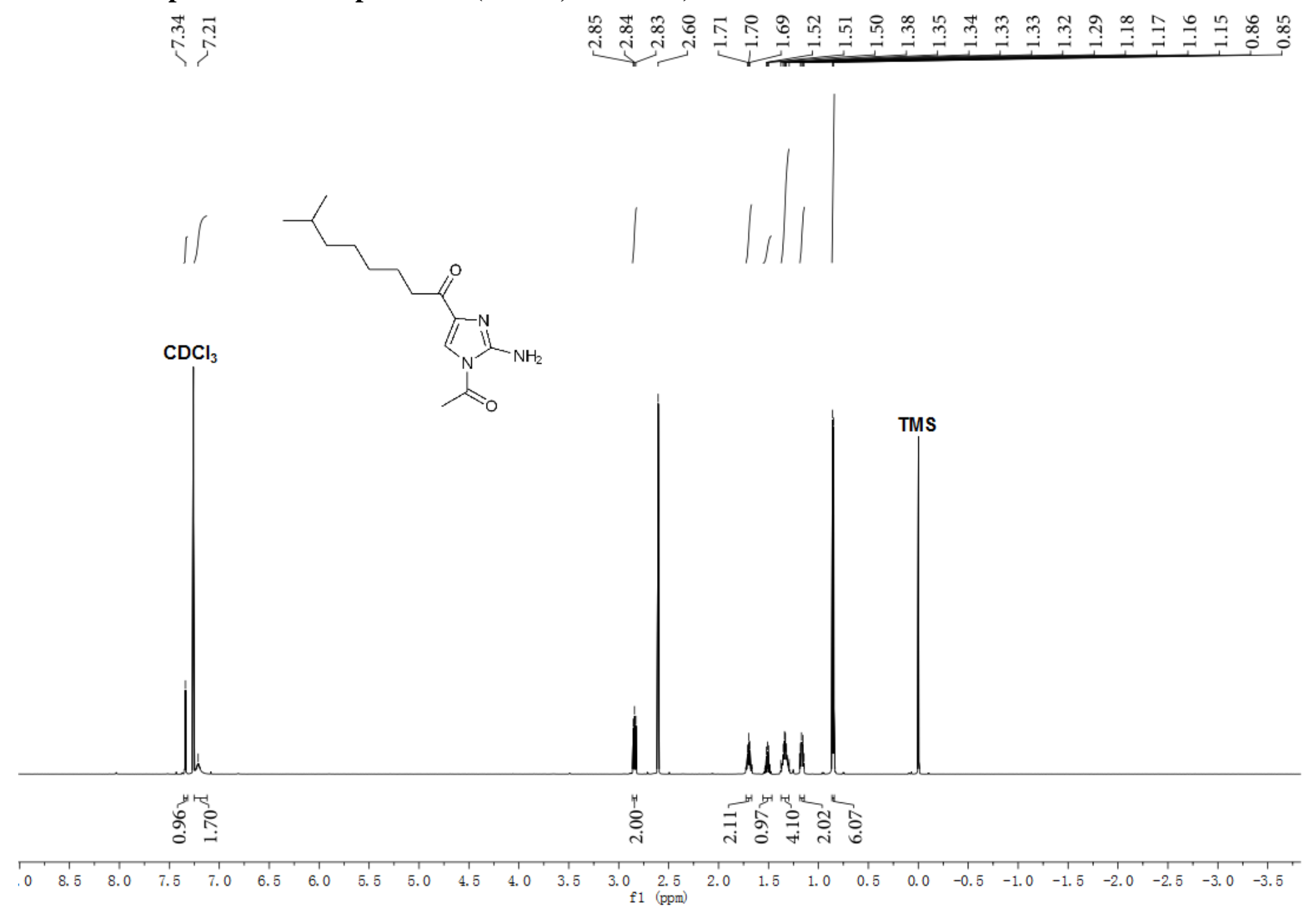


Figure S51. The ${ }^{13} \mathrm{C}$ NMR spectrum of compound $4 \mathrm{a}\left(\mathrm{CDCl}_{3}, 150 \mathrm{MHz}\right)$

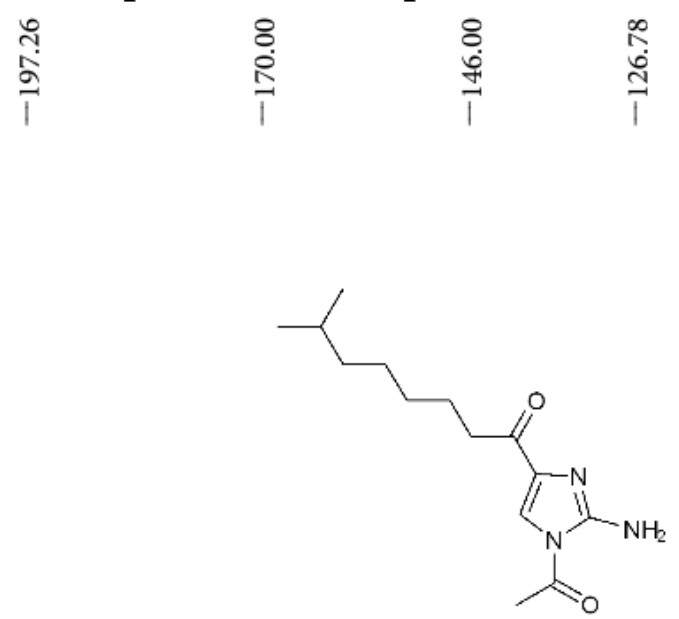

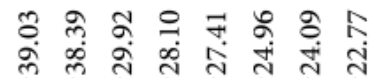

官

$\mathrm{CDCl}_{3}$
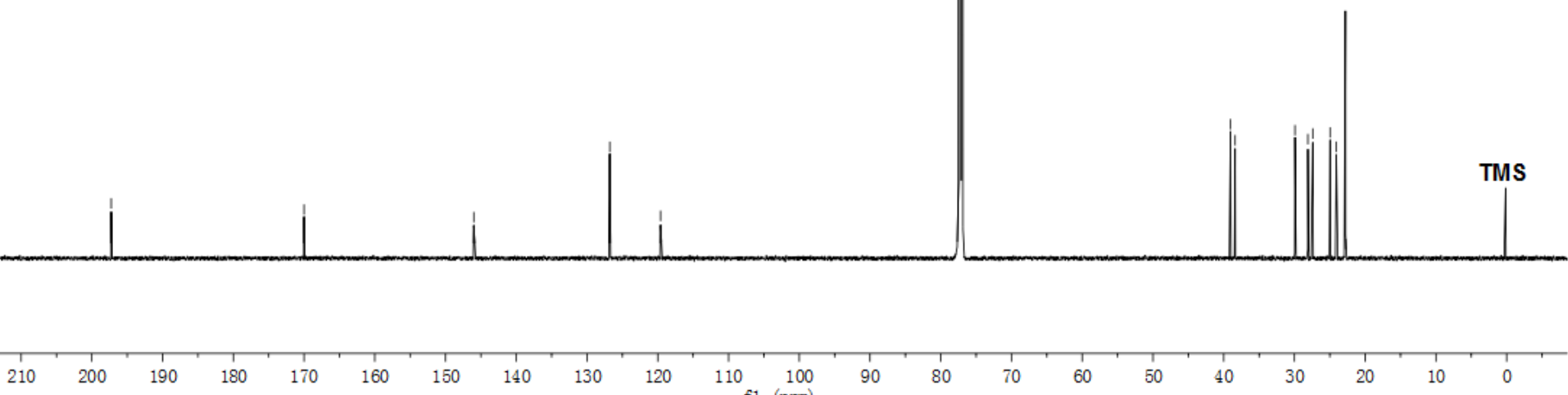

20

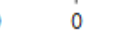


Figure S52. The COSY spectrum of compound $4 \mathrm{a}\left(\mathrm{CDCl}_{3}, 600 \mathrm{MHz}\right)$

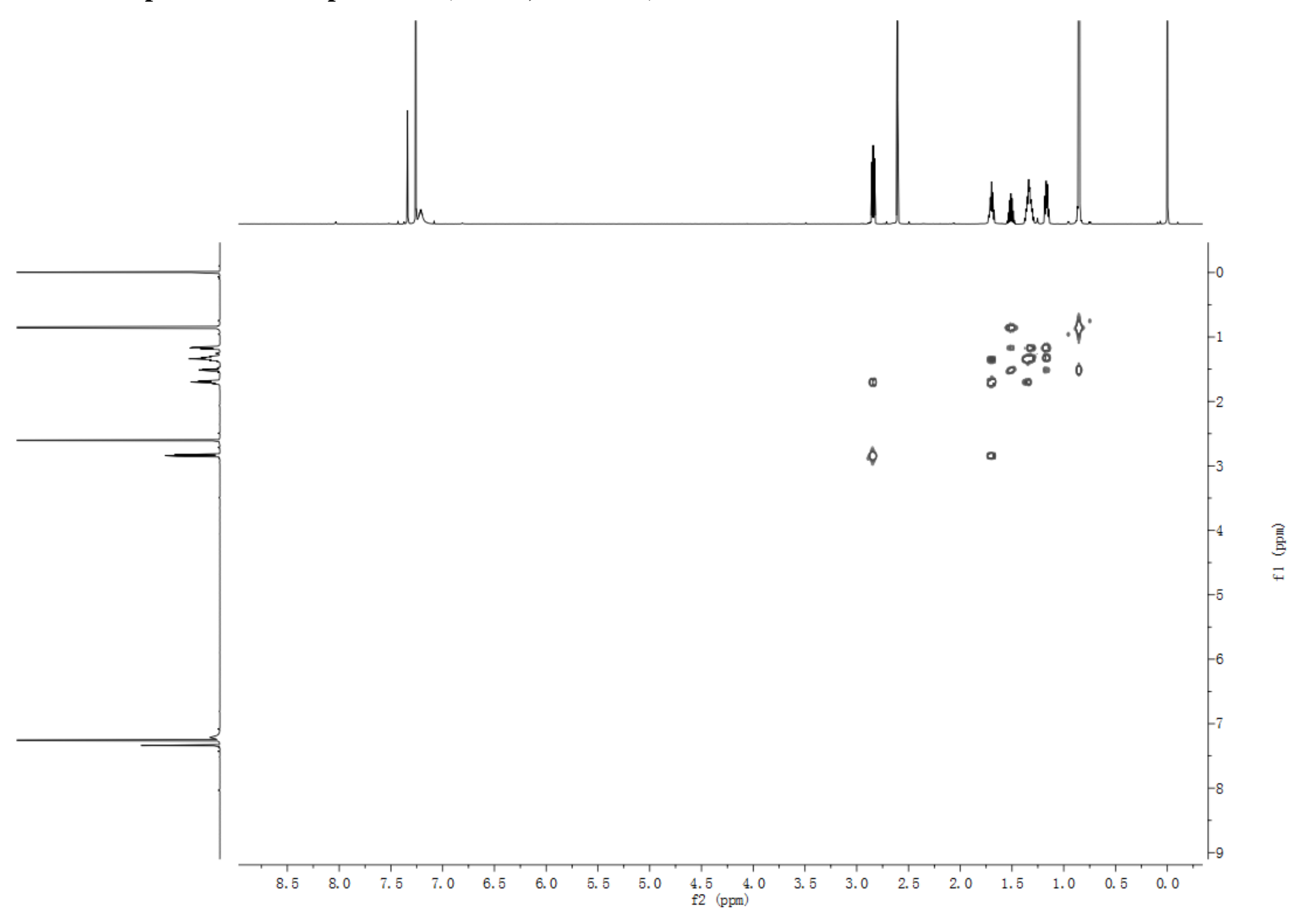


Figure S53. The HSQC spectrum of compound $4 \mathrm{a}\left(\mathrm{CDCl}_{3}, 600 \mathrm{MHz}\right)$

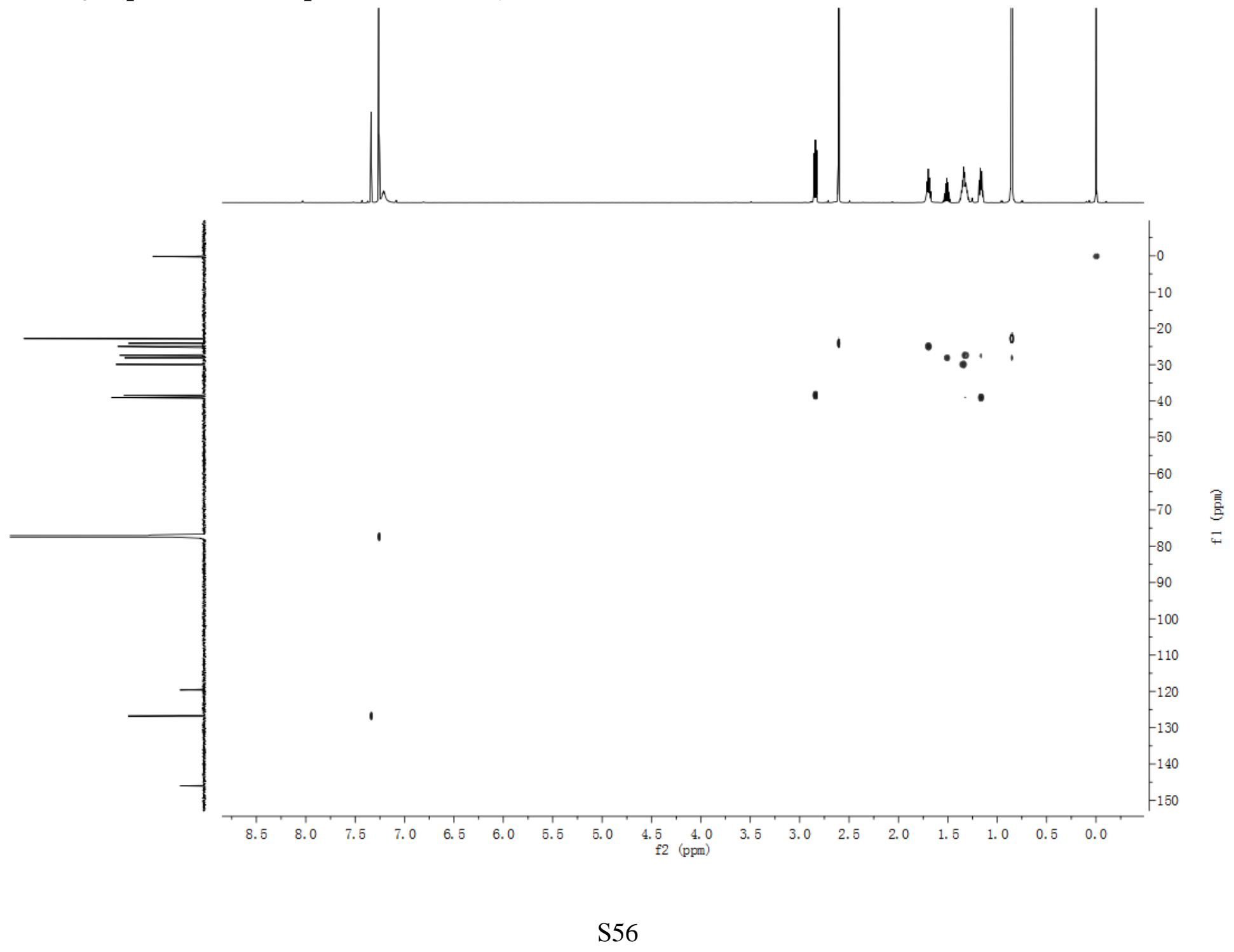


Figure S54. The HMBC spectrum of compound $4 \mathrm{a}\left(\mathrm{CDCl}_{3}, 600 \mathrm{MHz}\right)$

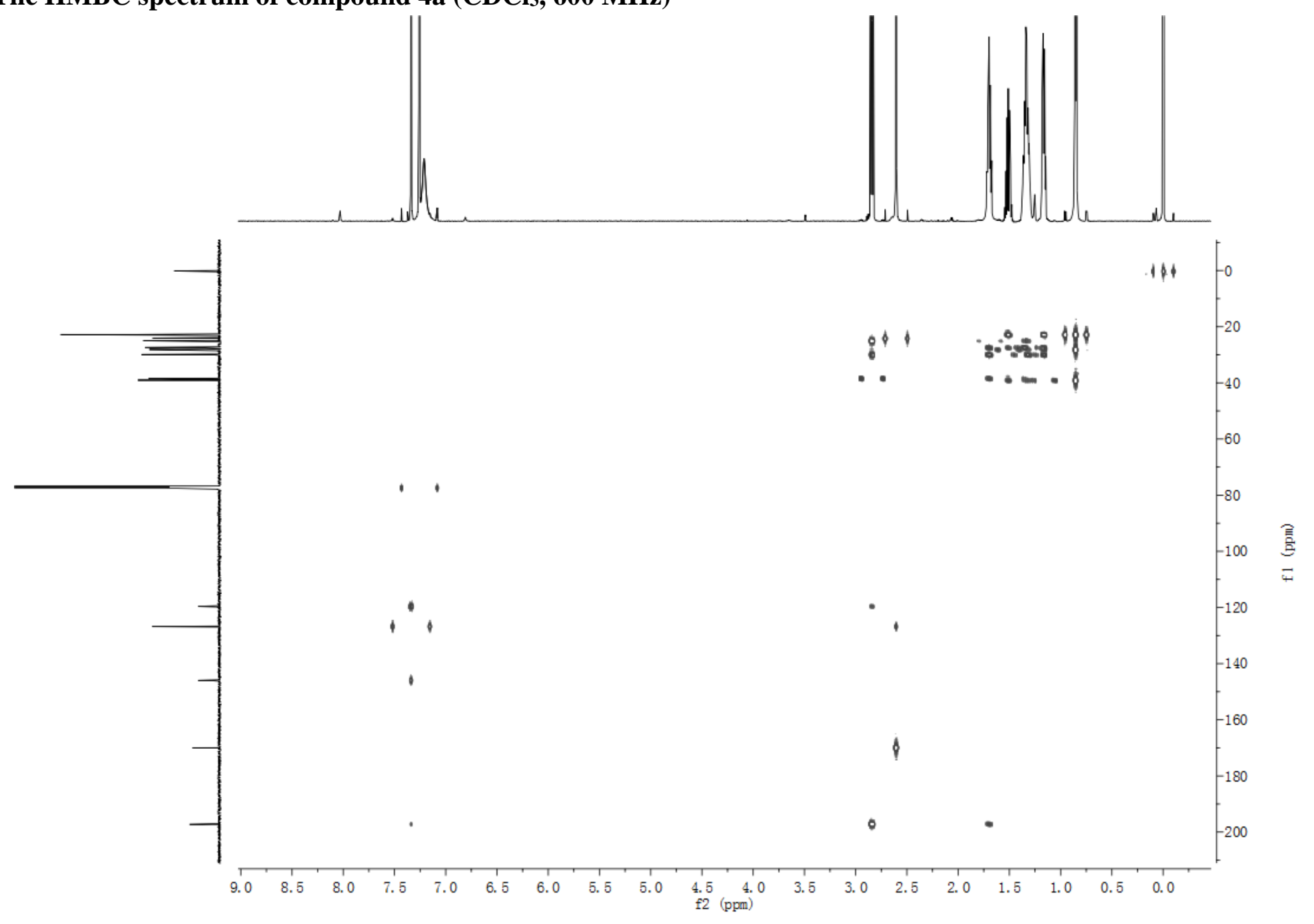


Figure S55. The HRESIMS spectrum of compound 4a

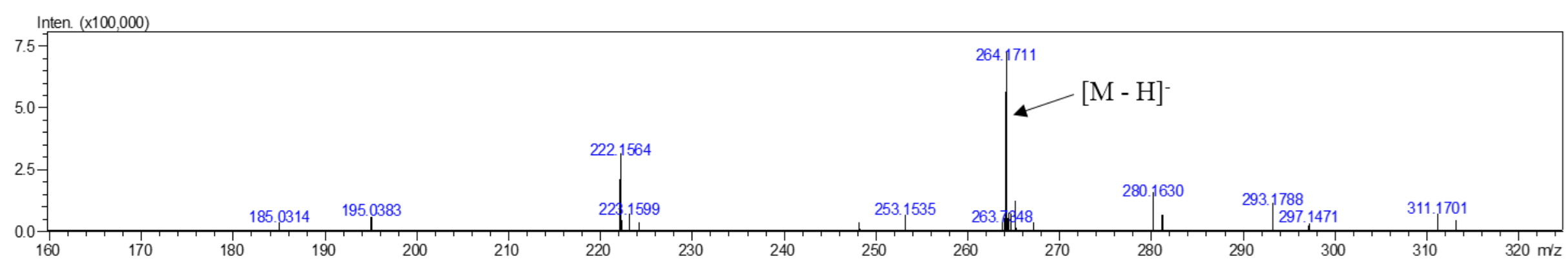


Figure S56. The ${ }^{1} \mathrm{H}$ NMR spectrum of compound $5\left(\mathrm{CDCl}_{3}, 400 \mathrm{MHz}\right)$
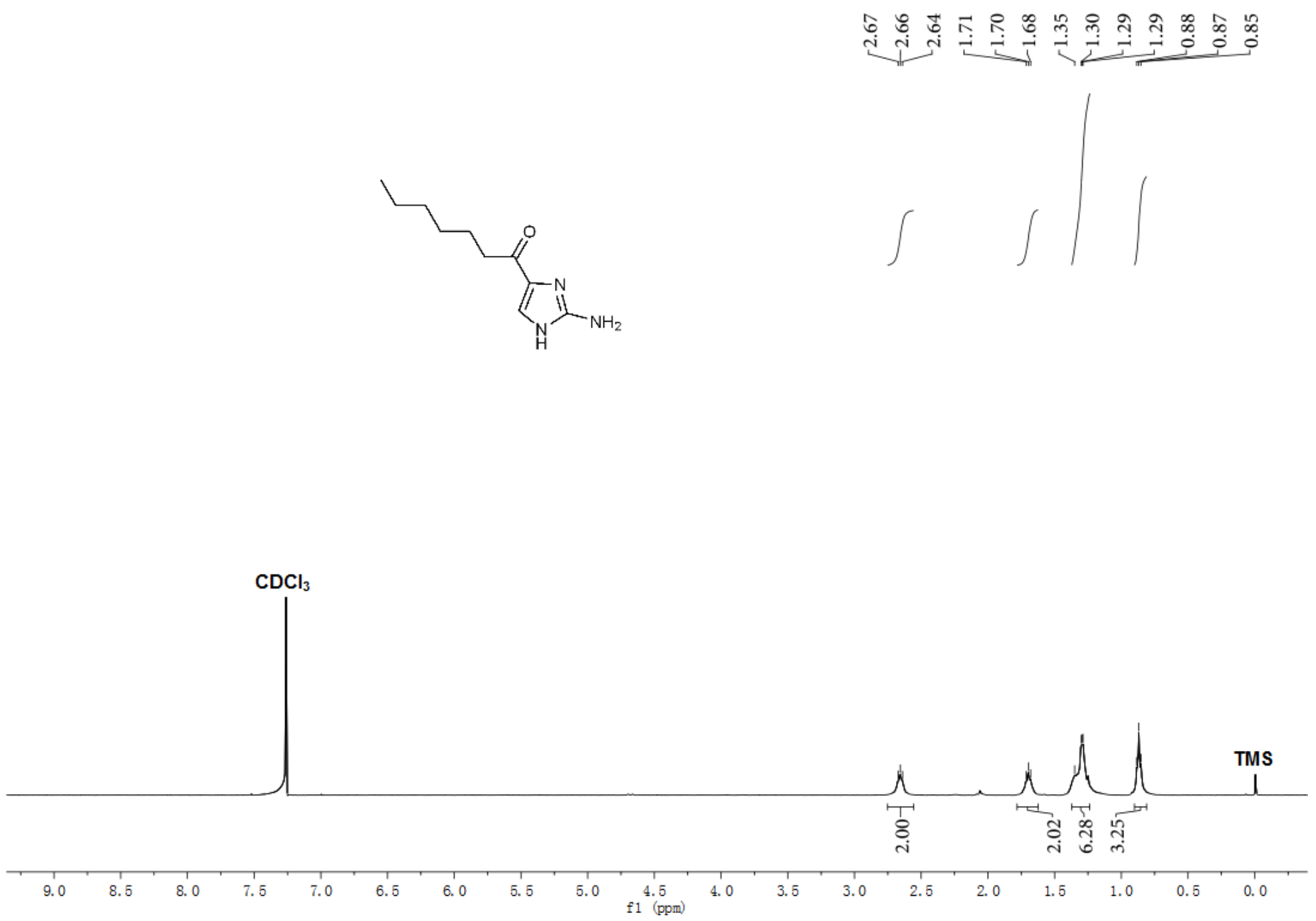
Figure S57. The ${ }^{13} \mathrm{C}$ NMR spectrum of compound $5\left(\mathrm{CDCl}_{3}, 100 \mathrm{MHz}\right)$

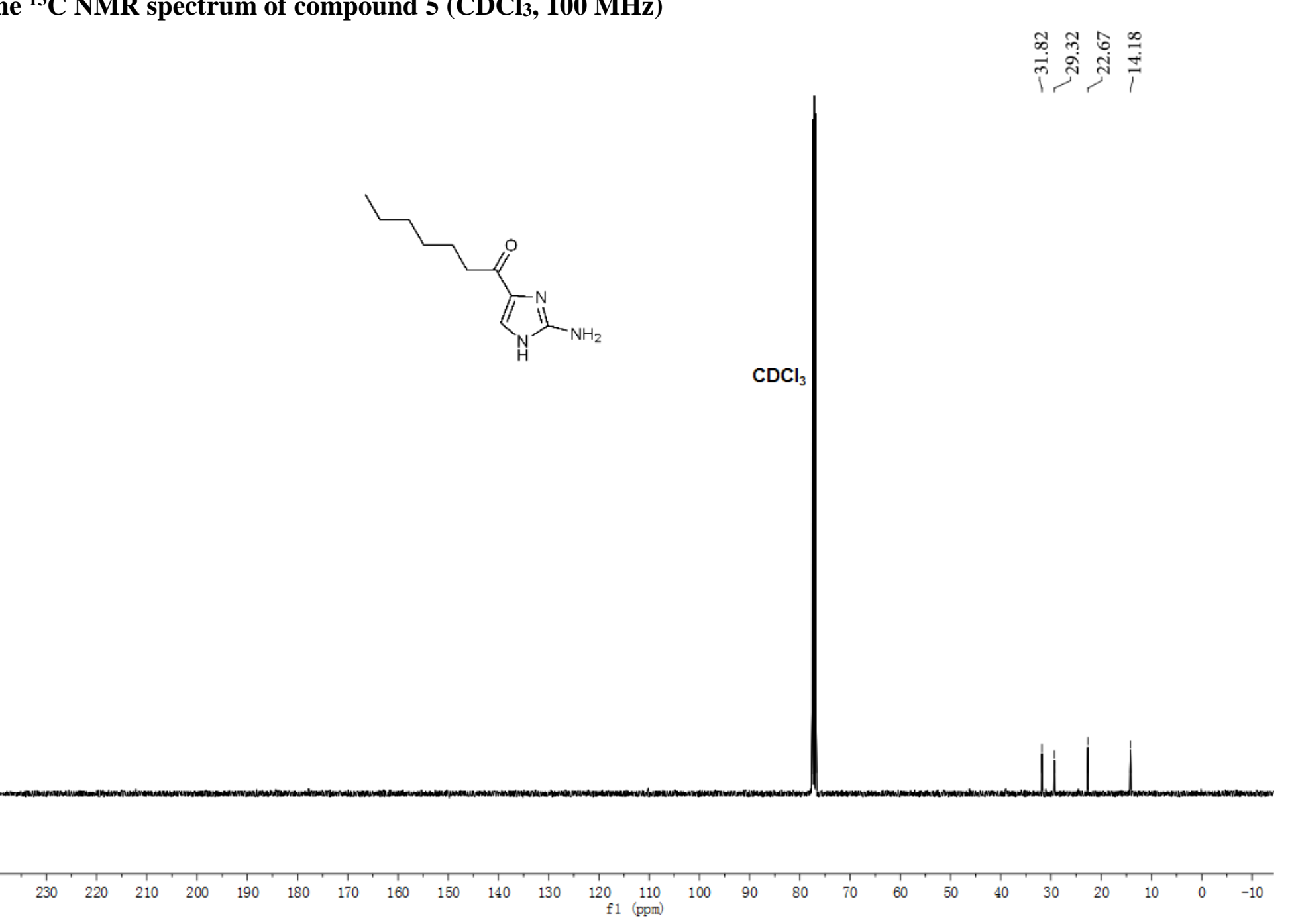




\section{Figure S58. The HRESIMS spectrum of compound 5}

\section{NEGXEVO-G2QTOF\#YCA166}

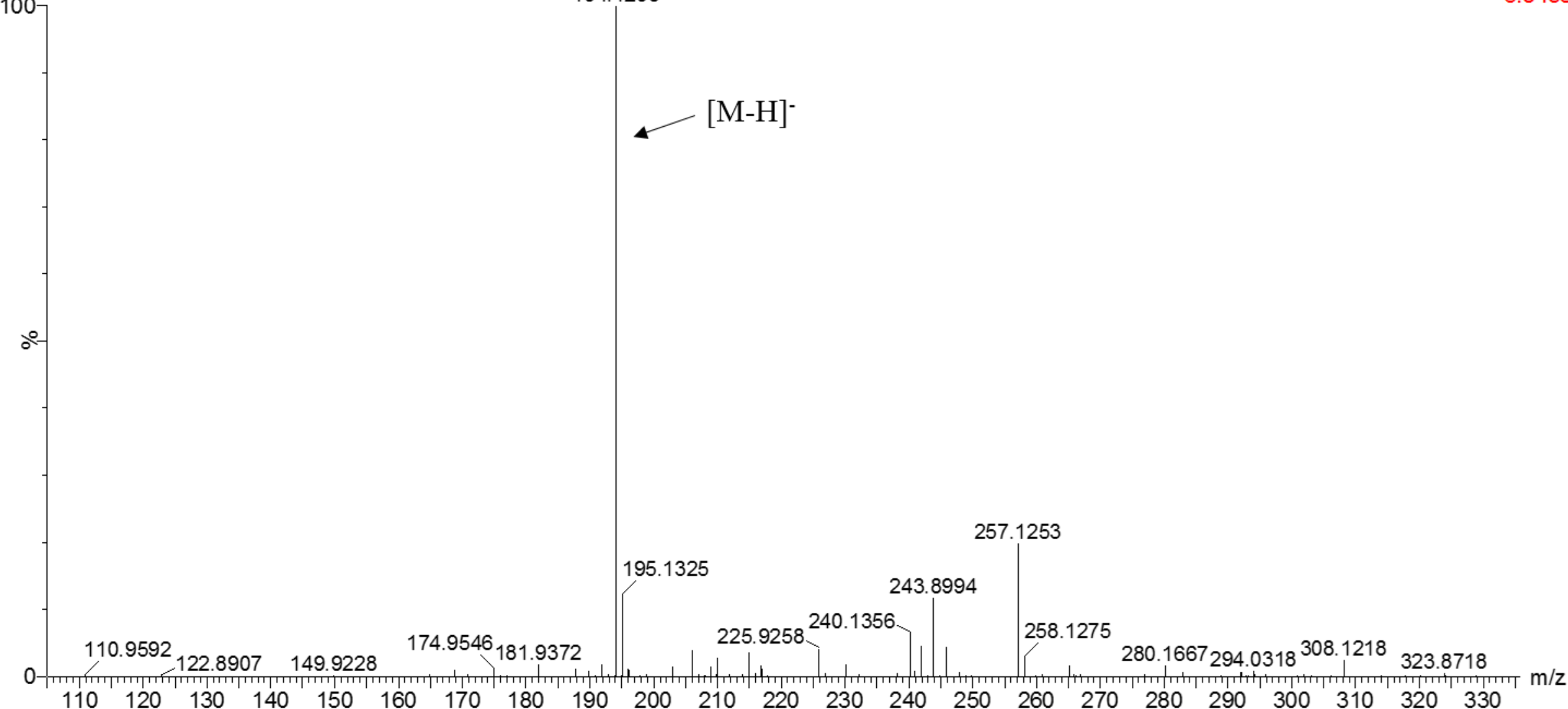


Figure S59. The IR spectrum of compound 5

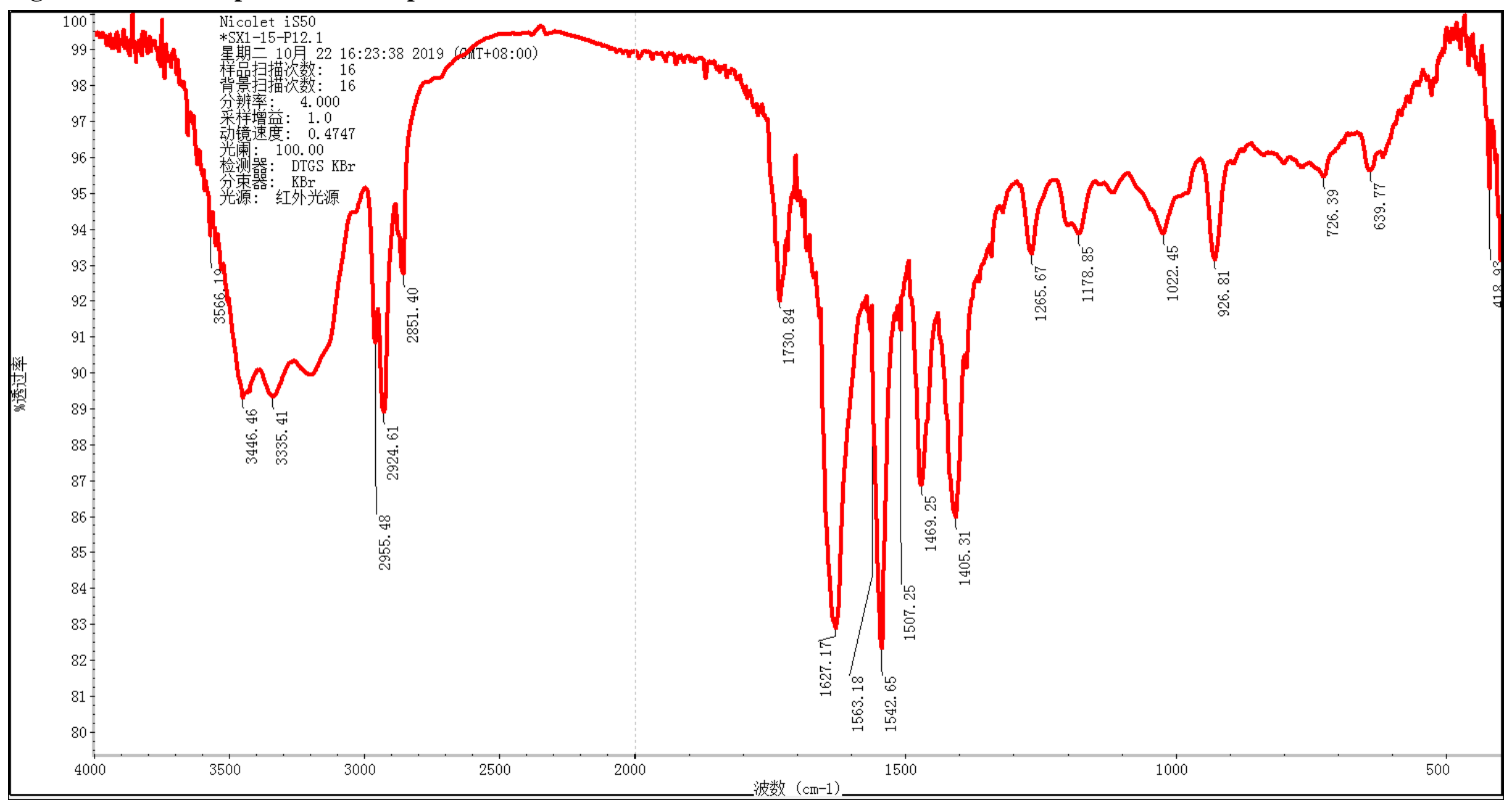


Figure S60. The ${ }^{1} \mathrm{H}$ NMR spectrum of compound 5 a $\left(\mathrm{CDCl}_{3}, 400 \mathrm{MHz}\right)$ iें i

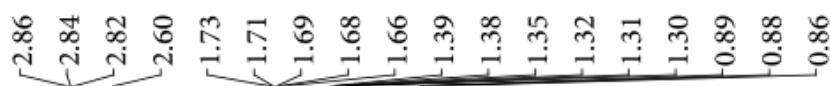

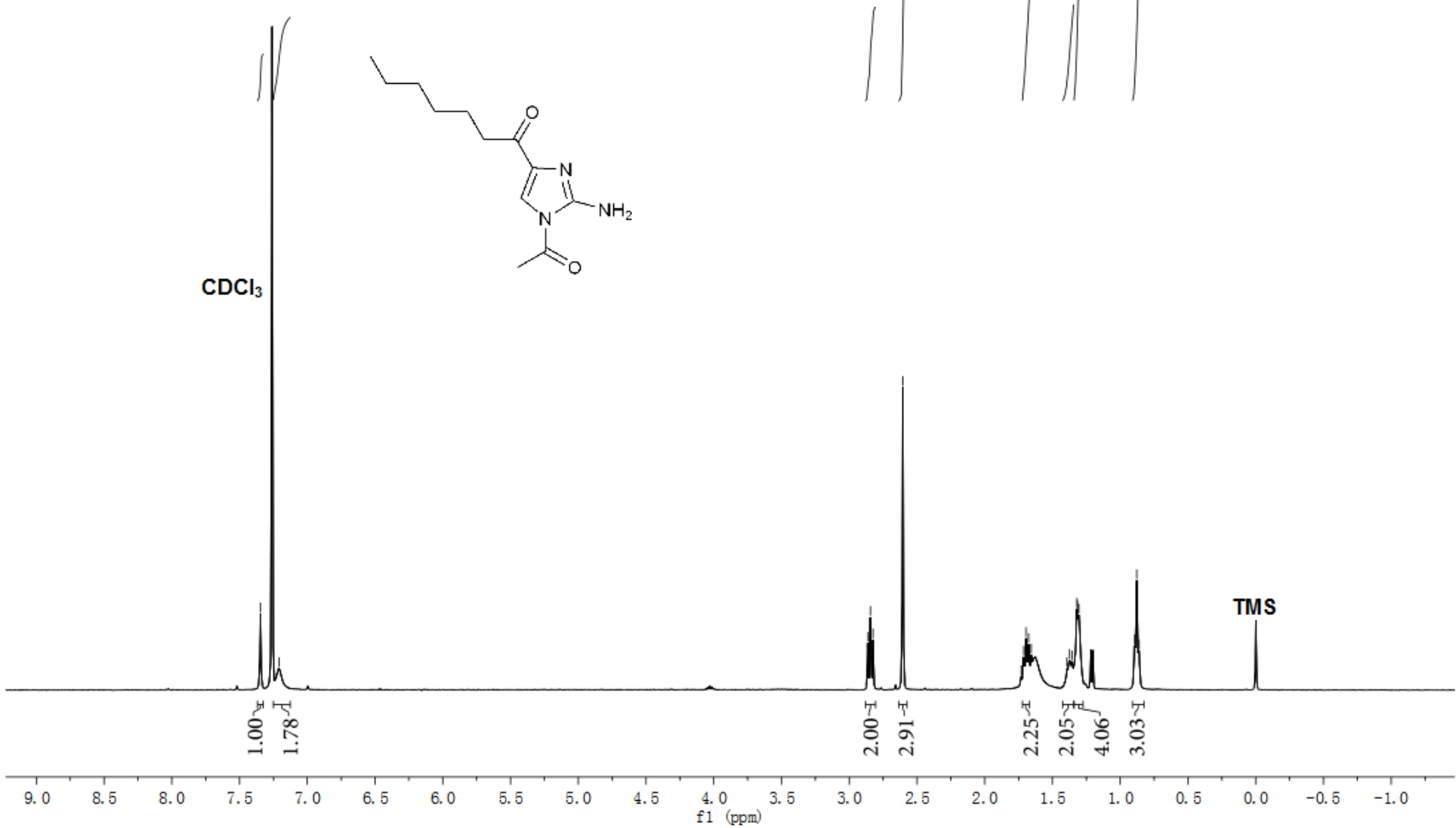


Figure S61. The ${ }^{13} \mathrm{C}$ NMR spectrum of compound $5 \mathrm{a}\left(\mathrm{CDCl}_{3}, 100 \mathrm{MHz}\right)$

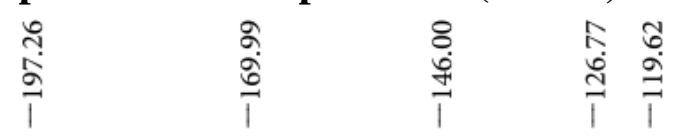

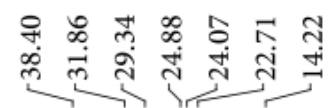
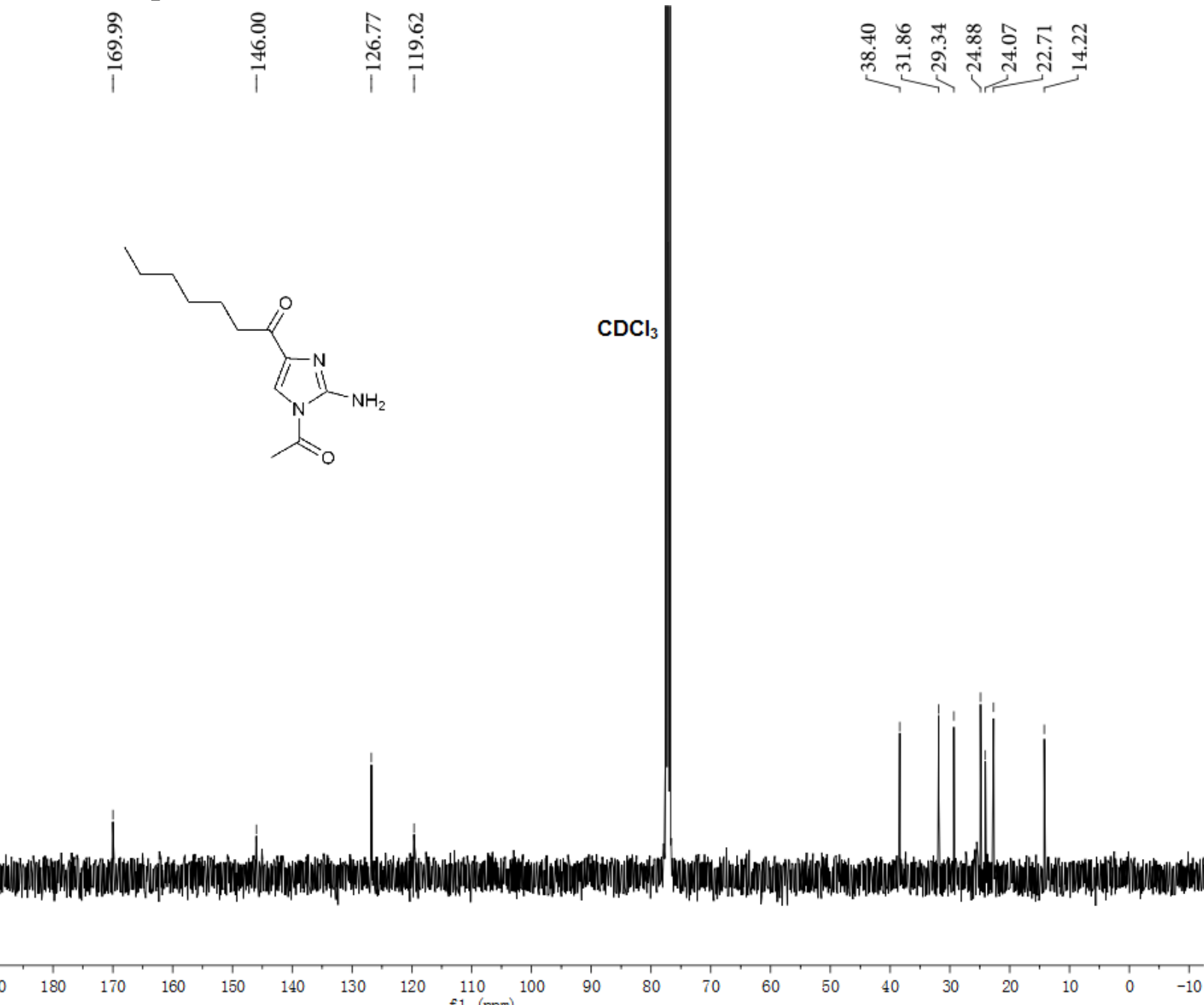

$120 \underset{f 1(\mathrm{ppm})}{110} 100$ 
Figure S62. The COSY spectrum of compound $5 \mathrm{a}\left(\mathrm{CDCl}_{3}, 400 \mathrm{MHz}\right)$

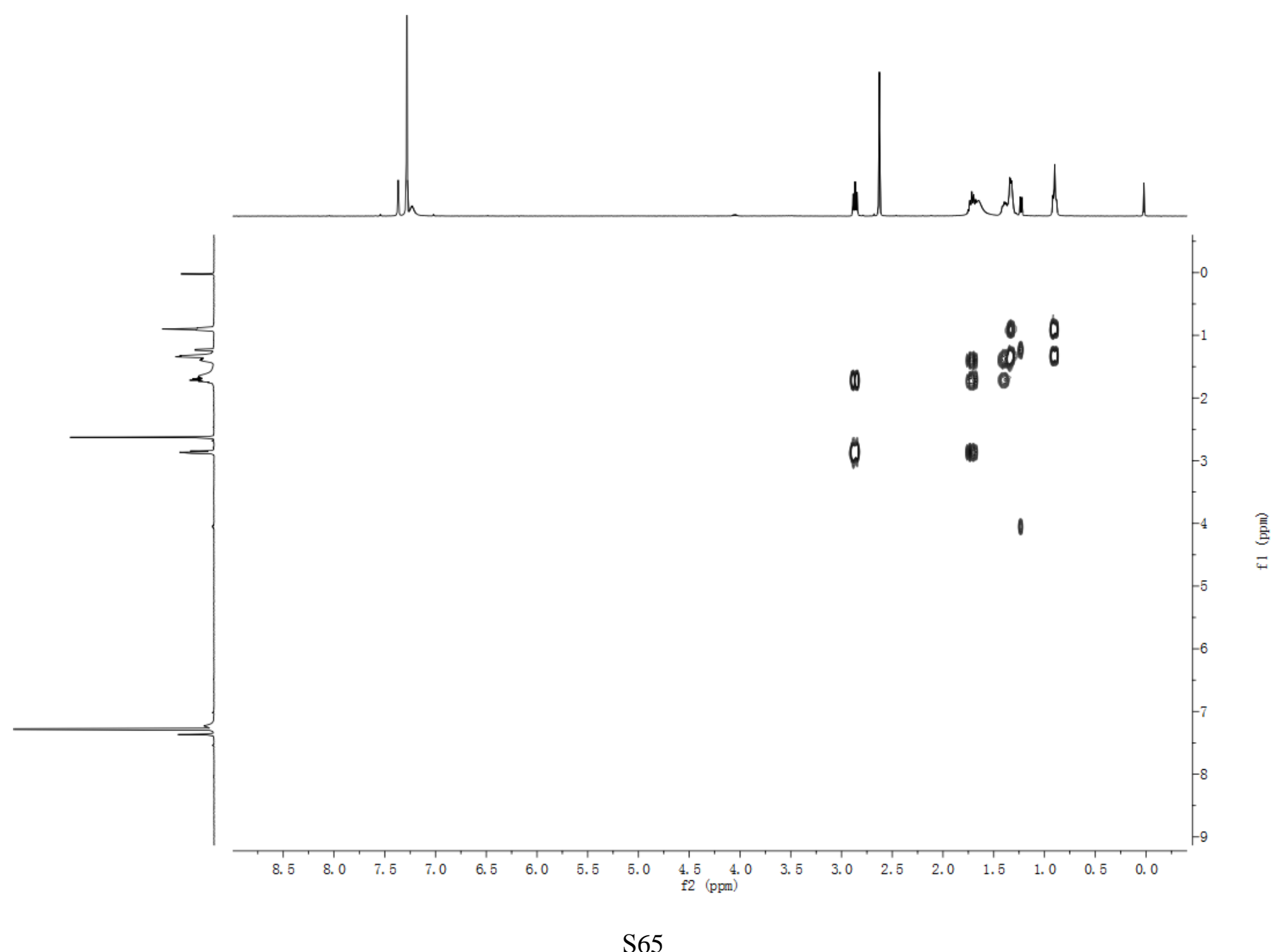




$$
1
$$




$$
1
$$


Figure S65. The HRESIMS spectrum of compound 5a

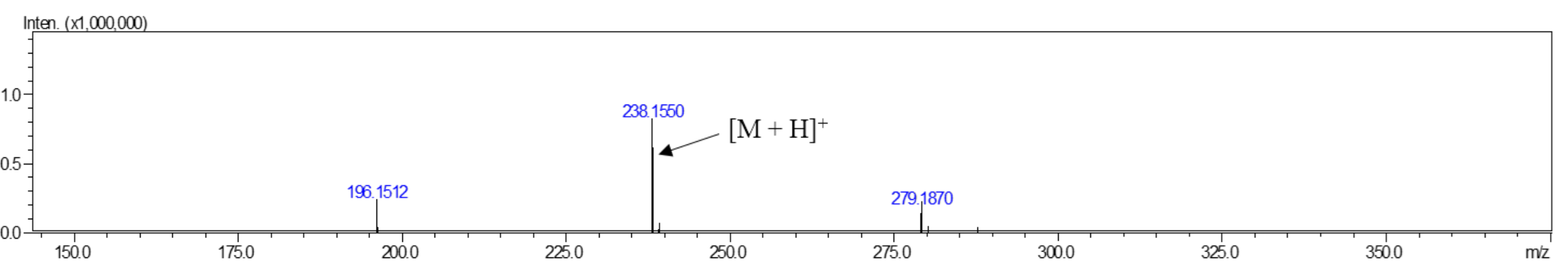


Figure S66. The ${ }^{1} \mathrm{H}$ NMR spectrum of compound 6 (DMSO-d6, $400 \mathrm{MHz}$ )
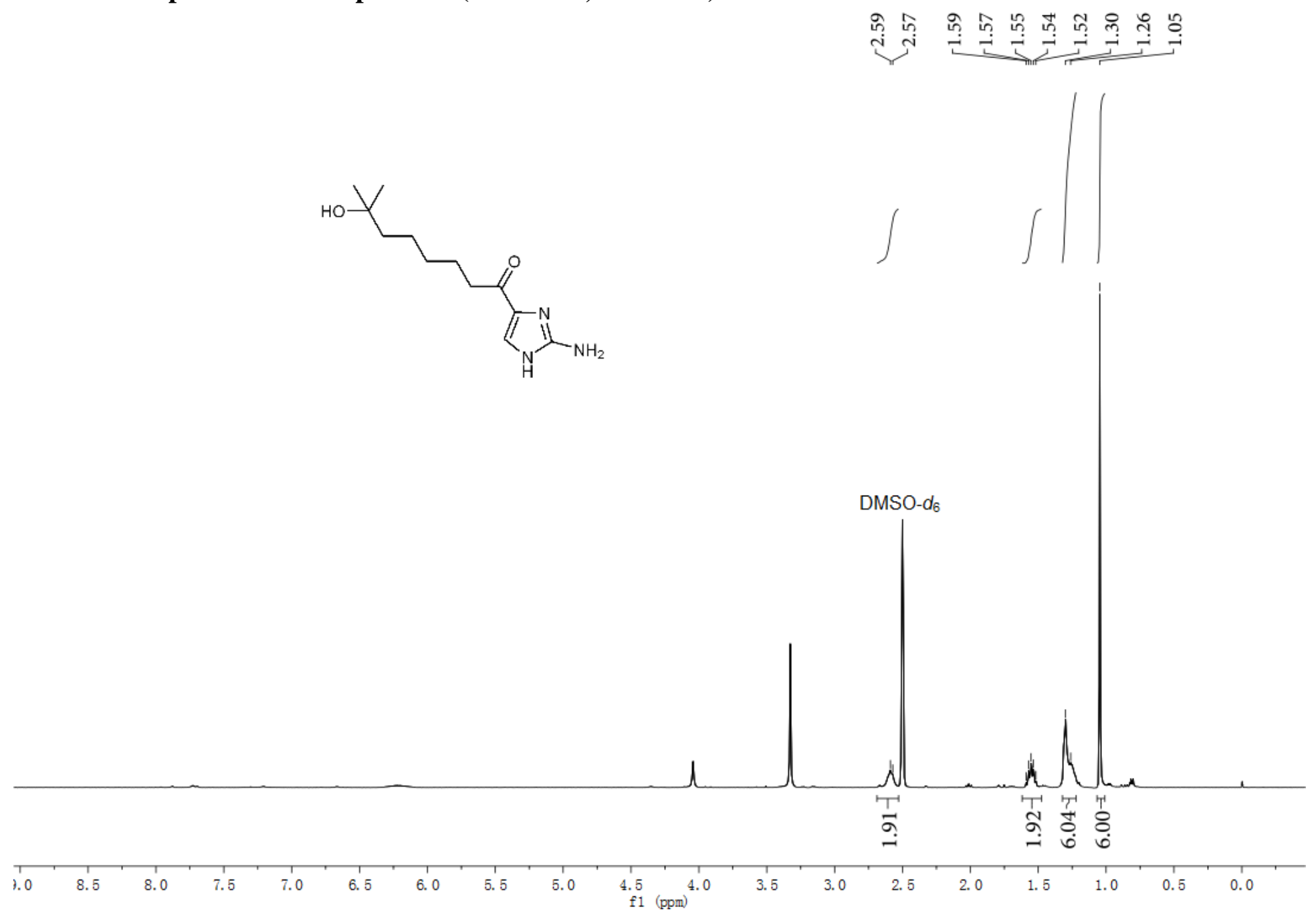
Figure S67. The ${ }^{13} \mathrm{C}$ NMR spectrum of compound 6 (DMSO-d, $100 \mathrm{MHz}$ )

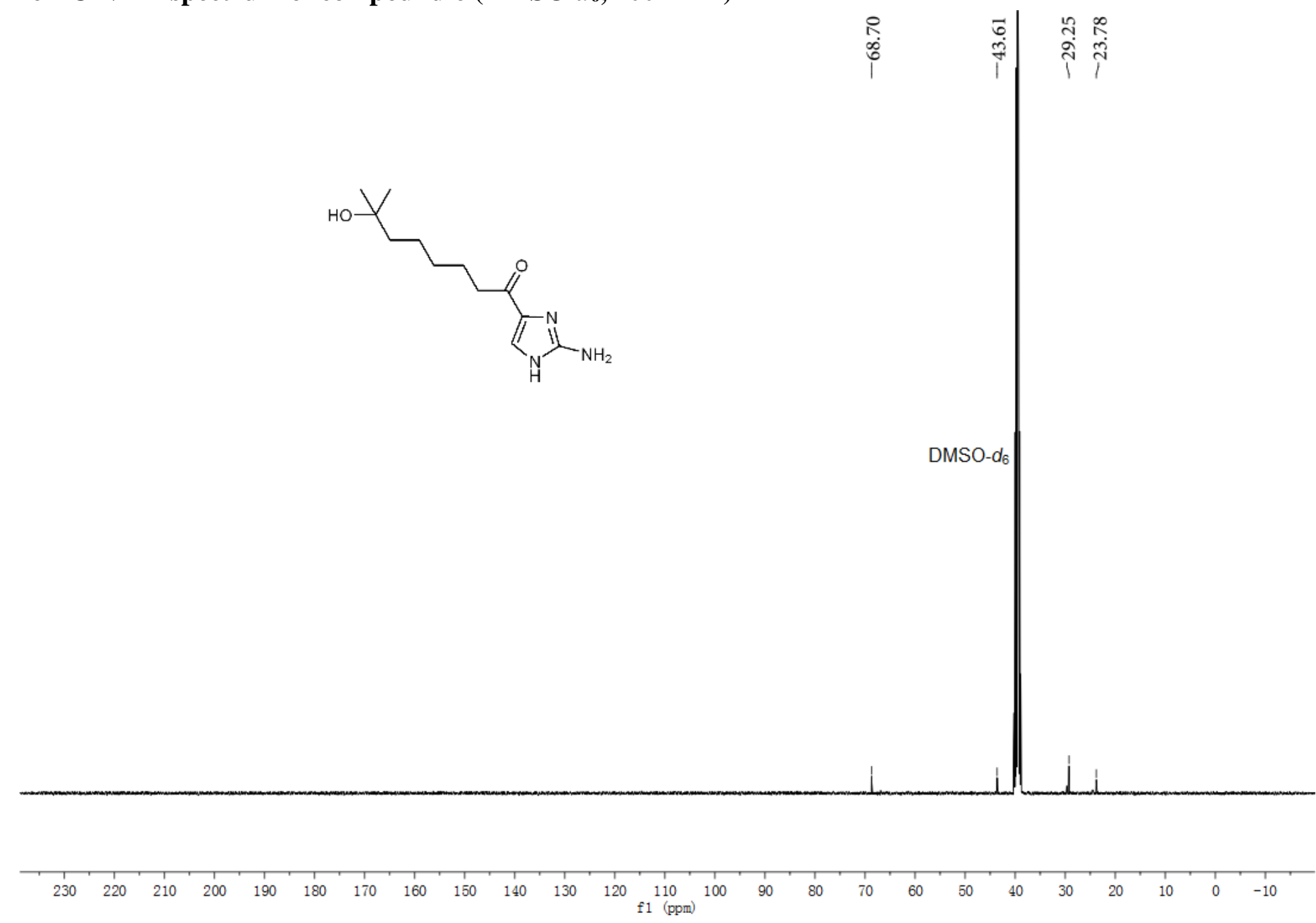


Figure S68. The HRESIMS spectrum of compound 6

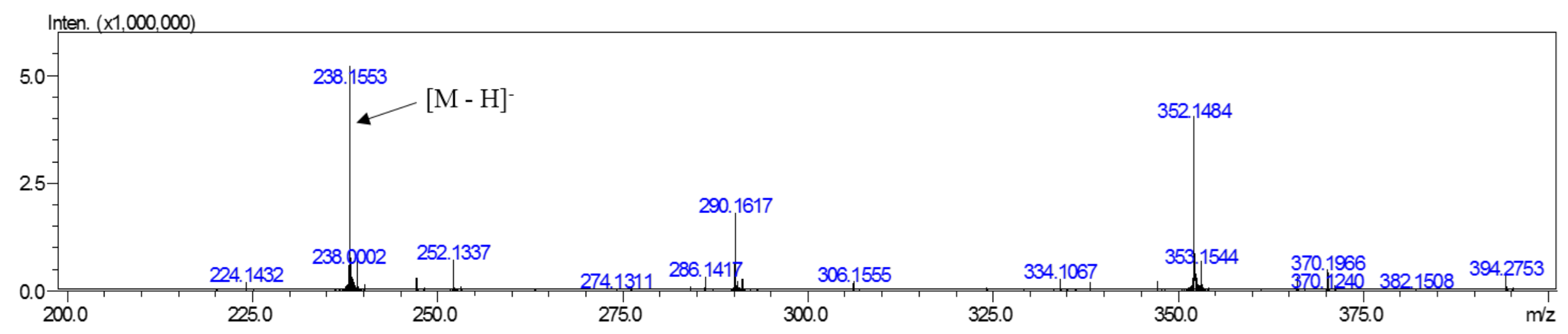


Figure S69. The IR spectrum of compound 6

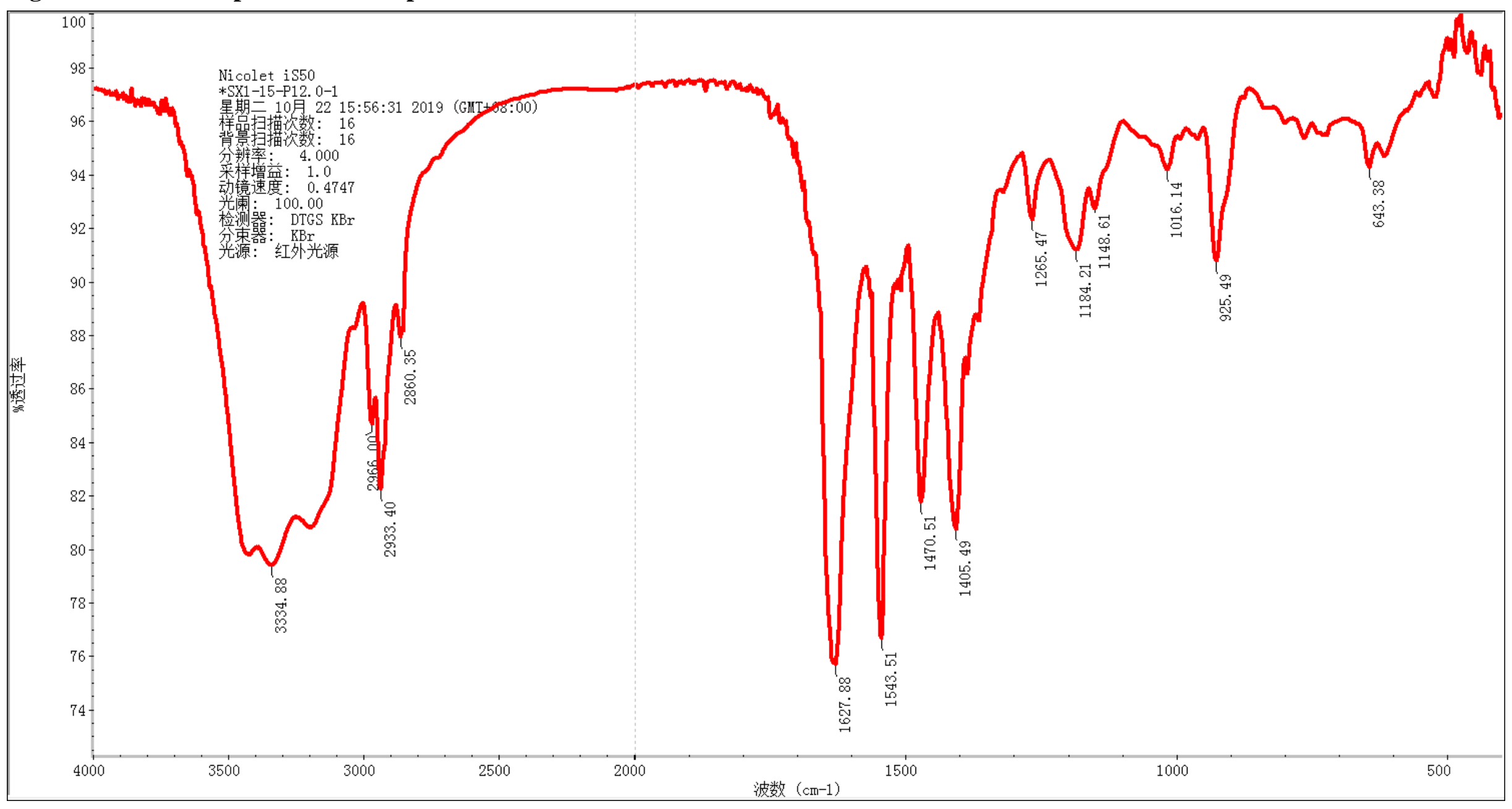


Figure S70. The ${ }^{1} \mathrm{H}$ NMR spectrum of compound $6 \mathrm{a}\left(\mathrm{CDCl}_{3}, 600 \mathrm{MHz}\right)$

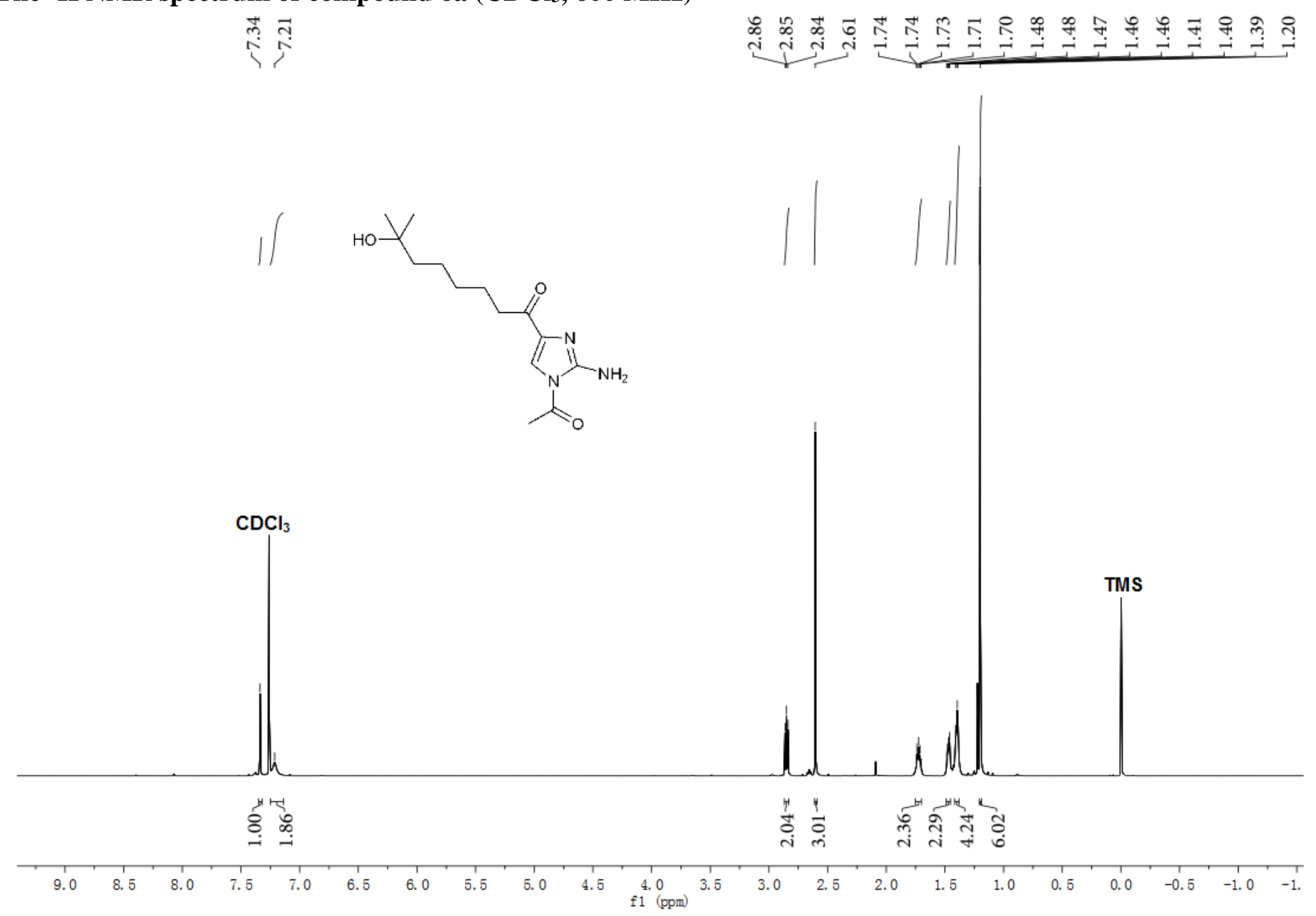


Figure S71. The ${ }^{13} \mathrm{C}$ NMR spectrum of compound $6 \mathrm{a}\left(\mathrm{CDCl}_{3}, 150 \mathrm{MHz}\right)$

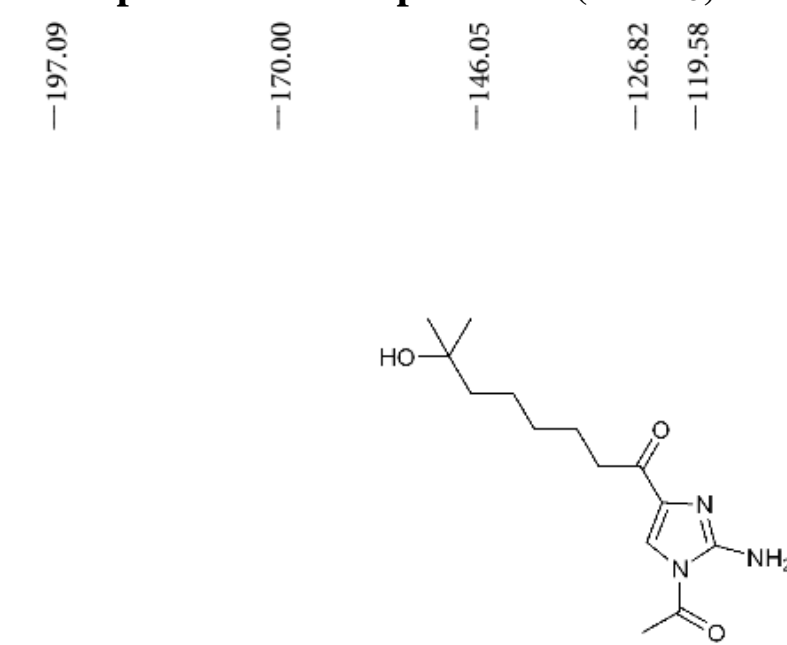

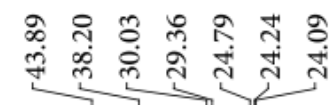

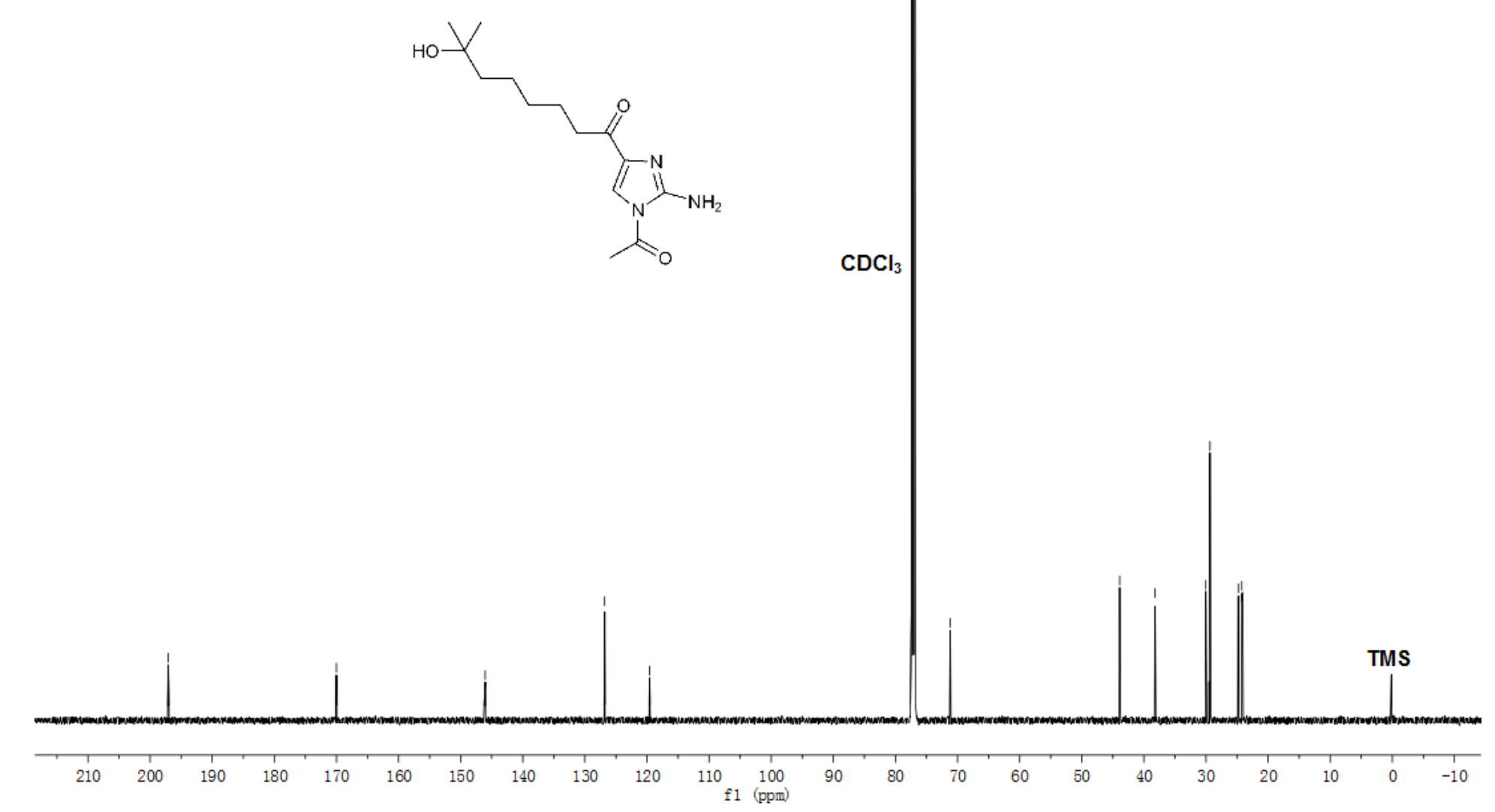


Figure S72. The COSY spectrum of compound $6 \mathrm{a}\left(\mathrm{CDCl}_{3}, 600 \mathrm{MHz}\right)$

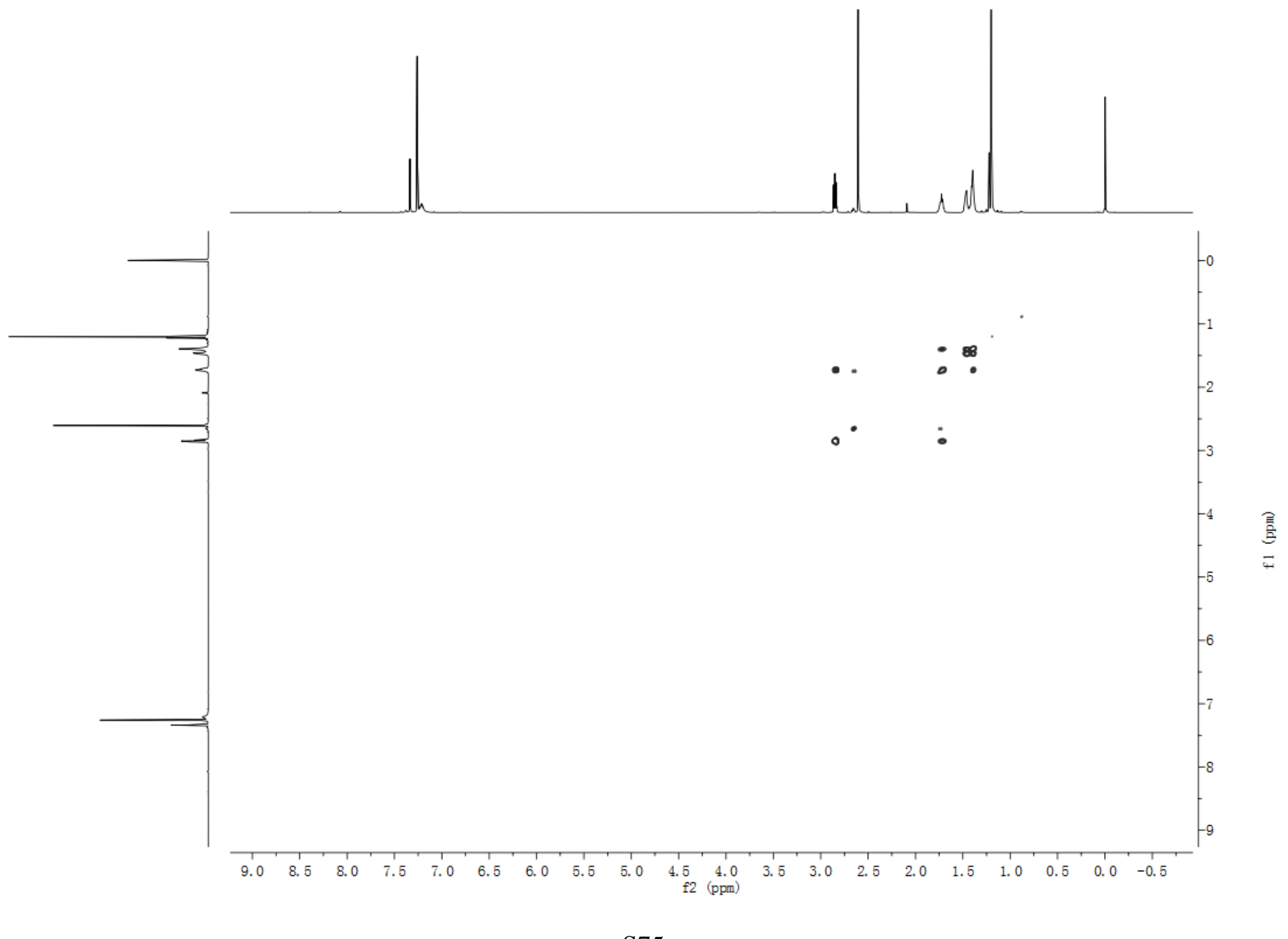


Figure S73. The HSQC spectrum of compound $6 \mathrm{a}\left(\mathrm{CDCl}_{3}, 600 \mathrm{MHz}\right)$

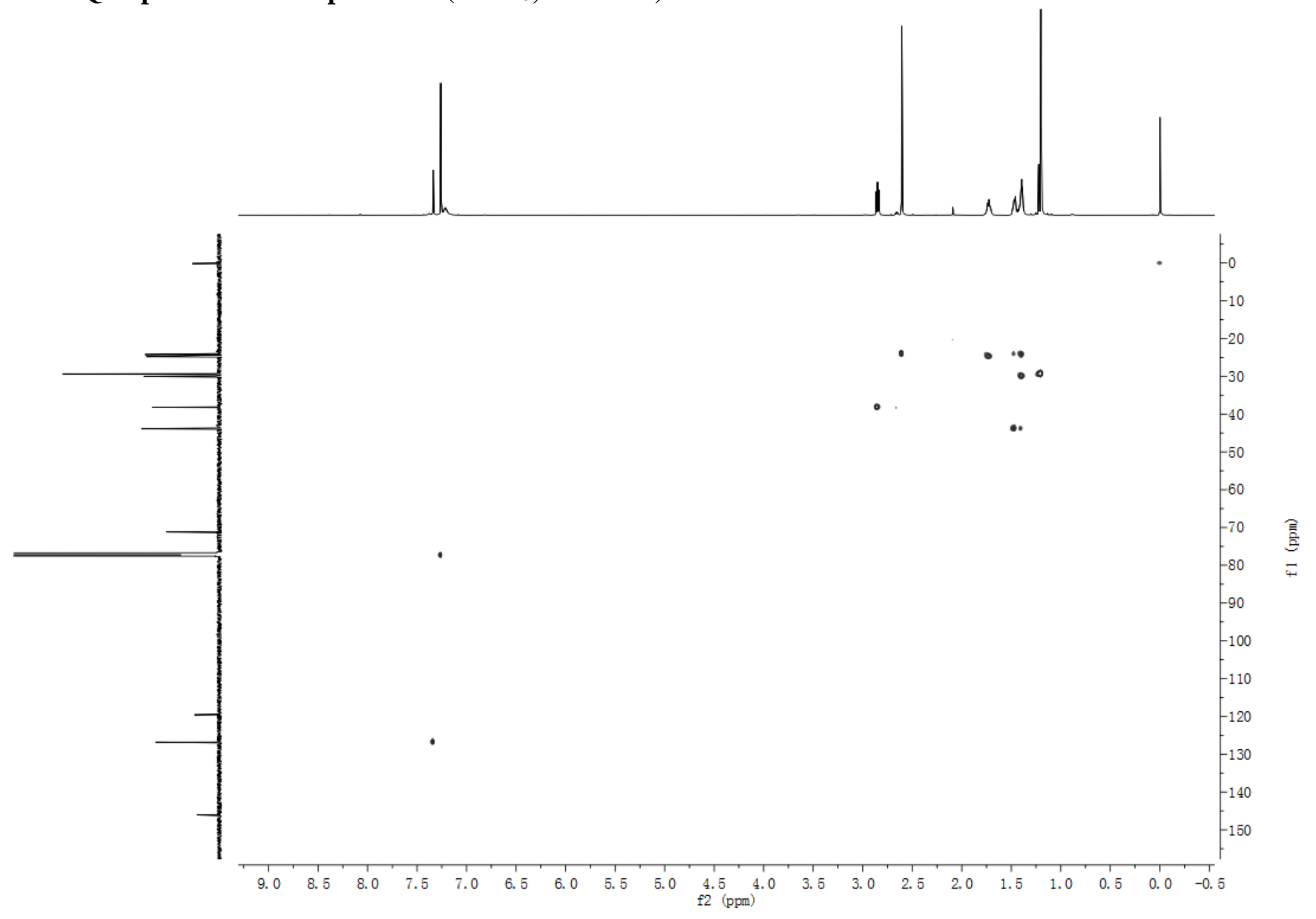


Figure S74. The HMBC spectrum of compound $6 \mathrm{a}\left(\mathrm{CDCl}_{3}, 600 \mathrm{MHz}\right)$

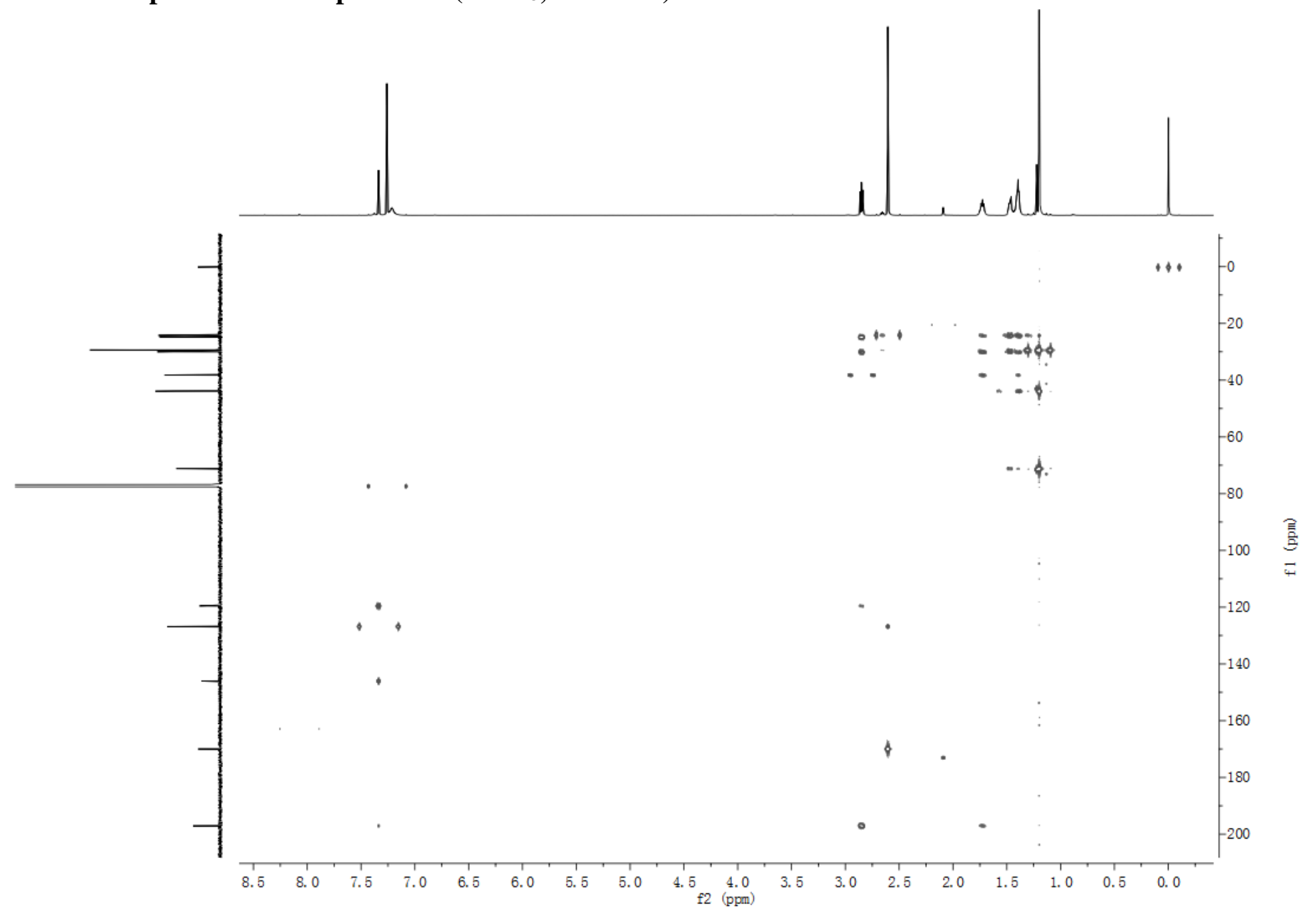


Figure S75. The HRESIMS spectrum of compound $6 a$

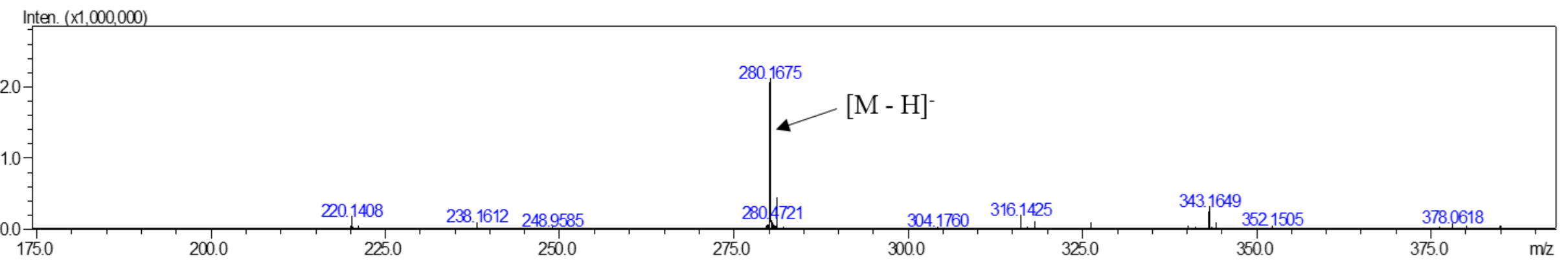


Figure S76. The ${ }^{1} \mathrm{H}$ NMR spectrum of compound 7 (DMSO-d6, $400 \mathrm{MHz}$ )

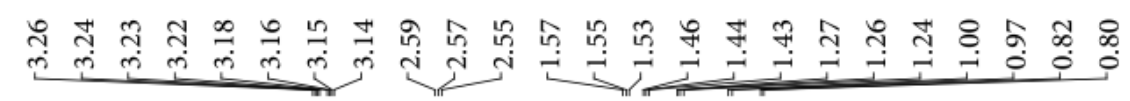
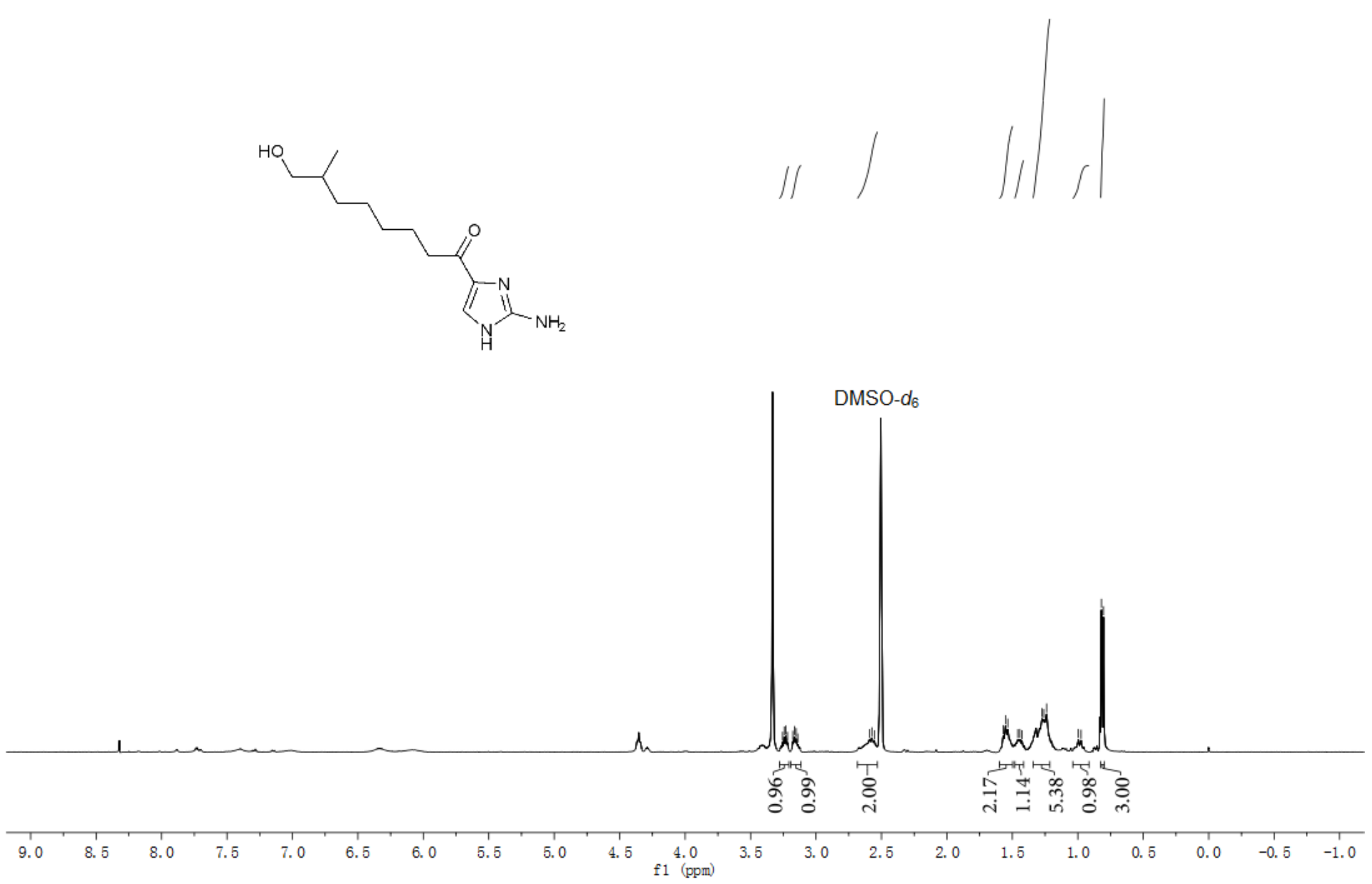
Figure S77. The ${ }^{13} \mathrm{C}$ NMR spectrum of compound 7 (DMSO-d6, 100 MHz)
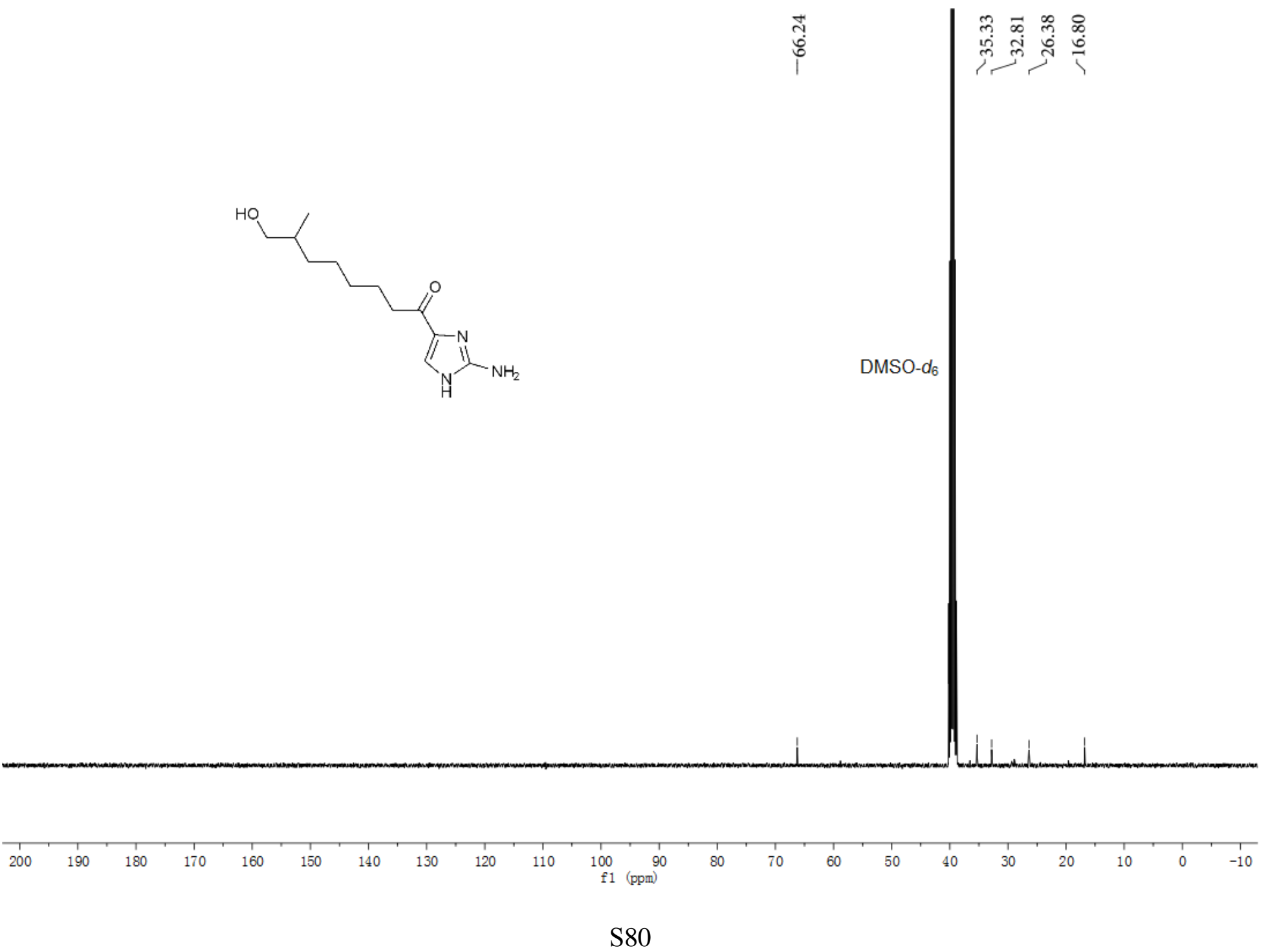
Figure S78. The HRESIMS spectrum of compound 7

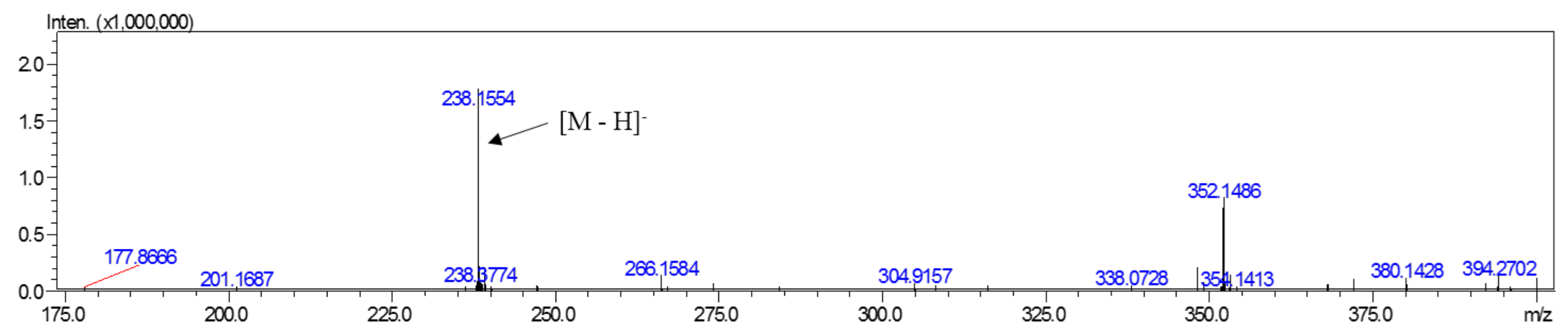


Figure S79. The IR spectrum of compound 7

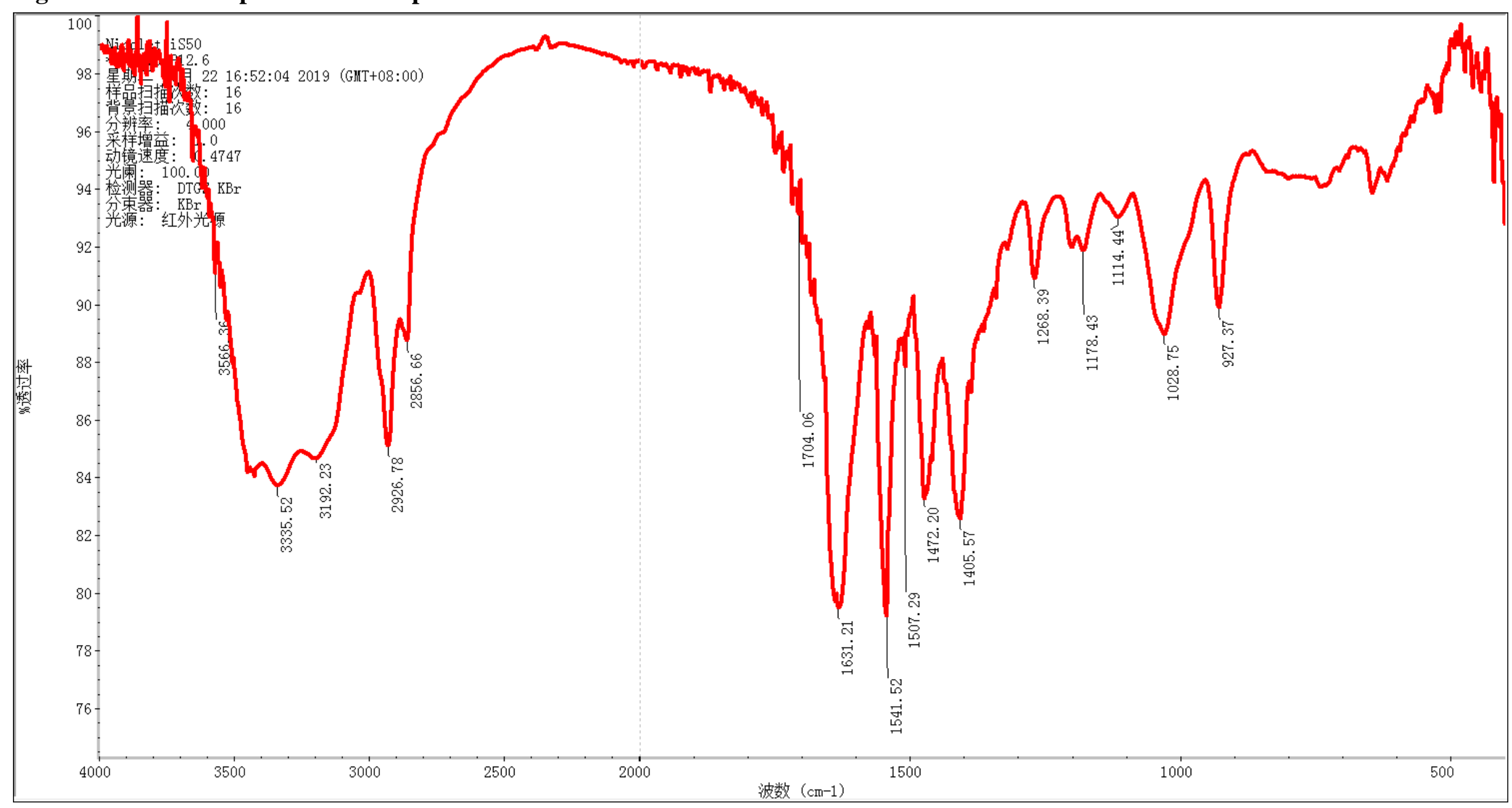


Figure S80. The ${ }^{1} \mathrm{H}$ NMR spectrum of compound $7 \mathrm{a}\left(\mathrm{CDCl}_{3}, 600 \mathrm{MHz}\right)$

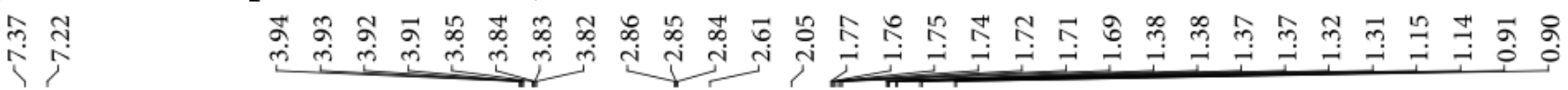

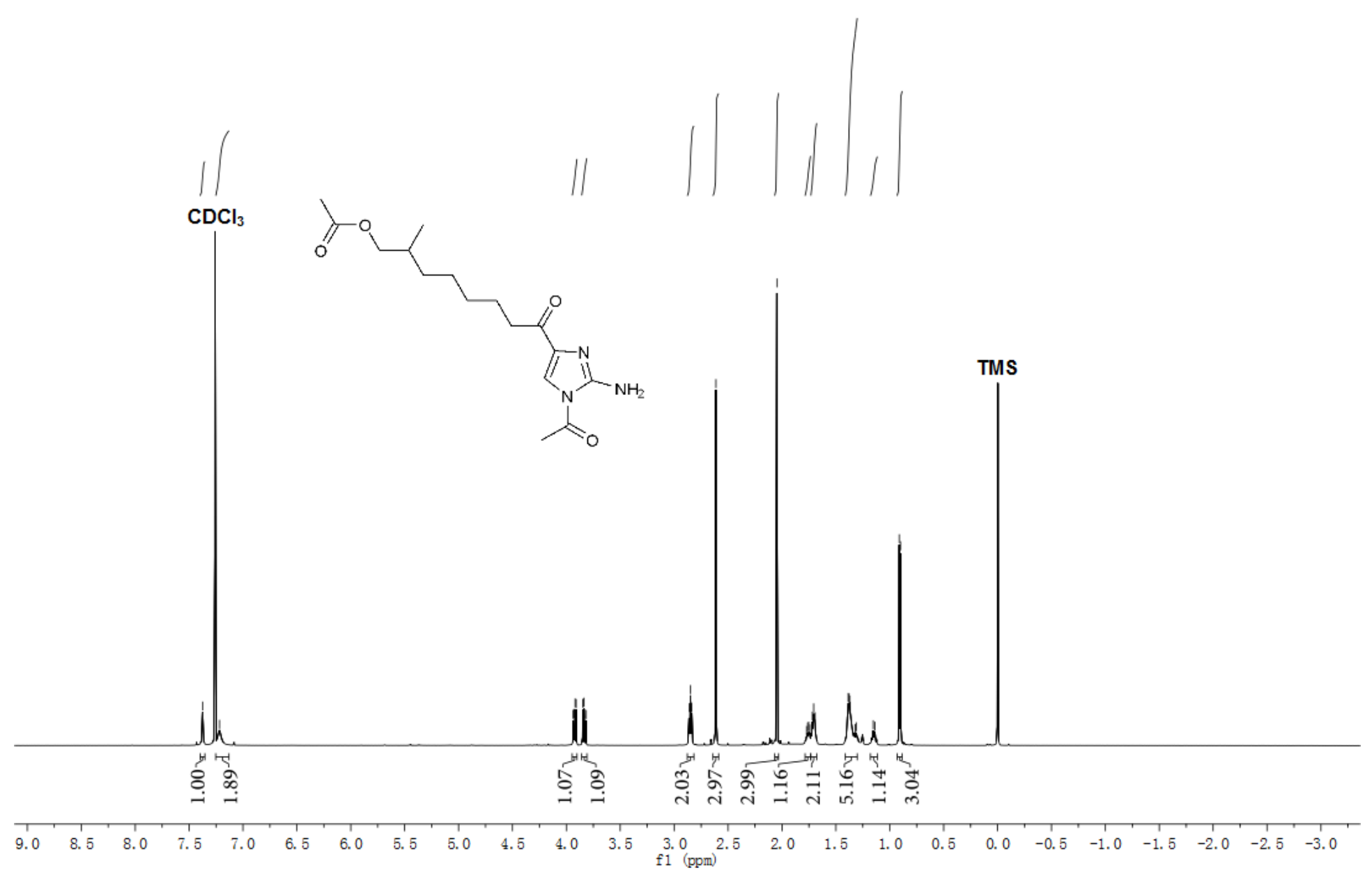


Figure S81. The ${ }^{13} \mathrm{C}$ NMR spectrum of compound $7 \mathrm{a}\left(\mathrm{CDCl}_{3}, 150 \mathrm{MHz}\right)$

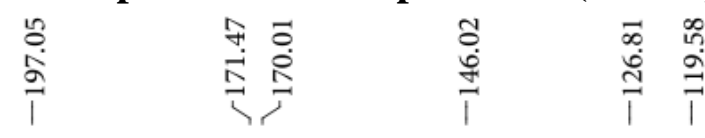

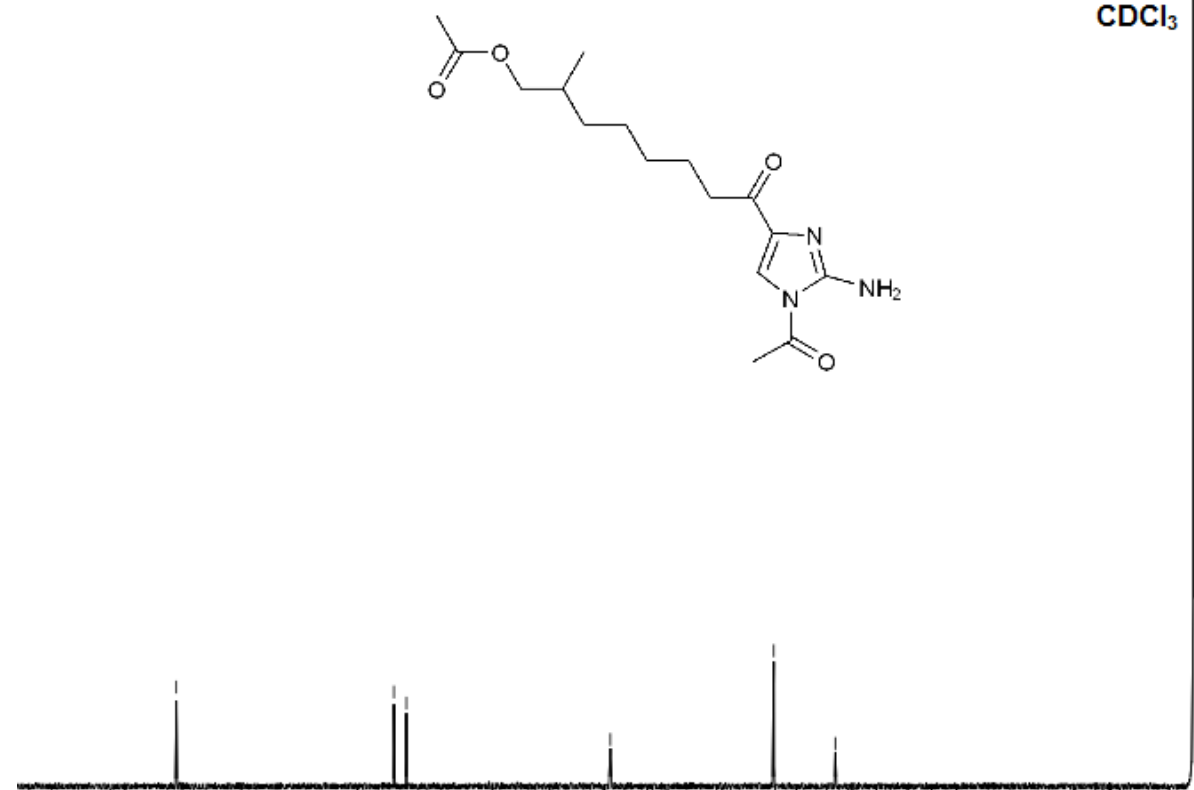

$\mathrm{CDCl}_{3}$
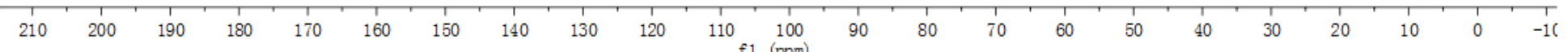
Figure S82. The COSY spectrum of compound $7 \mathrm{a}\left(\mathrm{CDCl}_{3}, 600 \mathrm{MHz}\right)$

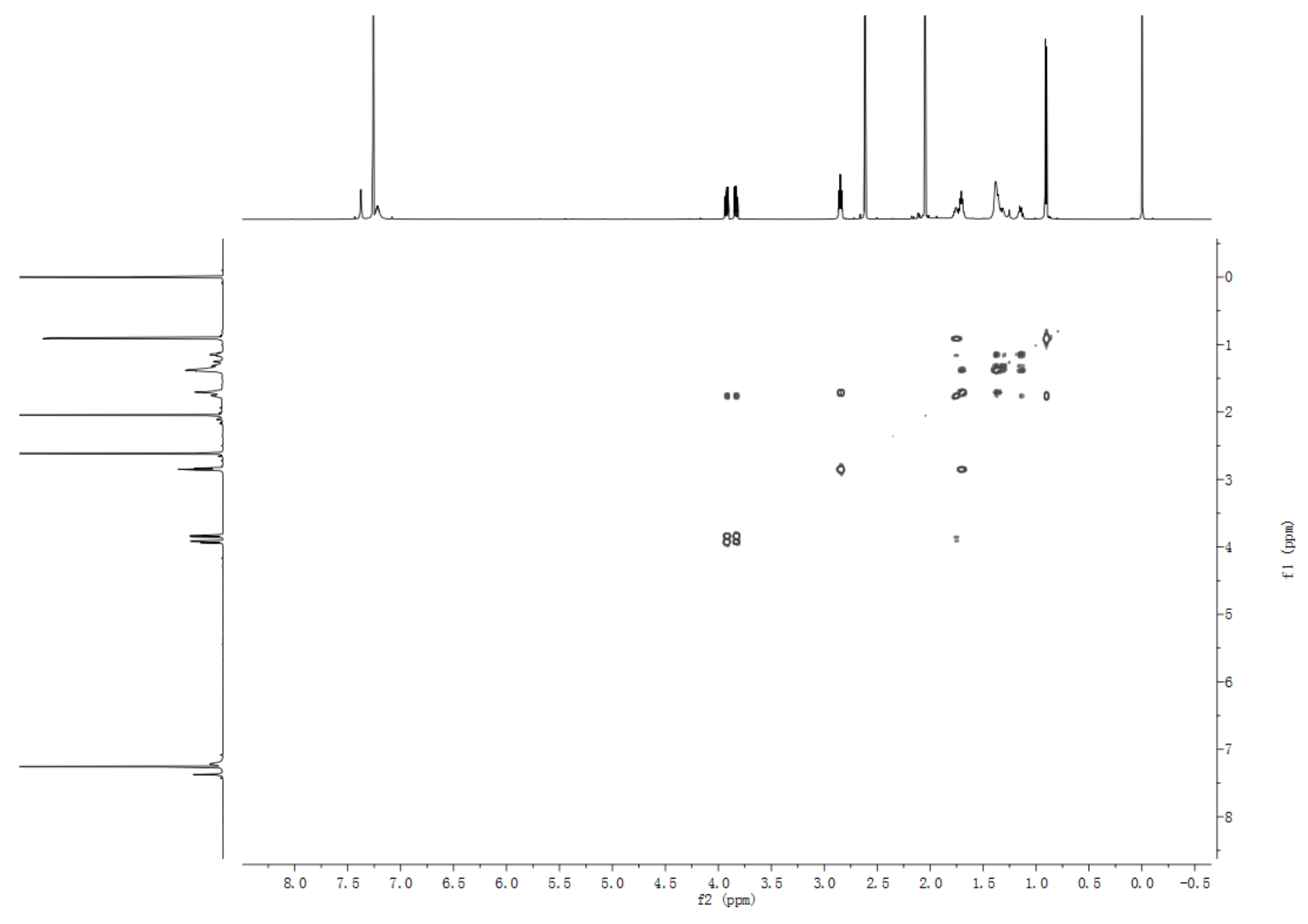




$$
+4
$$


Figure S84. The HMBC spectrum of compound $7 \mathrm{a}\left(\mathrm{CDCl}_{3}, 600 \mathrm{MHz}\right)$

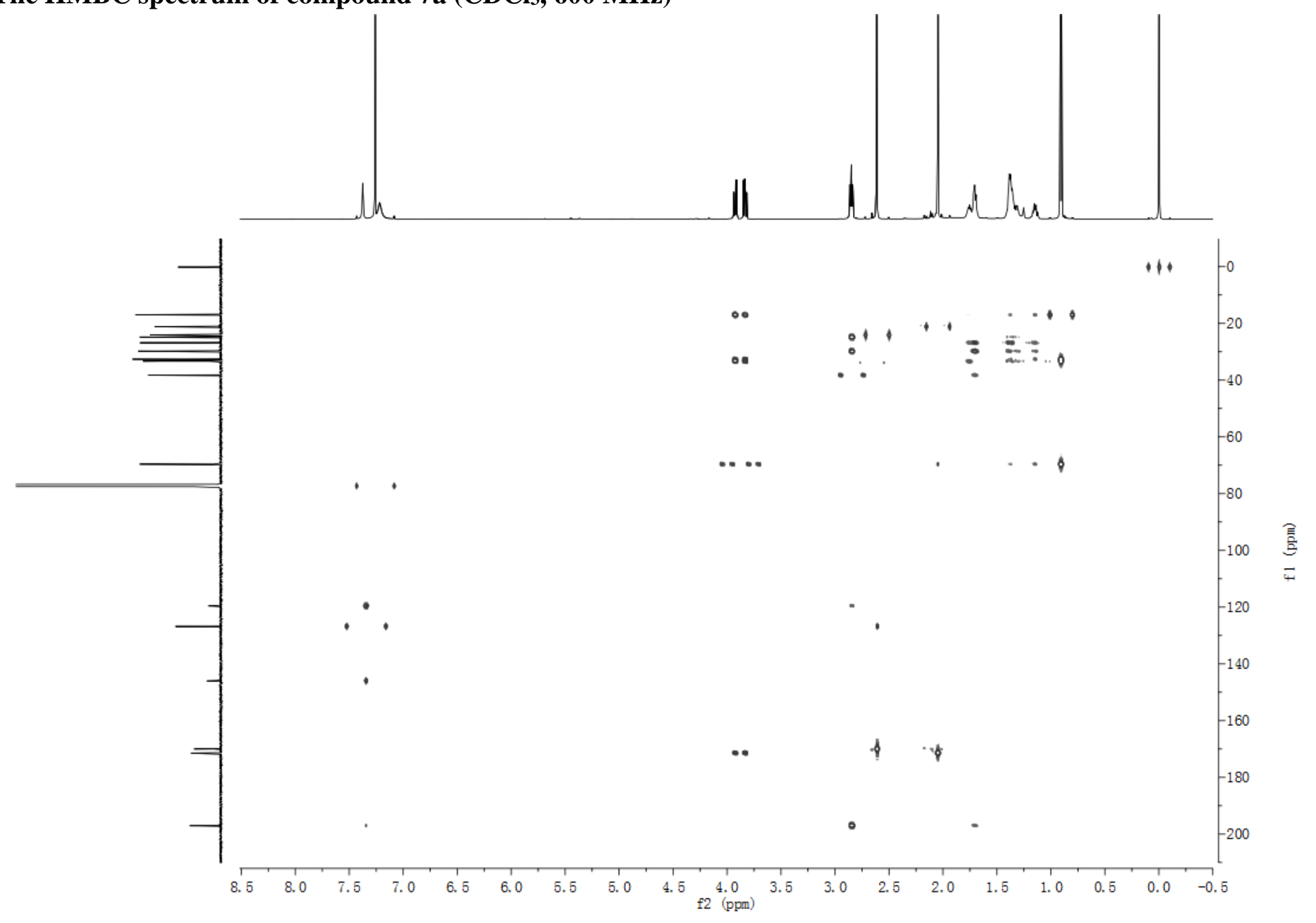


Figure S85. The HRESIMS spectrum of compound 7a

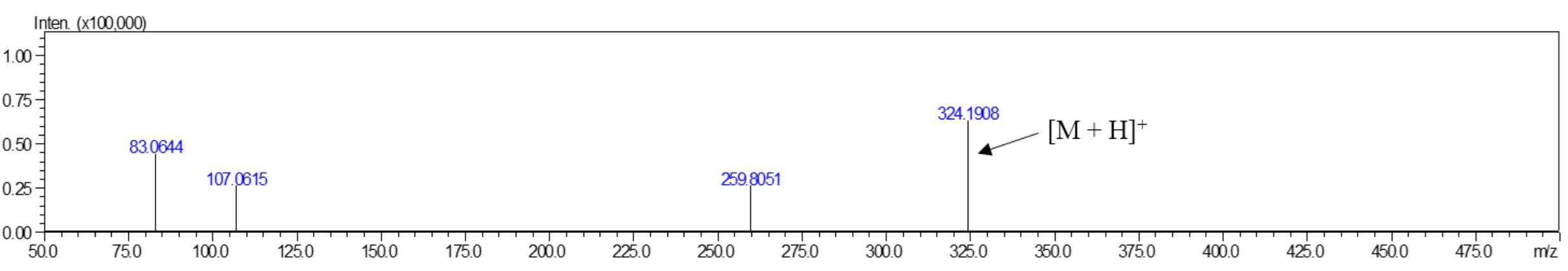

